\title{
AVALIAÇÃO DO POTENCIAL DE INFECÇÃO MICORRÍZICA E CARACTERIZAÇÃO GENÉTICO-CITOLÓGICA DE ISOLADOS DE Pisolithus tinctarius
}

\author{
LILIANA KEIKO MITSUNAGA
}

\begin{abstract}
Dissertação apresentada à Escola Superior de Agricultura "Luiz de Queiroz" da Universidade de São Paulo para obtenção do Titulo de Mestre em Agronomia, Área de Concentração: Genética e Melhoramento de Plantas.
\end{abstract}

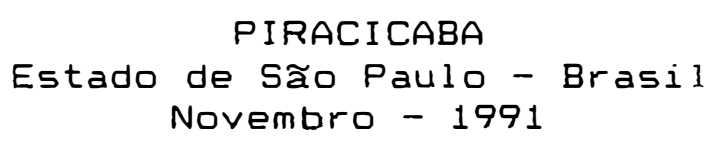




\title{
AVALIAÇÃO DO POTENCIAL DE INFECÇÃO MICORRIZIICA E CARACTERIZAÇÃO GENÉTICO-CITOLÓGICA DE ISOLADOS DE Pisolithus tinetorius
}

\author{
LILIANA KEIKO MITSUNAGA \\ Bióloga
}

Orientador: Profa. Dra. ALINE A. PIZZIRANI-KLEINER

\begin{abstract}
Dissertação apresentada d̀ Escola Superior de Agricultura "Luiz de Queiroz" da Universidade de São Paulo para obtenção do Titulo de Mestre em Agronomia, Área de Concentraçă: Genetica e Melhoramento de Plantas.
\end{abstract}

PIRACICABA

Estado de São Paulo - Brasil

Novembro - 1991 
Ficha catalográfica preparada pela Seção de Livros da Divisão de Biblioteca e Documentação - PCAP/USP

Mitsunaga, Liliana Keiko

M684a Avaliação do potencial de infecção micorrizica e carac terização genético-citológica de isolados-te Pisolithus tinctorius. Piracicaba, 1991.

143p. ilus.

Diss. (Mestre) - ESALQ

Bibliografia.

1. Fungo - Citologia 2. Fungo - Genética 3. Micorriza Potencial infeccioso 4. Micorriza - Protoplasto I. Escola Superior de Agricultura Luiz de Queiroz, Piracicaba

CDD $\quad 589.2$ 


\section{AVALI AÇ.̃̃O DO POTENCIAL DE INFEC.C.T̃O MIC.ORRIZIC.A \\ E C.ARACTERIZAÇ.̃̃o GENETICO-CITOLoGICA DE \\ ISOLADOS DE Pisalithus tinctorius}

Liliana Keiko Mitsunaga

Aprovada em: $12 \cdot 12.1991$

Comissão julgadora:
Profa. Dra. Aline A. Pizzirani-Kleiner
ESALQ/USP
Profa. Dra. Maria Helena'P. Fungaro
UEL /PR
Dr. Itamar Soares de Melo
EMBRAPA

$$
\begin{gathered}
\text { Hhit } \rho \text {. Pagrara: - Kunie } \\
\text { Profa. Dra. Aline A. Pizzirani-Kleiner } \\
\text { Orientadora }
\end{gathered}
$$


$i j i$

Ao

Henrique N. Yamauchi

com carinho. 
Aos meus pais

Sigeo Mitsunaga e

Mitiko Mitsunaga,

$D E D I C O$ 


\section{AGRADECIMENTOS}

- Á Profa. Aline A. Pizzirani-kleiner, pela orientação, confiança e incentivo;

- Ao Prof. Dr. João Lúcio de Azevedo pelas sugestões, apoio e amizade;

- Ao Prof. Dr. Cyro Grossi ("in memorian") por ter me iniciado na pesquisa;

- Ã pesquisadora Maria Eunice Assis Castro pela valiosa colaboraçăo, dedicaçăo, amizade e estímulo;

- Ao Dr. Ming Tien Lin pela concessão dos isolados de Eucalyptus e por colocar à disposição o laboratório de Microbiologia e Fitopatologia da Bioplanta Tecnologia de Plantas Ltda. para realização deste trabalho;

- Ao Prof. Tasso Léo Krügner pela concessão dos isolados de Pinuș utilizados neste trabalio;

- Ao Prof. Dr. Yoshitaka Tanaka, pelo empenho na realização dos estudos citológicos;

- Aos professores do Departamento de Genetica da ESALQ pelos ensinamentos e contribuição à minha formação profissional;

- Ao amigo Ederson Akio Kido pelo auxilio nas anslises estatisticas;

- Á amiga Benedita Aparecida da Silva, pelo constante incentivo e amizade; 
- Aos colegas do laboratório de Genetica de Microrganismos, pela amizade e convivencia;

- A Rosmary dos Santos, pelo auxilio na listagem bibliográfica;

- Aos funcionários do Laboratório de Genética de Microrganismos, Sandra R. Campos, Carlos A. Nolasco e em especial ao $\mathrm{Sr}$. Antonio Rocha Campos, pela colaboração cotidiana;

- Aos funcionários do Laboratório de Microbiologia e Fitopatologia da Bioplanta Tecnologia de Plantas Ltda. pela amizade, colaboraçăo e convivencia;

- Ao Conselho Nacional de Desenvolvimento Cientifico e Tecnologico (CNPG) pela bolsa de estudos concedida;

- Á todos que manifestaram colaboração, apoio, incentivo ou critica, no sentido de motivar a realização desse trabalno. 


\section{IND ICE}

Pagina

LISTA DE TABELAS ......................

LISTA DE FIGURAS ..................... x... $x$. $\ldots \ldots$

RESUMO $\ldots \ldots \ldots \ldots \ldots \ldots \ldots \ldots \ldots \ldots \ldots \ldots \ldots \ldots \ldots \ldots \ldots \ldots \ldots \ldots \ldots$

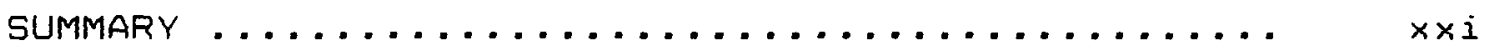

1. INTRQDUÇAR ..........................

2. REVISATo de literatura ..................

2.1. Aspectos citogenéticos em fungos ......... 04

2.1.1. Componentes do núcleo ............ 04

2.1.2. Divisão somática .............. 06

2.2. Protoplastos de fungos basidiomicetos ..... 12

2.3. Fatores que influenciam a infeç̧a ectomicorrizica ........................ 18

2.3.1. Influência de metais pesados na infeç̧ăo micorrizica ............ 20

3. material e metodos ...................... 23

3.1. Isolados utilizados ................ 23

3.2. Manutenção dos isolados .............. 24

3.3. Esterilização e incubação ............ 25

3.4. Meios de cultura utilizados ............ 25

3.4.1. Meio MNM (Melin Norkrans - modificado), de acordo com MARX, $1969 \ldots . .25$

3.4.2. Meio BDA .................. 26

3.4 .3$. Meio BDA-D .................. 26

3.4.4. Meio BDMT ................. 27

3.4 .5$. Meio MNMB ............... 27 
Página

3.4.6. Meio MNM liquido (Melin Norkrans modificado) MARX, $1969 \ldots \ldots \ldots . \ldots . . .27$

3.4.7. Meio BDA liquido ............. 27

3.4.8. Meio BDA-D liquido ............. 28

3.4.9. Meio BDMT líquido ............. 28

3.4 .10$. Meio MNMB 1 iquido ............... 28

3.4.11.Meio MNM+M semi sólido para regeneração de protoplastos ........... 28

3.4 .12 .Meio MNM+M liquido ............ 28

3.5. Soluçช̋es utilizadas ................. 29

3.5.1. Soluçåo de FeCl3 $1 \% \ldots \ldots \ldots . \ldots . . . .29$

3.5.2. Solução de Albumina $50 \% \ldots . . \ldots \ldots . . .27$

3.5 .3$. Solução de Giemsa .............. 29

3.5.4. Tampăo fosfato $0,07 M \mathrm{pH} 7,0 \ldots 30$

3.5.5. Tampåo fosfato $0,02 M \mathrm{pH} 5,8 \ldots . . . .30$

3.5.6. Solução estoque de acrilamida ..... 31

3.5.7. Tampão do gel separador ......... 31

3.5.8. Tampão do gel empilhador ......... 31

3.5.9. Tampão do tanque .............. 31

3.5.10.Tampão da amostra ............ 32

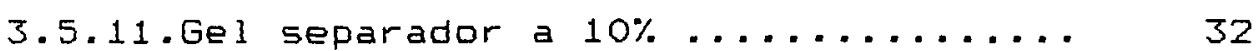

3.5 .12$. Gel empilhador a $4 \% \ldots \ldots \ldots \ldots \ldots . \ldots . \ldots 32$

3.5.13.Solução de persulfato de amónia (AP) 33

3.5 .14$. Solução Tris-HCl $0,5 M \ldots \ldots \ldots . . . .33$

3.5 .15 .501 ução $\alpha, \beta-n a f t i l$ acetato $1 \% \ldots 33$

3.5.16.Solução para revelação de esterases. 33

3.5 .17 .501 ução de $\mathrm{NaOH} 5 \mathrm{~N} \ldots . . . \ldots . \ldots . . .33$

3.5 .18$. Solução manitol $0,6 M \ldots . . \ldots \ldots . . . .34$

3.5.19.5olução de enzima para produção de protoplastos ..................

3.5.20. Solução de complexo litico I para produção de protoplastos .........

3.5.21. Solução de complexo l1tico II para produção de protoplastos .......... 
3.5 .22 . Solução estoque 1 da solução nutritiva .....................

3.5 .23 . Solução estoque 2 da solução nutritiva .....................

3.5 .24 . Solução estoque 3 da solução nutri-

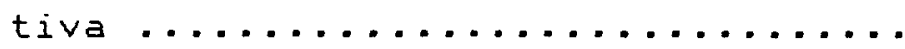

3.5.25. Solução estoque 4 da solução nutri-

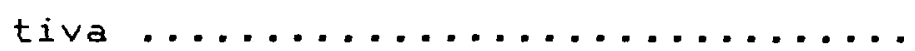

3.5 .26 . Solução estoque 5 da solução nutri-

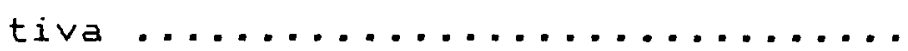

3.5 .27 . Solução estoque 6 da soluçăo nutritiva .................... 36

3.5.28. Solução nutritiva (Furlani, 1984) .. 36

3.5.29. Solução nutritiva 5 ppm de aluminio. 37

3.5.30. Solução nutritiva 10 ppm de alumínio 37

3.5.31. Soluça nutritiva 15 ppm de aluminio 37

3.5.32. Solução nutritiva 20 ppm de alumínio 37

3.5 .33 . Solução estoque de alumínio ...... 38

3.5.34. Solução nutritiva para fertilizaçăo de plantas de Eucalyptus de acordo com RUEHLE \& WELLS $(1984) \ldots \ldots \ldots \ldots .38$

3.5 .35 . Solução de $\mathrm{kOH} 10 \% \ldots \ldots \ldots . \ldots . \ldots 38$

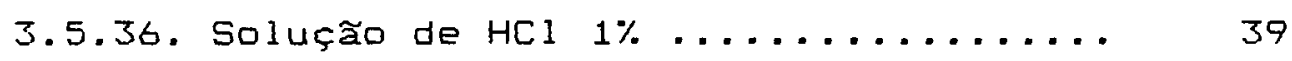

3.5 .37 . Solução descorante ............ 39

3.5.38. Soluçăo corante trypan-blue ....... 39

3.6. Substratos utilizados ................ 39

3.6.1. Substrato turfa-vermiculita - Meio MNM para produção de inoculante .... 39

3.6.2. Substrato Turfa-Vermiculita - Meio BDA para produção de inoculante .... 40

3.6.3. Substrato Turfa-Vermiculuta - Meio BDA-D para produção de inoculante .. 
Pagina

3.6.4. Substrato Turfa-Vermiculuta - Meio BDMT para produção de inoculante ...

3.6.5. Substrato Turfa-Vermiculita - Meio MNMB para prrodução de inoculante..

3.6.6. Substrato Turfa - Vermiculita para produção de mudas ................ 41

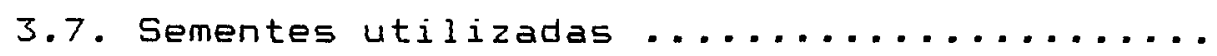

3.8. Caracterização do crescimento dos isolados de Pisolithus tinctorius em diferentes



3.9. Produção de biomassa dos isolados de Pisolithus tinctorius em diferentes meios

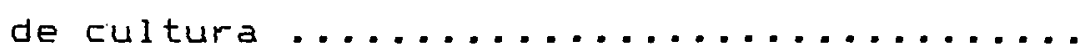

3.10. Técnica para coloraça de núcleos (TANAKA

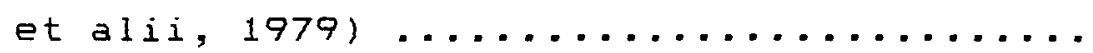

3.10.1. Determinação do número de núcleos por célula somática micelial .....

3.10.2. Medida do tamanto de núcleos ......

3.10.3. observaçôes da divisão nuclear em células somáticas do micelio.....

3.11. Caracterização eletroforetica (PACCOLA-MEI-



3.11 .1 . Preparação das amostras ......... 46

3.11.2. Placa de gel de acrilamida ....... 47

3.11.3. Aplicação das amostras e corrida da

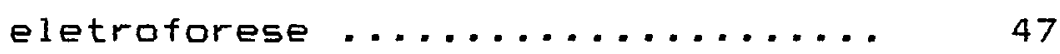

3.11 .4 . Revel ação das esterases .......... 48

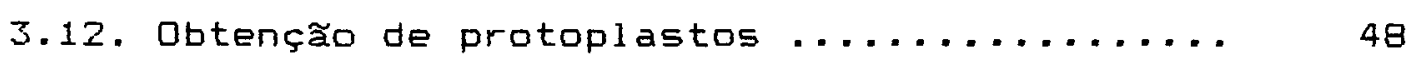

3.12.1. Avaliação da idade do micélio na 1 iberação de protoplastos ........

3.12.2. Comparação de diferentes enzimas na 1 iberação de protoplastos ......... 
Página

3.12.3. Determinação do número de protoplastos ................... 50

3.12.4. Medida do tamanho dos protoplastos. 50

3.12.5. Regeneração de protoplastos ...... 50

3.12.6. Coloração de núcleos dos protoplastos (Borges, 1987) .............

3.13. Sintese de ectomicorriza em Eucalyptus com isolados de pisolithus tinctorius em diferentes niveis de aluminio em casa de vege-

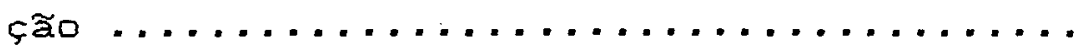

3.13 .1 . Produção de inoculante ..........

3.13.2. Inoculação do substrato ........

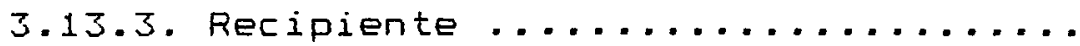

3.13.4. Semeadura ................

3.13.5. Local da instalação do experimento.

3.13.6. Delineamento estatístico ........

3.13.7. Desbaste .................

3.13.8. Adubação e aplicação do aluminio no substrato .................. 54

3.13.9. Avaliação visual de colonização ...

3.13.10. Coloração de raizes para avaliação de colonização .............. 55

3.13.11. Análise química do substrato .....

3.14. Coleta $e$ isolamento de Pisolithus tincto-



3.15. Seleção de isolados de Pisolithus tinctorius para tres espécies de Eucaliptus quanto à eficiencia para formação de micor-



3.15 .1 . Producãa de inoculante .......... 56

3.15.2. Inoculação do substrato ..........

3.15.3. Recipiente ................. 
Página

3.15.5. Local de instalação do experimento. 58

3.15.6. Delineamento estatistico ........ 58

3.15 .7 . Destaste .................. 58

3.15 .8 . Adubaçăo .................. 58

3.15.9. Avaliaçăo ................. 59

3.16. Avaliação do grau de micorrização de mudas de Eucalyptus urophylla proveniente de semeio direto e plantulas, inoculadas com isolados de Pisolithus tinctorius ........

3.16.1. Produção de inoculante ......... 59

3.16 .2 . Inoculação do substrato ......... 59

3.16.3. Recipiente ................ 60

3.16 .4 . Semeadura ................. 60

3.16.5. Transplante de plântulas ......... 60

3.16.6. Local de instalação do experimento. 61

3.16.7. Delineamento estatistico ........ 61

3.16.8. Desbaste .................. 62

3.16 .9 . Adubaçăo ................. 62

3.16.10. Avaliaçฐ̃o ................. 62

3.17. Produção de inoculante de um isolado de Pisolithus tinctorius em diferentes subs-

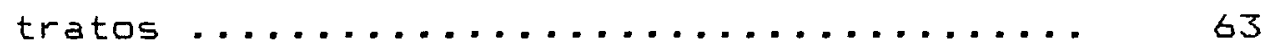

3.17.1. Preparo do substrato ........... 63

3.17 .2 . Produção de inoculante ......... 63

3.17.3. Delineamento estatistico ........ 63

3.17 .4 . Avaliação .................. 64

4. REsultados E discussão .................. 65

4.1. Caracterização do crescimento dos isolados de Pisolithus tinctorius em diferentes

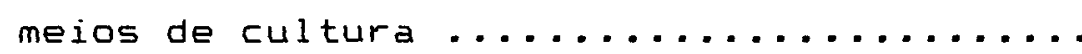


4.2. Produção de biomassa dos isolados de Pisolithus tinctorius em diferentes meios

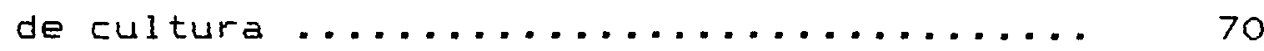

4.3. Caracterização citologgica ............. 77

4.4. Padrão eletroforético de esterases ....... 83

4.5. Obtenção de protoplastos .............. 85

4.6. Avaliação da formação de ectomicorriza em Eucalyptus com isolados de Pisolithus tinctorius em diferentes concentraçōes de



4.7. Coleta e isolamento de Pisolithus

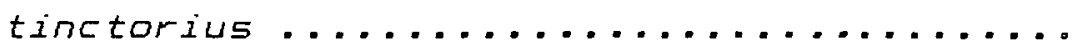

4.8. Avaliaçăo da seleção de isolados de Pisolithus tinctorius para três especies de Eucalyptus quanto a eficiéncia para formação de micorriza ...................

4.9. Avaliação do grau de micorrização de mudas de Eucalyptus urophylla provenientes de semeio direto e plântulas, inoculadas com isolados de Pisolithus tinctorius ........

4.10. Avaliação da produção de inoculante de um isolado de Pisolithus tinctorius em dife-

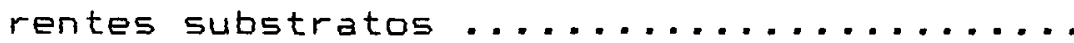

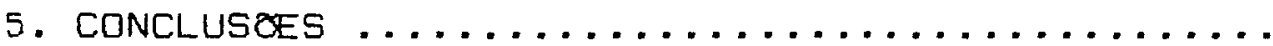


01 Valores e significâncias dos quadrados médios da análise de variância dos dados das medidas dos diâmetros das colónias em placas contendo diferentes meios de cultura.

02 Comparação das médias (diámetros de colónias) de isolados pelo teste de Tukey ....

03 Comparação das medias (diámetros de colônias) de meios pelo teste de Tukey .......

04 Comparação das médias de diâmetros das colónias dos isolados em função da idade (dias) pelo teste de Tukey .............

05 Valores e significancias dos quadrados médios da análise de variáncia dos dados das medidas de pesos secos de micelio de diferentes isolados em diferentes meios de



o6 Comparação das médias (peso seco de micélio) de isolados inoculados em diferentes meios de cultura pelo teste de Tukey .....

07 Comparação das médias (peso seco de micélia) dos isolados dentro de cada meio ....

o8 Comparação das médias (peso seco de micélio) de meios pelo teste de Tukey ........ 
Comparação das medias de meios (peso seco de micelia) dentro de cada isolado .......

10 Liberação de protoplastos de Pisolithus tinctarius usando diferentes preparaçós enzimáticas ......................

86

11 Valores e significâncias dos quadrados médios da análise de variância dos dados da avaliação da sintese de ectomicorriza em Eucalyptus em diferentes niveis de aluminio atraves de coloração de raizes ......

12 Resultado da análise química do substrato utilizado para o experimento da sintese de ectomicorriza em Eucalyptus em diferentes concentraçőes de alumínio ............

13 Dosagem de aluminio nos substratos no final do experimento $\ldots \ldots \ldots \ldots \ldots \ldots \ldots \ldots$

14 Concentração final da solução nutritiva ..

15 Avaliação do grau de micorrização de três espécies de Eucalyptus, inoculados com nove isolados de Pisolithus tinctorius ....

16 Valores e significancias dos quadrados médios da análise de variância dos dados do grau de micorrização de mudas de Eucalyptus provenientes do semeio direto e plántulas com isolados de $P$. tinctorius ...... 100 
17 Comparação das médias (grau de micorrização) de isolados de Pisolithus tinctorius pelo teste de Tukey ................

18 Comparação das medias (grau de micorrizaça) de isolados dentro de sementes e plântulas do fator fases de inoculação ... 101

19 Comparação das medias (grau de micorrizaçăo) de fases de inoculação pelo teste de Tukey ........................

20 Comparação das médias (grau de micorrização) de sementes e plântulas do fator fases de inoculação dentro de cada isolado.

21 Crescimento do isolado PI 314 em diferentes substratos ................... 


\section{LISTA DE FIGURAS}

FIGURA No

Página

01

a - d) Desenvolvimento de hifas de Pisolithus tinctarius. Presença de dois núcleos por celula micelial .........

02 Fases da divisão mitótica em célula samática de micélio de Pisolithius

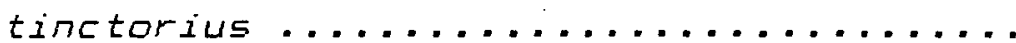

Padrão eletroforético de esterases de diferentes isolados de Pisolithus

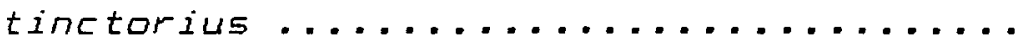

04 Influencia da idade do micélio na liberação de protoplastos do isolado FEP3 de Pisolithus tinctorius em diferentes tempos de incubaçăo com Novozyme 234 .....

05 1) Corpos de frutificação do fungo Pisolithus tinctorius; 2) Fase inicial da sintese de ectomicorriza em Eucalyptus urophylla; 3) Ectomicorriza em Eucalyptus urophylla ............. 


\section{AVALI AÇOTO DO POTENCI AL DE INFECÇAO MICORRIZICA \\ E CARACTERIZAÇÃO GENETTCO-CITOLOGICA DE \\ ISOLADOS DE Pisolithus tinctarius}

Autor: Liliana Keiko Mitsunaga Orientadora: Profa. Dra. Aline A. Pizzirani-Kleiner

\section{RESUMO}

o presente trabalto foi realizado com a finalidade de estudar alguns isolados de Pisolithus tinctorius quanto aos aspectos básicos de crescimento, características citologicas, padrão de esterases e obtenção de protoplastos e quanto ao potencial de infecção desses isolados em espécies de Euralyptus.

A caracterização do crescimento em diferentes meios de cultura mostrou que os isolados AC 12, PI 314 e PI 203 apresentaram um bom crescimento em todos os meios testados, enquanto que os outros isolados mostraram modificaçß̊ses no hábito de crescimento micelial, e não apresentaram diferenças quanto a produção de biomassa nos diferentes meios. Na análise citológica, verificou-se que as hifas apresentam espessuras diferentes, cada célula micelial possui dois núcleos com diâmetro medio de $2,439 \mathrm{\mu m}$ a a presença de pontes de conexão entre as células. O estudo do comportamento do núcleo durante a divisão de células somáticas demonstrou que a mitose é similar a que ocorre em 
outros fungos com agregação dos cromossomos formando duas barras paralelas. O número de cromossomos não pode ser determinado. Os isolados de $P$. tinctorius obtidos de Pinus apresentaram um padrão eletroforetico de esterases com quatro bandas. Para esses isolados foram padronizados a idade da cultura, a metodologia para extração das enzimas e a concentração das amostras. Para os isolados de Eucalyptus, não se obteve resultado satisfatório para esterases. Quanto a obtenção de protoplastos, fez-se a avaliação de algumas condições para o isolamento dos mesmos obtendo-se maior produção com a utilizaçăo de micélio com quatro dias de idade, Novozym 234 e manitol como estabilizador osmotico.

Quanto aos aspectos mais praticos, fez-se a avaliação de alguns isolados para a sintese de micorriza em especies de Eucalyptus em diferentes concentraçöes de aluminio. Os resultados obtidos não foram satisfatórios devido a grande falha na micorrizaçăo das plantas. Novos isolados foram obtidos e entre esses, selecionou-se a AT so1 e a AT 502 para Eucalyptus urophylla e E. paniculata e O AT 502 e AT 508 para E. torelliana. Para os outros isolados, mais de 50\% das plantas năo apresentaram micorrizas. Para superar a não infecção observada, fez-se a inoculação de plantulas ao inves de sementes como havia sendo feito anteriormente. Com essa alteração, o problema da falha de micorrização foi eliminado porque provavelmente as particulas de vermiculita 
utilizadas para a produção de inóculo, estivessem mais externamente tomadas pelas hifas do fungo as quais não sobreviveram no periodo entre a inoculação e o desenvolvimento de raizes curtas das plantas. 
POTENTIAL OF MYCORRHIZAL INFECTION, GENETIC AND CYTOLOGICAL CHARACTERIZATION OF ISOLATES OF Pisolithus tinctarius

Author: Liliana Keiko Mitsunaga Adviser: Prof. Dra. Aline A. Pizzirani-kleiner

\section{SUMMARY}

The present research was carried out in order to study basic aspects of growth, cytological characteristics, patterns of esterases and protoplast isolation of some isolates of Pisolithus tinctorius as well as their potential of mycorrhizal infection in Eucalyptus.

Growth characteristics in different media has shown that the isolates AC 12, PI 314 and PI 203 had good growth in all of them, while the other ones showed changes in mycelium growth and didn't show a difference in the biomass production. Cytological analysis of these isolates indicated that the hyphae had different widths, each mycelial cell had two nuclei with a diameter of 2.439 $\mu m$ and the presence of clamp connexion between the cells. The study of the nuclei during the division of somatic cells showed that the mitosis is similar to that which occurs in other fungi, with the chromossomes forming two parallel bars. The cromossome number could not be determinated. Pisolithus tinctorius isalated from Pinus showed an eletra- 
phoretic pattern of esterase with four bands. For the Eucalyptus isolates, there were no satisfactory results. An evaluation of different conditions was made for the isolation of protoplasts. Optimal yield were obtained with four day old mycelia, Novozym 234 and the osmotic stabilizer, mannitol.

For practical aspects, some strains were evaluated for their potential in mycorricizal infection on Eucalyptus species in different concentrations of iron. The results were not satisfactory because of the failure to obtain infection of the plants. New strains were isolated and among them AT 501 and AT 502 were selected for Eucalyptus urophylla and E. paniculata and AT 502 and AT 508 for E. torelliana. The other strains did not infect more than 50\% of the plants. In order to try to overcome this problem the inoculation of a few plants, instead of inoculation of seeds, was made. With this alteration, the problem of non infection was solved, probably because the fungi grown on particles of vermiculite were not able to survive during the period of root formation, when inoculated an seeds. 


\section{INTRODUÇÃO}

As micorrizas, associaçôes simbioticas entre raiz e fungo do solo, vém despertando grande interesse dos cientistas devido aos beneficios que elas podem oferecer às plantas. Estas associaçôs simbióticas permitem uma melhoria na absorção de água e nutrientes pela planta, aumentando sua capacidade de sobrevivencia e tolerância a condiçơs adversas (seca, extremos de temperatura, etc.) e agentes patogenicas. Existem dois tipos de fungos entre as micorrizas mais disseminadas: aqueles que se desenvolvem intercelularmente na raiz da planta, formando a rede de Hartig e crescem extensivamente fora a raiz, formando um manto; a esta associaçăo denomina-se ectomicorriza, e, aquela com desenvolvimento predominante no interior das células da raiz, denomina-se endomicorriza.

Nas plantas de interesse florestal, as ecto e as endomicorrizas săo frequientes, sendo que em condiçōes naturais um ou outro tipo predomina de acordo com a regiao considerada. 
A importância dos fungos micorrizicos no desenvolvimento e sobrevivencia de plantas florestais é evidente quando se tenta introduzi-las em solos desprovidos de inoculo natural destes fungos e o crescimento vegetal falho (MIKOLA, 1973).

o setor florestal contribui de modo significativo para a economia nacional. Ds produtos florestais representam $3 \%$ do produto nacional bruto $e 3,5 \%$ de suas exportaçơes. Atualmente cortes de 500 a 600 milhơes de hectares devem ser feitos para atender ao consumo dos programas de papel, celulose, siderurgia e carvão vegetal e, nos proximos vinte anos, $5 \mathrm{milh}$ bes de hectares deverao ser reflorestados principalmente com Pinus spp e Eucalyptus spp ( ZAMBOLIM \& SIQUEIRA, 1985).

Entre as diversas especies de fungos ectomicorrizicos que se associam às plantas florestais, a fungo Pisalithus tinctorius e comumente isolado em condiçzes naturais, sendo também utilizado como inoculante e apresentando especificidade para Pinus e Eucalyptus (KRÜGNER \& TOMAZELLO FILHO, 1979). E um fungo da classe Basidiomiceto, ordem Sclerodermatales, familia Pisolithaceae. Segundo MULLETTE (1776), a primeira associação descrita desse fungo em Eucalyptus foi na Africa do Sul por A.A. van der Bijl, em 1917 .

o Pisalithus tinctarius é uma espécie importante no estabelecimento de programa de micorrização e, no 
entanto, émito pouco conhecido quanto a sua biologia. Uma previsão do seu comportamento pode ser feita atraves de estudos fisiologicos, geneticas e ecológicos realizados em lahoratorio que em uma segunda fase muito contribuirao para o aumento da eficiencia nos seus hospedeiros.

Diante destes fatos, o presente trabaliho foi desenvolvido com o objetivo de estudar alguns isolados de Pisolithus tinctorius sob dois aspectos:

a. Conhecimento básico desses isolados considerando-se a análise citologica, crescimento em diferentes meios de cultura, caracterização eletroforética e obtenção e regeneração de protoplastos;

b. Avaliação sob o ponto de vista mais aplicado considerando-se coleta, isolamento e seleçăo dos novos isolados de $P$. tinctorius, estudos sobre a interaçăo entre aluminio e infeç̧ăo micorrizica e a produção de mudas micorrizadas. 


\section{REVISÃo DE LITERATURA}

\subsection{Aspectos citogenéticos em fungos}

\subsubsection{Componentes do núcleo}

o envelope nuclear que envolve grande parte do DNA en fungos, consiste, como em eucariotos superiores, de duas membranas paralelas (FINCHAN et alii, 1979). Possuem poros que podem estar espalhados pela sua superficie ou, algumas vezes, concentrados em regibes especificas (BURNETT, 1976 ).

Em muitos organismos, o envelope nuclear dispersa-se durante a prófase, como em animais e plantas superiores; mas, em outros, permanece intacto durante a mitose, como observado em Blastocladiella emersonit (TURIAN \& CANTINO, 1960), Macrophomina phaseali (KNOX-DAVIES, 1967) e Catenaria anguillulae (ICHIDA \& FULLER, 1968). Em alguns casos ocorre formação de abertura nos polos do envelope nuclear (MARTIN \& MILLER, 1986). Segundo HEATH (1980a) estes săo os três padrơes mais comuns do comportamento do envelope nuclear na divisão do núcleo em fungos. 
o nuclélo, uma estrutura tipicamente eucariótica, é um corpúsculo esférico, rico em ácido ribonucleico. Originam-se de um ponto especifico em um dos cromossomos, a organizador do nucleolo (FINCHAN et alii, 1979) e, segundo HEATH (1980a) exibem uma serie de padräs de comportamento durante a mitose, podendo persistir na sua forma interfásica contraindo-se e originando duas partes aproximadamente iguais na telofasel ou dispersar-se durante a prófase. No entanto, entre estes extremos podem ser encontrados padräes de comportamento intermediários.

Outro componente, muito importante do núcleo E a cromatina, que é um complexo de DNA nuclear intimamente associado com proteinas histónicase so podem ser vistos como corpúsculos separados durante a divisão nuclear. Em Aspergillus, Neurospora e Saccharomyces os componentes HzA, $\mathrm{H}_{2} \mathrm{~B}, \mathrm{H}_{3} \mathrm{e} \mathrm{H}_{4}$ das histonas são muito parecidos ou, em alguns casos, quase identicos aos dos eucariotos superiores (FINCHAN et alii, 1979). Verifica-se nåo somente a presença de histonas, mas também de nucleossomos tipicos.

A maioria dos eucariotos inferiores apresentam um padrão tipico de heterocromatina-eucromatina na interfase, mas em alguns organismos a cromatina năo se condensa em nentum estágio do ciclo nuclear (HEATH, 1980b). a autor sugere que a heterocromatinizaçăo aparentemente năo é um meio universal de controle génico e que a condensação da cromatina nåo e um requerimento universal para a mitose. 
HEATH (1980a) relata em sua revisăo, fungos e protistas que apresentam esta falta de condensação da cromatina.

\subsubsection{Divisão somâtica}

Em muitos fungos podemos observar a condensaçă da cromatina e cromossomos independentes. Geralmente admite-se que a mitose nestes fungos segue o mesmo curso que em organismos superiores; porém, alguns autores encontraram que a mitose ocorria por divisåo nuclear direta, atraves de along a mento, constricção e separação do núcleo em duas partes, sem formaçăo de fases mitóticas ou cromossomos individualmente distintos.

Os trabalhos mostram que as mitoses fúngicas possuem particularidades que os colocam fora das formas mais comuns de divisão celular. As diferenças mais interessantes encontradas em alguns fungos incluem a segregação de cinetocoras em dois grupos durante a proffase, a ausencia de condensação da cromatina e de placa metafásica, e a formação de um feixe central de microtúbulos (HEATH, 1980a).

\section{Interfase}

o núcleo interfásico dos fungos é morfologicamente similar ao núcleo interfásico de plantas superiores. São esféricos ou ovais, limitados por um envelope composto de duas membranas unitárias, contendo um proeminente nu- 
cleola. Em Poria manticala foram vistos filamentos duplos de cromatina; segundo BRUSHABER \& JENKINS (1971) este é um fator comumente observado em núcleos interfásicos de fungos. SOMERS et alii (1960), observaram, em Neurospora crassa, segmentas heterocromáticos e um grande nuclélo. Os nucleolos em Ceratocystis fagacearum frequentemente estao localizados sobre a periferia da cromatina e, ocasionalmente, os núcleos redondos ou ovais tornam-se um pouco atenuados, parecendo uma massa de cromatina de contorno irregular, com os nucleolos ligados na extremidade dos cromossomos nucleolares (AIST \& WILSON, 1967b). Em núcleos interfásicos de olpidiopsis varians, alem do nucleolo foram encontrados comumente inclusáes de lipidios e, algumas vezes, dictiossomos associados ao núcleo (MARTIN \& MILLER, 1986).

Algumas vezes, sobre ou próximo ao envelope nuclear, há uma organela que durante a divisão do núcleo está associada ao fuso. Esta organela apresenta ampla variaçăo morfológica, podendo ser um centrílo ou uma estrutura mais simples que recebe varias denominaçóes. ICHIDA \& FULLER (1968) observaram em Catenaria anguillulae um simples par de centrílo, acompanhada por microtúbulos que irradiavam da região dos centriolos. Os centriolos neste fungo consistem de nove conjuntos de "triplets" arranjados em um padrão cilindrico. Já em Basidiomicetos não foram descritos centriolos tubulares (BRUSHABER \& JENKINS, 1971 ). 


\section{Prófase}

A mitose praticamente inicia-se com a
prófase, que é a fase mais interessante da divisão, pois é
nesta etapa que a cromatina prepara-se para a divisăo. Em Neurospora crassa, a prófase procede de maneira convencional. No estágio inicial os cromossomos são mais dificeis de serem observados, mas durante a profase ocorre a espiralizaçăo e os cromossomos individualizados podem ser observados, bem como suas espirais (SOMERS et alii, 1960).

Já em Ceratocystis fagacearum, além de ocorrer o espessamento dos cromossomos, pode-se distinguir uma prófase inicial, observando-se a espessura dos cromossomos nucleolares que durante a interfase são muito finos $e$ o nucleolo está a vários mícrons do corpúsculo de cromatina principal; mas, durante a prófase, o cromossomo nucleolar torna-se mais espesso e o nucleolo tende a permanecer dentro da massa de cromatina principal (AIST \& WILSON, 1967b).

Segundo HEATH (1980a), a prófase é a fase mais negligenciada na literatura dos fungos. A metáfase e as figuras subsequentes så facilmente reconhecidas, mas alguns eventos da profase se confundem com os da interfase.

De acordo com FULLER (1976), a reconhecimento de dois pares de centriolos e primeiro sinal de que o núcleo está em prófase. Durante o estágio inicial da prófase em Saprolegnia ferax, cada núcleo é acompanhado por um simples par de centrílos extranucleares e, dentro do nú- 
cleo, numa região diferenciada do envelope nuclear, adjacentes aos centriolos, formam-se microtúbulos curtos. Com o progresso da prófase, os centriolos se duplicam para formar dois pares e, durante este processo, os microtúbulos também separam-se em dois grupos discretos que depois se reorientam para formarem fusos metafásicos bipolares.

\section{Metáfase}

Em alguns fungos, os eventos da metáfase são convencionais: mostram placas metafásicas tipicas. Já em outros, as cromossomos estão dispersos ao longo do fuso. A metafase, em fungos centrialares, geralmente é clássica - os pares de cromatides estão alinhados sobre a placa equatorial. Em Neurospora crassa as cromossomos assumem configuraçôes similares à metáfase mitótica regular. Os cromossomos individuais podem ser vistos alinhados na placa metafásica e, neste estágio, a morfologia dos cromossomos podem ser distinguidas (SOMERS et alii, 1960). Uma placa metafásica tipica também foi observada por WARD \& CIURYSEK (1961) em um Basidiomiceto onde todos os cromossomos também foram distinguidos.

Durante a metáfase em Catenaria anguillulae, a estrutura dos corpúsculos polares do fuso e claramente vista e a conexão das fibras com os cromossomos săo evidentes (ICHIDA \& FULLER, 1968). Nestes casos, os cromossomos são claramente separados de maneira tradicional; mas, em 
alguns casos, foi observado que frequentemente os cromossomos estavam aglomerados na metáfase, formando uma massa compacta (KNOX-DAVIS, 1967 e BRUSHABER \& JENKINS, 1971 ).

Qs núcleos, em Humicula sp, apresentam corpos cromatínicos em forma de rosário, ou irregulares e năo diferenciados em cromossomos (RODRIGUES, 1987).

Em Marasmius foi detectada uma curiosa configuração cromossomal, o material cromatínico torna-se orientado em duas ou, raramente, mais cadeias paralelas enfileiradas ao redor e ao longo do fuso. Esta configuraçăo foi chamada de "estágio de trilho" ou de "duplo trilho" (BURNETT, 1976). Este estágio de trilho, não tem equivalente nas formas usuais da mitose e foi observado em outros fungos, como: Aspergillus nidulans (ROBINOW \& CATEN, 1969), Fusarium axysporum (AIST \& WILSON, 1967a) e Ceratocystis fagacearum. (AIST \& WILSON, 1966).

HEATH (1980a) concluiu que a aquisição de um equilibrio dos cromossomos na posição equatorial não é um prérequisito para a subseqüente separação e movimento anafásico e que o comportamento dos cromossomos é controlado a nivel de cromossomos individuais.

\section{Anáfase - Telof ase}

FULLER (1976) define a anáfase como o estágio caracterizado pela separação e polarização do material genómico duplicado e, telófase inclui os eventos envolvidos na 
posterior separação das cromátides polarizadas e a formação de núcleos filhos com seus envelopes nucleares.

WARD \& CIURYSEK (1961), estudando Um Basidiomiceto, observaram que oito cromátides originaram-se de quatro cromossomos metafásicos e que estes se separaram regularmente em dois grupos de quatro para polos opostos do fuso. Em Macrophomina phaseoli foram observados regularmente pontes cromossomicas e cromossomos retardatarios (KNOX-DAVIES, 1967). As pontes cromossomicas também foram observadas em Poria manticola por BRUSHABER \& JENKINS (1971).

Segundo HEATH (1980a), dois tipos de movimentos ocorrem durante a anáfase e telófase: o encurtamento dos microtúbulos cinetocoros, movendo a cinetocoro ligado ao cromossomo e, em adiçăo, o alongamento do fuso, aumentando a distancia interpolar. O arranjo destes dois processos varia de organismo para organismo.

Em Catenaria anguillulae foram observados núcleos alongados na fase anafásica. ICHIDA \& FULLER (1968) sugerem que os cromossomos são puxados ou empurrados pelo alongamento do núcleo e a separação dos pólos. Foi observado que as fibras continuas do fuso se alongam quando os pólos tornam-se mais distantes um do outro e este alongamento poderia servir para separar os cromossomos irmãos. Após a separaçăo a regiao interzonal e comprimida próximo aos núcleos irmãos. 
Segundo FULLER (1976) o alongamento de túbulos interpolares durante a telofase ocorre em todos os fungos centrialares.

Em fungos onde foi observado o estágio de "duplo trilho", o alongamento do núcleo e do fuso parece quebrar as barras transversalmente na região equatorial e, posteriormente, as duas partes migram para extremidades opostas do fusa. A cromatina se acumula nas extremidades da barra dupla e se condensa para formar dois núcleos filhos.

2.2. Protoplastos de fungos basidiomicetos

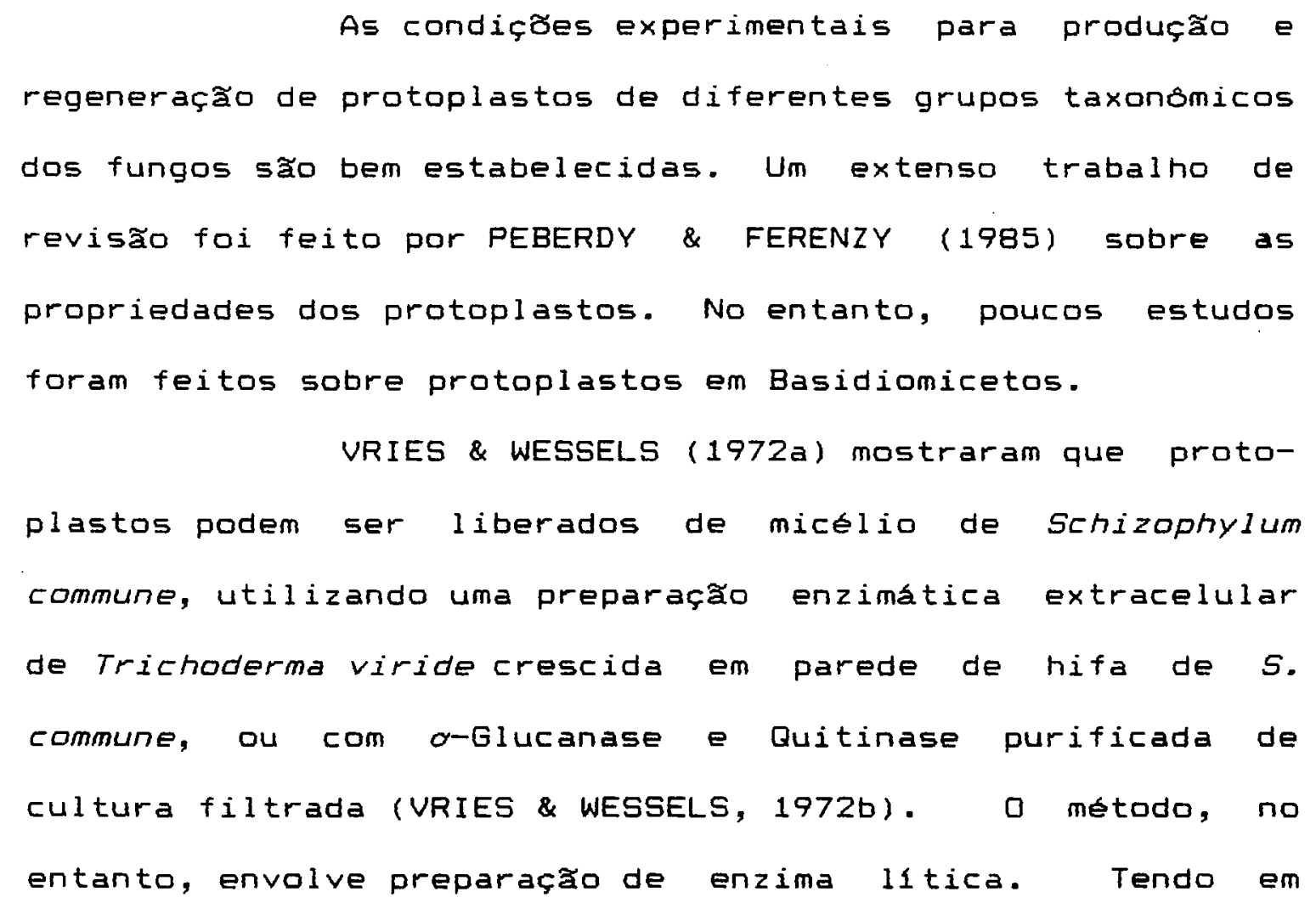


vista que a preparação da enzima é um processo demorado, numerosas enzimas comerciais estão disponiveis e têm sido utilizadas para isolar protoplastos de fungos filamentosos. GOLD et alii (1983) demonstraram que a combinação de duas enzimas comerciais, Novozyme 234 e Celulase CP foi muito eficiente para Phanerochaete chrysosporium: obteve-se $3 \times 10^{9}$ protoplastos por grama de peso úmido depois de 3 horas de incubação. Os autores observaram que estas enzimas utilizadas individualmente produzem aproximadamente 5 e 50\% respectivamente do número obtido quando utilizadas juntas. Devido à complexidade e diversidade da parede celular das hifas, muitas vezes a combinaça de enzimas liticas promove melhores resultados na liberaçăo de protoplastos.

A enzima Novozyme 234 também foi utilizada por MUKHERJEE \& SENGUPTA (1986) para produzir protoplastos de micelio de Volvariella volvacea com 18 horas de incubação. a período de incubação e uma consideração importante durante a liberação dos protoplastos, pois a incubação prolongada pode causar a degeneração dos protoplastos formados inicialmente ou, em alguns casos, regenerar hifas aberrantes (Gabriel, 1968, citado por PEBERDY \& FERENZY, 1985).

YANAGI \& TAKEBE (1984) desenvolveram um processo altamente eficiente para isolamento de protoplastos de micélio de várias espécies de Basidiomicetos, utilizando uma 
combinaçăo de Quitinase e Celulase Onozuka R10. Depois de 1 hora de incubaçăo, $10^{\mathbf{B}}$ protoplastos/ml foram liberados de Coprinus macrorhizus e a suplementaçăo da mistura com zymo-


mistura destas quatro enzimas foi utilizada com sucesso por MORINAGA et alii (1985) para outras duas especies de Caprinus, Coprinus cinereus e Coprinus pellucidus, e por WAKABAYASHI et alii (1985) para Pleutorus cornucopiae.

YANAGI et alii (1985) utilizaram Celulase Onozuka R10, Quitinase e Zymaliase para Coprinus macrorhizus e constataram que o acréscimo de Novozyme 234 a esta solução também podia elevar significativamente a produção de protoplastos e, mesmo sozinha, grande número de protoplastos foram liberados, mas eram relativamente pequenos e havia uma grande proporçă anucleada. Esta solução enzimática também foi eficaz para a obtenção de protoplastos de outras espécies de Basidiomicetos como Flammulina velutipes, Ganoderma lucidum, Grifola frondosa, Lentinus edodes, Lyophyllum ulmarium, Pleurotus ostreatus, Pholiota nameko e Tremella fuciformes.

TOYOMASU et alii (1986) demonstraram que a combinação de driselase com celulase e $\beta$ - glucuronidase são eficientes para produzir protoplastos a partir de micelio de Pleurotus ostreatus e Pleurotus salmoneo stramineus.

A produçå e a estabilidade dos protoplastos 
podem ser influenciadas pelo tipo e concentração do estabilizador osmótico e estes fatores variam de organismo para organismo.

Em Schizophyllum commune a densidade dos protoplastos isolados pode ser afetada por diferentes estabilizadores. Em Sorbitol, Manitol, NaCl e KCl, os protoplastos sedimentam por gravidade, mas em Sucrose as protoplastos permanecem em suspensao, indicando que eles tem uma densidade similar à da soluçăo. Quando MgSO4 foi utilizado como estabilizador, os protoplastos liberados eram altamente vacuolados (VRIES \& WESSELS, 1972a). No entanto, MgSO4 foi o estabilizador mais satisfatorio para Coprinus cinereus e Coprinus pellucidus (MORINAGA et alii, 1985) e tambem para Phanerochaete chrysosporium (GOLD et alii, 1983).

Segundo DAVIS (1985), os sais inorganicos em geral, são os estabilizadores mais apropriados para fungos filamentosos. Porém, muitos pesquisadores tém obtido melhores resultados utilizando açúcares como estabilizadores para muitos fungos Basidiomicetos.

Para Coprinus macrorhizus a produção de protoplastos foi mais elevada em Manitol, mas os protoplastos isolados usando Sucrose como estabilizador, mostraram uma maior freqüencia de regeneração (YANAGI et alii, 1985 e KIGUCHI \& YANAGI, 1985). Semelhante observação foi feita para Pleurotus cornucopiae (WAKABAYASHI et alii, 1985 e MAGAE et alii, 1986). 
Enquanto protoplastos têm sido produzidos de vários fungos basidiomicetos, sao raros os trabalhos sobre obtenção de protoplastos de fungos basidiomicetos ectomicorrizicos.

Um trabalno histórico que relata obtenção de protoplastos de um fungo basidiomiceto ectomicorrizico foi feito por GILES \& WHITEHEAD (1976) em Rhizapogon sp com preparação enzimática obtida de Trichoderma viride. Estes autores introduziram células de Azotobacter vinelandii em protoplastos de Rizopogon Sp e demonstraram a capacidade de redução de acetileno e a sintese de micorriza pelo micélio modificado.

Mais recentemente, KROPP \& FORTIN (1985) relataram o sucesso da aplicação de algumas enzimas comerciais para obtençăo de protoplastos de Laccaria bicolor. Foram testados Novazyme 234, Celulase TV e Quitinase, individualmente combinaçăes entre elas. O melhor resultado fai abtido com Novozyme 234. A adição de Quitinase ou Celulase não produziu nenhum aumento quando comparado ao obtido com Novozyme sozinha. A produçăo foram grandemente influenciada pela natureza do estabilizador osmotico: $12-13 \times 10^{\circ}$ protoplastos $/ \mathrm{cm}^{3}$ de micelio foram produzidos com Manitol ou Sucrose, mas somente 7 a $12 \%$ desta produção foram obtidas com KCl, NaCl ou MgSO4. HEBRAUD \& FEVRE (1988) demonstraram que a mistura de celulase Onozuka R10 e Driselase em combinação com MgSO4 como estabilizador $㇒$ a mistura mais eficiente para 
Hebeloma cylindrosporum, Hebeloma edurum, Hebeloma sinapizans e Suilis bellini, mas não para Pisolithus tinctorius Manitol e Sorbitol foram utilizados no meio para regeneração dos protoplastos e cerca de $25 \%$ dos protoplastos nucleados de Hebeloma cylindrosporum regeneraram.

Mutantes de $H$. Cylindrosporum resistentes a fungicidas foram isolados por radiaça dos protoplastos com luz ultravioleta. A mutação e uma ferramenta comum em genetica, usada para modificar a expressao de genomas existentes e introduzir variabilidade genetica.

Similarmente a KROPP \& FORTIN (1985), protoplastos de Hebeloma circinans, Hebeloma cylindrosporum, Laccaria bicolor, Laccaria laccata (3 isolados), Pisolithus tinctarius, Suillus luteus e Thelephora terrestris foram obtidos com Novozyme 234 por BARRETT et alii (1989). a Manitol foi utilizado como estabilizador para todos estes basidiomicetos. A regeneração dos protoplastos só não foi obtida de Pisolithus tinctorius e Suillus luteus, pois os protoplastos destes dois fungos mostraram ausencia de núc leos.

Além das enzimas e dos estabilizadores, a idade da cultura tem sido analisada na tentativa de elevar a produção de protoplastos. Em geral, a produção máxima de protoplastos é obtida de micelio na fase exponencial de crescimento.

Segundo KROPP \& FORTIN (1985), a produção de 
protoplastos de L. bicolor variou grandemente, dependendo das condiçôes usadas para digestão. Concluiram que o fator mais importante é a idade da cultura sendo digerida. Numerosas pontas de hifas jovens, suceptiveis à digestăo, foram produzidas depois de 4 dias de crescimento do inóculo homogeneizado. Com seis dias de crescimento, a nivel de liberação de protoplastos diminuiu muito. Para $H$. cylindrosporum a mais alta produção foi obtida com micelio de 2 dias de crescimento (HEBRAUD \& FEVRE, 1988).

Ainda dentro deste contexto, BARRETT et alii (1989) testaram a formação de protoplastos com micelio de 2 , 4 e 10 dias de crescimento de sete fungos basidiomicetos ectomicorrizicos e também concluiram que o isolamento de protoplastos foi grandemente afetado pela idade da cultura.

2.3. Fatores que influenciam a infecção ectomicorrizica

Segundo RIFFLE \& MARONEK (1982), a interação entre o fungo e o hospedeiro $e$ influenciada por processos bioqurmicos, fisiológicos e condiçôses ambientais.

A alta fertilidade comumente utilizada na produção de mudas, restringe ou impede o desenvolvimento micorrizico. Muitos experimentos comprovam que a reduçăo do nivel de fertilidade melhora significantemente o desenvalvimento micorrizico (MOLINA \& TRAPPE, 1982). 
Pisolithus tinctorius parece especialmente sensivel a alta fertilidade no substrato. MULLETTE (1976) estudou o desenvolvimento de micorriza sob 5 niveis de fósforo em Eucalyptus gummifera por Pisolithus tinctorius e observau que houve pelo menos $70 \%$ de formacão em niveis favoraveis desse elemento (1-5 ppm). Nentuma micorriza foi desenvolvida em concentraçơes acima de 10 ppm e, na ausencia de fósforo, o desenvolvimento foi relativamente moderado.

A temperatura também pode influenciar na infecção micorrizica. MARX (1969) obteve com Pisolithus tinctorius uma maxima sintese de micorriza em Pinus taeda a $34 \circ \mathrm{C}$.

Alguns fatores também podem afetar a efetividade do inóculo e, com isso, comprometer a formação das micorrizas. A idade da cultura pode ser um destes fatores. o inoculo preparado com micelio de $P$. tinctorius, crescido em meio liquido, tem uma ativide máxima com tres semanas de crescimento - que coincide com a concentração máxima de ATP (LAPEYRIE \& BRUCHET, 1985). MARX et alii (1982) concluiram que o inóculo de $P$. tinctorius mais efetivo e aquele com abundante hifa do fungo protegida dentro das particulas de vermiculita, $\mathrm{pH}$ entre 4,5 e 6,0, minima quantidade de contaminantes microbianos e baixa quantidade de Glicose residual. 


\subsubsection{Influencia de metais pesados na infecção micorrízica}

Já está bem estabelecido que a infecção micorrizica pode levar a um aumento da eficiencia na absorçăo de nutrientes restritos e que isto pode levar ao melhoramento do crescimento de plantas micorrizadas. No entanto, pouca atenção tem sido data para o papel da micorriza em ambientes contendo niveis tóxicos de elementos minerais. Nestas circunstancias o resultado poderia ser fisiologicamente prejudicial em vez de benefico para o hospedeiro.

Sob condiçớes ácidas e deposição de metais

pesados, a infecção pelo fungo endomicorrizico Glomus faciculatum elevou grandemente a absorça de metais, reduzindo o crescimento de Ehrharta calycina (KILLHAM \& FIRESTaNE, 1983). Alguns metais pesados são muito tóxicos para os organismos, embora eles sejam essenciais para o crescimento normal dos mesmos como micronutrientes.

MELo et alii (1987) observaram que a taxa de infeção radicular com Glomus leptotichum em duas cultivares de Leucaena leucocephala diminuiu com a aumento do nivel de Al disponivel no substrato; por outro lado, o estabelecimento de micorriza na cultivar Al-intolerante proporcionou caracteristicas de toleráncia das plantas ao Al. GILDON \& TINKER (1983) sugeriram que concentraçชes intracelulares de 
metais pesados nas raizes podem limitar a expansão do micelio em micorriza vesicular arbuscular.

BRADLEY et alii (1981) estudaram a relação entre infecção micorrizica e resistencia à toxicidade de metais em trés plantas Ericaceae e observaram que plantas micorrizadas mostraram crescimento em todos os tratamentos com metais, enquanto que plantas não micorrizadas cresceram somente no nivel mais baixo do metal. Foi proposto que as hifas complexas do endofito iricóde prove uma superficie de absorção dentro das celulas corticais das ralzes do hospedeiro, facilitando exclusão de metais nos brotos e, assim, escapando da toxicidade - as plantas micorrizadas apresentaram uma concentração significantemente mais baixa de metais em seus brotos e mais altas nas ralzes. Estes resultados confirman suas observaçôs anteriores em Colluna vulgaris inoculada com pezizella ericae (BRADLEY et alii, $1981)$.

0 mecanismo pelo qual ectomicorriza influencia absorção de metais pesados pelas mudas pode ser associado com proteção das raizes pelo manto do fungo ou modificações da rizosfera pelo fungo associado (DIXON \& BUSCHENA, 1981). No entanto, metais pesados podem ser fungitóxicos e podem influenciar na formação de ectomicorriza. Segundo os autores, a adição de metais pesados no meio, decresceu significantemente a infecção ectomicorrizica por Suillus luteus em associação com pinus banksiana e Picea 
glauca. O mecanismo preciso de inibição ectomicorrizica não conhecido.

Em Pinus rigida, a porcentagem de micorriza foi maior em raizes tratadas com 25 ppm de Al que em ralzes tratadas com 0 ou 50 ppm, porque neste nivel o efeito inibitorio foi maior sobre crescimento de raizes do que sobre a infecção com Pisolithus tinctorius. Já para 50 ppm, o aluminio teve um alto efeito inibitorio em ambos: crescimento e infecção (McQUATTIE \& SCHIER, 1986).

VIEIRA (1984), estudando a interação entre aluminio e infeç̧ăo micorrizica em Eucalyptus grandis encontrou um isolado de $P$. tinctarius tolerante a elevados teores de aluminio, capaz de formar micorriza em substratos com $300 \mathrm{Hg} \mathrm{Al}^{3+} / \mathrm{ml}$. Nesta concentração as plantas apresentam um decrescimo de $25 \%$ no peso da materia seca em relação a mudas não inoculadas. $\quad$ autor propåe que, em determinadas condiçoses, o fungo induz um efeito parasftico.

A comparação entre os fungos deve ser feita com cautela visto que a toleráncia a metais pesados pode variar com o fungo simbionte. 


\section{MATERIAIS E MÉTODOS}

\subsection{Isolados utilizados}

Foram utilizados os seguintes isolados de Pisolithus tinctorius (Pers.) Coker et Couch:

\begin{tabular}{lll}
\hline Isolado & Local de coleta & Hospedeiro \\
\hline 1. Pt 185 & Estados Unidos & Pinus sp \\
2. Pt taeda & França & Pinus sp \\
3. FEP 2 & Amapá (reisolado & Pinus sp. \\
& do 185) & \\
4. FEP 3 & Piracicaba (reiso- & Pinus sp. \\
& lado do 185) & \\
5. FEP 5 & Lavras (reisolado & Pinus sp. \\
6. ITA 6 & do 185) & \\
7. ITA 11 & Itamarandiba-MG & Eucalyptus sp. \\
8. AC1 & Timóteo-MG & Eucalyptus pilularis \\
9. ACS & Timoteo-MG & Eucalyptus citriodara \\
& & Eucalyptus torelliana
\end{tabular}




\begin{tabular}{|c|c|c|c|}
\hline Isolado & Local de coleta & Hospedeiro & t \\
\hline 10. ACS & Timoteo-MG & Eucalyptus & tarelliana \\
\hline 11. ACB & Timóteo-MG & Eucalyptus & paniculata \\
\hline 12. $A C 12$ & Timóteo-MG & Eucalyptus & paniculata \\
\hline 13. PI 0203 & Parque Itaja1 & Eucalyptus & sp \\
\hline 14. PI 0312 & Parque Itajal & Eucalyptus & $5 p$ \\
\hline 15. PI 0314 & Parque Itajal & Eucalyptus & sp \\
\hline 16. PI 0316 & Parque Itajal & Eucalyptus & sp \\
\hline 17. AT 0501 & Atibaia-SP & Eucalyptus & sp \\
\hline 18. AT 0502 & Atibaia-SP & Eucalyptus & sp \\
\hline 19. AT 0503 & Atibaia-SP & Eucalyptus & sp \\
\hline 20. AT 0504 & Atibaia-SP & Eucalyptus & sp \\
\hline 21. AT 0505 & Atibaia-SP & Eucalyptus & sp \\
\hline 22. AT 0506 & Atibaia-SP & EucaIyptus & $\mathrm{sp}$ \\
\hline 23. AT 0507 & Atibaia-SP & Eucalyptus & sp \\
\hline 24. AT OSOB & Atibaia-SP & Eucalyptus & $5 p$ \\
\hline 25. AT 0509 & Atibaia-SP & Eucalyptus & sp \\
\hline 26. AT 0510 & Atibaia-SP & Eucalyptus & sp \\
\hline
\end{tabular}

Os isolados de 1 a 16 foram gentilmente cedidos pelo Dr. Krügner, T.L. (ESALq/USP) e pela Dr. Lin, M.T. (Bioplanta Tecnologia de Plantas Ltda.), os demais foram isolados no presente trabalio.

\subsection{Manutenção dos isolados}

Ds isolados foram mantidos em laboratorio atraves de repiques periódicos em meio Melin Norkrans modi- 
ficado. o inóculo foi cultivado por vinte (20) dias a 26-28.C e, posteriormente, estocado sob refrigeração, ate um perído máximo de um més.

\section{3. Esterilização e incubação}

Os meias de cultura e as soluçres utilizadas foram esterilizadas em autoclave por vinte (20) minutos sob pressã de uma atmosfera.

Os substratos utilizados para produçao de inoculante foram esterilizados em autoclave por quarenta (40) minutos a uma atmosfera de pressa.

A temperatura de incubação foi de $26-28^{\circ} \mathrm{C}$.

3. 4. Meio de cultura utilizados

3.4.1. Meio MNM (Melin Norkrans - modificado), de acordo com MARX, 1969




Agua destilada até completar .... $1000 \mathrm{ml}$

$0 \mathrm{pH}$ do meio foi ajustado a 5,5 com soluçå de ácido cloridrico $1 \mathrm{~N}$.

\section{4.2. Meio BDA}

Decocto de $200 g$ de batata

Dextrose ................ 209

Agar .................. 18 g

Água destilada até completar .. $1000 \mathrm{ml}$

$0 \mathrm{pH}$ do meio foi ajustado a 5,5 com soluça

de ácido cloridrico $1 N$.

\section{4. 3. Meio BDA-D}

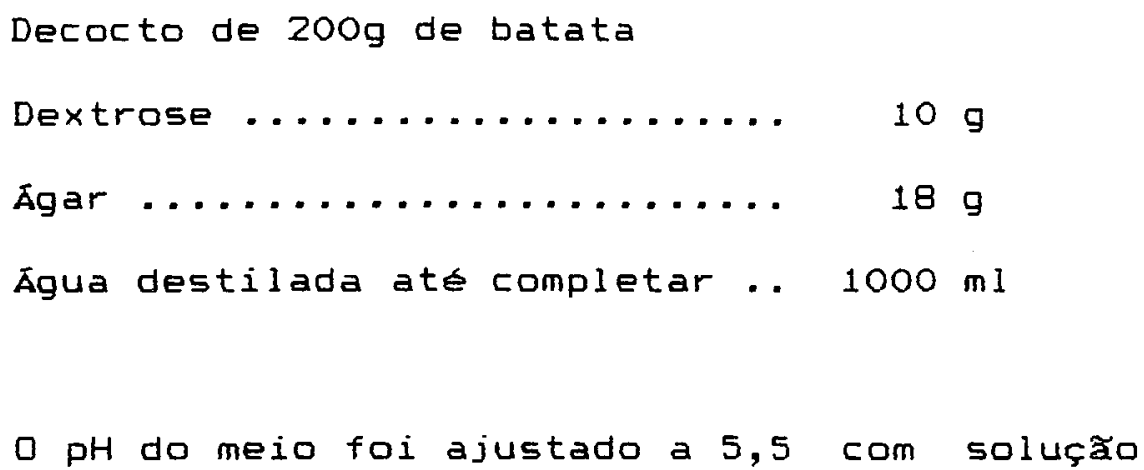

de ácido cloridrico $1 \mathrm{~N}$. 


\section{4. 4. Meio BDMT}

Decocto de 2009 de batata

Dextrose ............... $10 \mathrm{~g}$

Extrato de malte .......... 39

Tiamina ............... $100 \mu g$

Agar .................. 189

Agua destilada até completar . $1000 \mathrm{ml}$

0 pH do meio foi ajustado a 5,5 com soluçao

de ácido cloridrico $1 \mathrm{~N}$.

\section{4.5. Meio MNMB}

Preparado segundo o item 3.4 .1 , sendo adicionado decocto de $200 \mathrm{~g}$ de batata.

3. 4.6. Meio MNM liquido (Melin Norkrans modificado) MARX, 1969

Preparado segundo $\circ$ item 3.4 .1 sem a adição de agar.

3.4.7. Meio BDA 11 quido

Preparado segundo o item 3.4 .2 sem a adição de agar. 


\section{4. 8. Meio BDA-D 11 quido}

$$
\text { Preparado segundo o item } 3.4 .3 \text { sem a adição }
$$

de agar.

3. 4.9. Meio BDMT 11 quido

$$
\text { Preparado segundo o item } 3.4 .4 \mathrm{sem} \text { a adição }
$$

de agar.

3.4.10. Meio MMMB 1 iquido

Preparado segundo o item $3.4 .5 \mathrm{sem}$ a adição

de agar.

3.4.11. Meio MMM+M semi sólido para regeneração de protoplastos

Ao meio MNM liquido, preparado segundo o item 3.4.6 foi adicionado manitol-o,6M; acido maleico - 0,05M; agar - 0,7\% o pH do meio foi ajustado a 5,5 com solução de Hidróxido de sódio $5 \mathrm{~N}$.

3.4.12. Meio MMM+M 11 quido para regeneraçăo de protoplastos

Preparado segundo o item 3.4 .11 sem a adiçăo de agar. 
3.5. Sol uções utili izadas

\title{
3.5.1. Solução de Feciı $1 \%$
}

\author{
Ig de FeCls em $100 \mathrm{ml}$ de aqua destilada. Con- \\ servou-se em frasco escuro à temperatura ambiente.
}

\subsubsection{Sol ução de Albumina $50 \%$}

\begin{abstract}
A albumina foi obtida a partir da clara de um ovo picotada e filtrada em papel de filtro por gravidade sob refrigeraçăo durante uma noite.

Preparou-se uma solução com uma parte de albumina para uma parte de glicerina. Conservou-se em frasco escuro a $4 \circ \mathrm{C}$ no refrigerador.
\end{abstract}

\subsubsection{Sol ução de Giemsa}

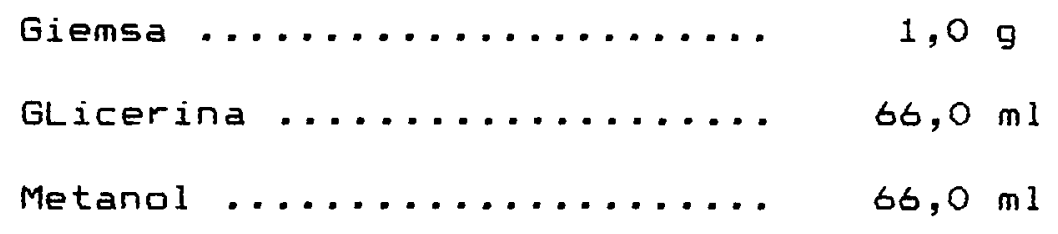

A soluçăo foi preparada pela dissoluçăo de Giemsa em glicerina a $60^{\circ} \mathrm{C}$ e, após resfriamento à temperatura ambiente, foi adicionado metanol. Esta solução foi mantida à temperatura ambiente. 
3.5.4. Tampão fosfato $0,07 \mathrm{MH} 7,0$

Solução A:

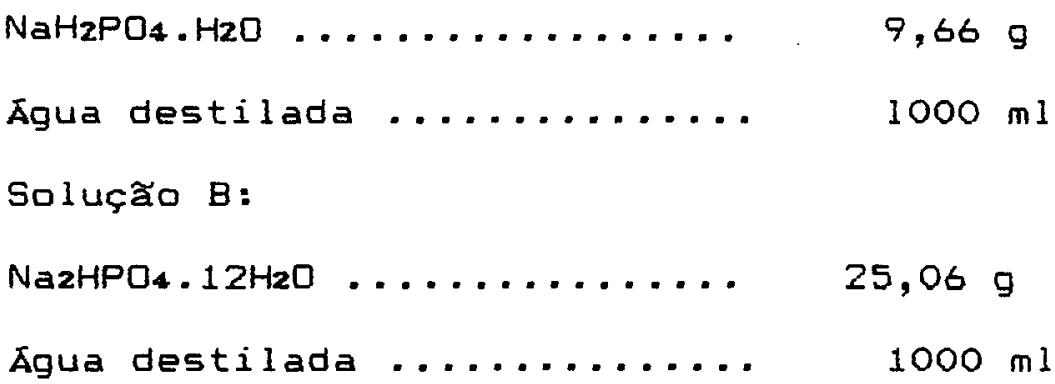

Misturou-se $51,0 \mathrm{ml}$ da solução $A$ e $49,0 \mathrm{ml}$ da soluçăo B. A esta mistura foram adicionados $900 \mathrm{ml}$ de água destilada. A mistura foi preparada no momento do uso e, a restante das duas soluçâes foi mantida sab refrigeraçăo a $4 \circ C$.

3.5.5. Tampão fosfato $0,02 M \mathrm{pH} 5,8$

Soluçaัo A:



Misturou-se $920,0 \mathrm{ml}$ da solução $A$ e $80 \mathrm{ml}$ da

solução B. As soluçơes A e B foram conservadas no refrigerador e o tampão fasfato foi preparado no momento do uso. 
3.5.6. Sol ução estoque de acrilamida

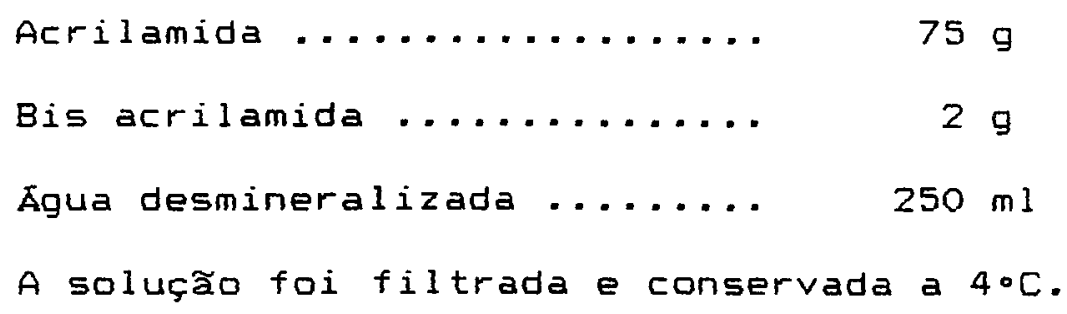

3.5.7. Tampão do gel separador

$$
\text { Tris base - 45,75 g. A soluçåo foi titulada }
$$

para pH 8,9 e seu valume completado com água destilada para $100 \mathrm{ml}$, sendo a seguir filtrada e armazenada à temperatura ambiente.

3.5.8. Tampão do gel empilhador

$$
\text { Tris base - 7,475 g. A solução foi titulada }
$$

para pH 6,8 com HCl puro e seu volume completado com água destilada para $100 \mathrm{ml}$.

3.5.9. Tampão do tanque

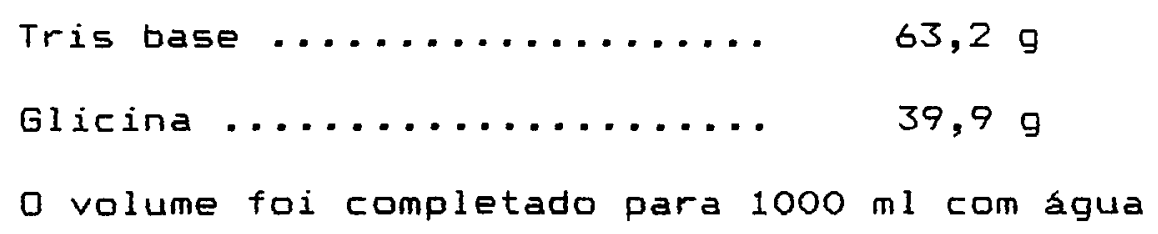

destilada e a soluçăo foi filtrada e armazenada à temperatura ambiente. 
No momento do uso, o tampão foi diluido: 100 ml de tampão completado para o volume de $1000 \mathrm{ml}$ com água destilada.

3.5.10. Tampão da amostra
Glicerol
$5 \quad \mathrm{ml}$
Tampão do gel empilhador ..... 2,5 ml
Azul de bromotenol .......... traços
o volume foi completado para $25 \mathrm{ml}$ com água

destilada e armazenado a $-10 \circ \mathrm{C}$.

3.5.11. Gel separador a $10 x$

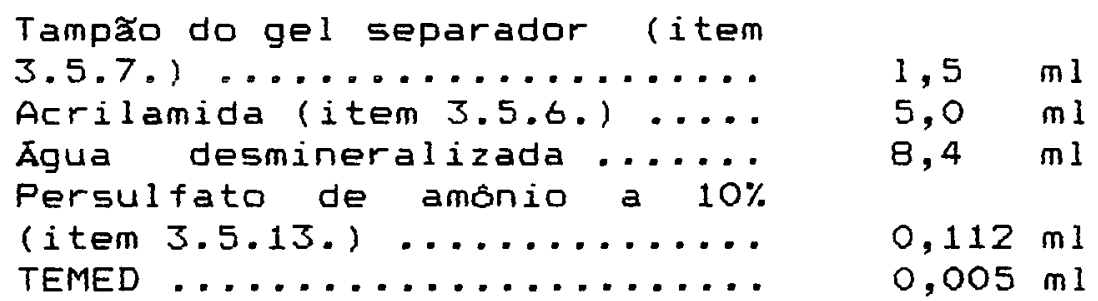

3.5.12. Gel empilhador a $4 x$

Tampão do gel empilhador (item 3.5 .8.) \ldots \ldots \ldots \ldots \ldots \ldots \ldots \ldots$ Acrilamida (item 3.5.6.) ..... Água desmineralizada ......... Persulfato de amónio a $10 \%$ $0,75 \mathrm{ml}$ $1,0 \quad \mathrm{ml}$

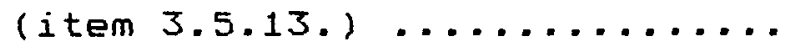
$5,7 \quad \mathrm{ml}$ TEMED $0,056 \mathrm{ml}$ $0,0075 \mathrm{ml}$ 
3.5.13. Sol ução de persulfato de amónia (AP)

Solução aquosa a $10 \%$ de AP

3.5.14. Soluçăo Tris-HCl $0,5 M$

Tris-HCl - 78,8 g. A solução foi titulada para pH 7,1 e seu volume completado para $1000 \mathrm{ml}$ com água destilada, sendo a seguir armazenada a $4 \circ \mathrm{C}$.

3.5.15. Sol ução $\alpha, \beta-$ naftil acetato $1 *$

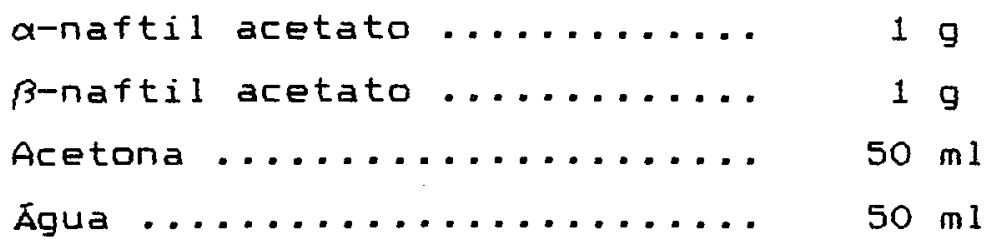

3.5.16. Solução para revelaçăo de esterases



3.5.17. Solução de $\mathrm{NaOH} 5 \mathrm{~N}$

$\mathrm{NaOH}, 200 \mathrm{~g}$ em $1000 \mathrm{ml}$ de áqua destilada. 
3.5.18. Sol ução manitol $0,6 M$

Para o preparo desta solução 21,869 de manitol foram dissolvidos com agitação e aquecimento em água destilada, sendo a seguir adicionados $1,16 \mathrm{~g}$ de acido maleico e $1,47 \mathrm{~g}$ de CaClz.2HzO. Levou-se a potenciometro e adicionou-se soluçăo de $\mathrm{NaOH} 5 \mathrm{~N}$ até atingir-se pH 5,5. O volume final foi ajustado para $200 \mathrm{ml}$ com água destilada.

3.5.19. Solução de enzima para produçăo de protoplastos

Para cada $1,0 \mathrm{ml}$ de solução manitol $0,6 M$ foram adicionados $5,0 \mathrm{mg}$ de Novozyme 234 .

3.5.20. Solução de complexo 11 tico I para produção de protoplastos

Para cada $1,0 \mathrm{ml}$ de solução manitol $0,6 \mathrm{M}$ foram adicionados $10 \mathrm{mg}$ de celulase Onozuka R10, $10 \mathrm{mg}$ de driselase, $2,5 \mathrm{mg}$ de $\mathrm{zimoliase} e 1 \mathrm{mg}$ de quitinase.

3.5.21. Sol ução de complexo 11 tico II para produção de protoplastos

Para cada $1,0 \mathrm{ml}$ de solução manitol $0,6 \mathrm{M}$ 
foram adicionados $10 \mathrm{mg}$ de celulase Onozuka R10, $10 \mathrm{mg}$ de



3.5.22. Solução estoque 1 da sol ução nutritiva

$$
\begin{aligned}
& \operatorname{Mg}\left(\mathrm{NO}_{3}\right) 2.6 \mathrm{H}_{2} \mathrm{O} \ldots \ldots \ldots \ldots \ldots \ldots \ldots . . .142,4 \mathrm{~g} \\
& \text { Água destilada até completar .. } 1000 \mathrm{ml}
\end{aligned}
$$

3.5.23. Sol ução estoque 2 da solução nutritiva

$$
\begin{aligned}
& \mathrm{KH}_{2} \mathrm{PO}_{4} \ldots \ldots \ldots \ldots \ldots \ldots \ldots \ldots \ldots \ldots \\
& \text { Água destilada até completar ... } 1000 \mathrm{ml}
\end{aligned}
$$

3.5.24. Sol ução estoque 3 da solução nutritiva

$$
\begin{aligned}
& \mathrm{Ca}\left(\mathrm{NO}_{3}\right)_{2} .4 \mathrm{H}_{2} \mathrm{O} \quad \ldots \ldots \ldots \ldots \ldots \ldots . \ldots .270,0 \mathrm{O} \\
& \mathrm{NH}_{4} \mathrm{NO}_{3} \ldots \ldots \ldots \ldots \ldots \ldots \ldots \ldots \ldots . \ldots . \ldots \\
& \text { Água destilada até completar ... } 1000 \mathrm{ml}
\end{aligned}
$$

3.5. 25. Solução estoque 4 da solução nutritiva



$$
\begin{aligned}
& \text { Naz EDTA ............... 29,6 g } \\
& \text { Água destilada até completar .. } 1000 \mathrm{ml}
\end{aligned}
$$


3.5. 26. Sol ução estoque 5 da sol uçăo nutritiva

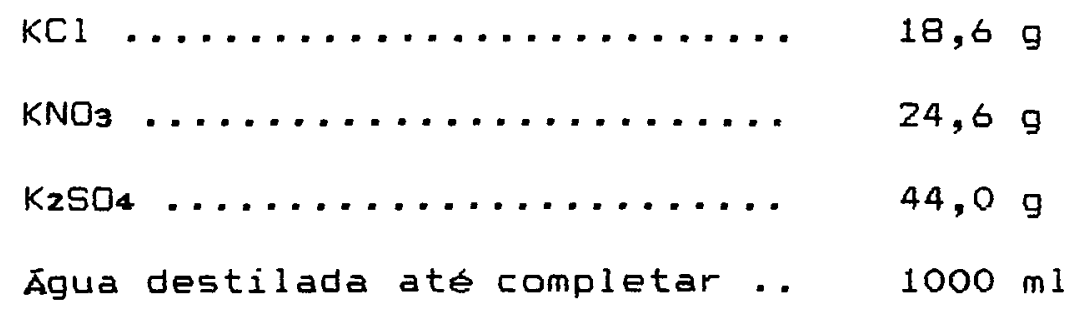

3.5.27. Solução estoque 6 da solução nutritiva

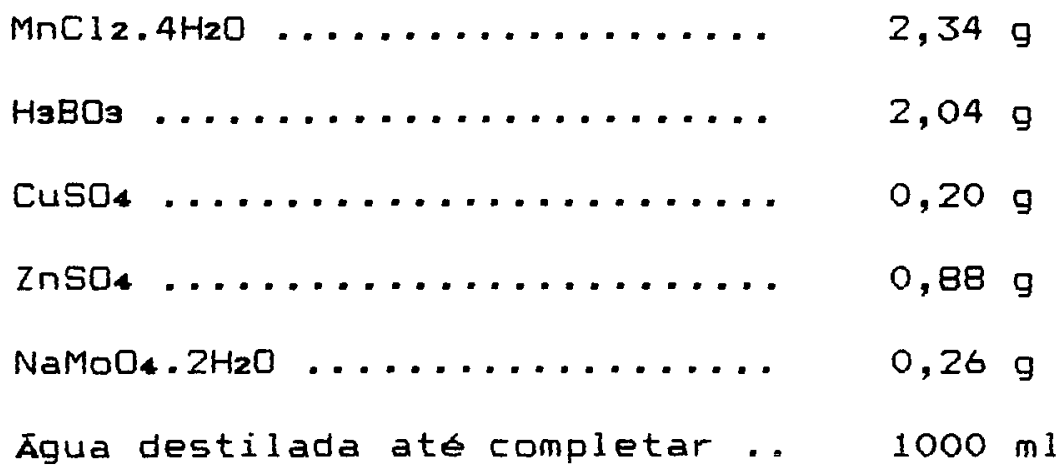

3.5.28. Solução nutritiva (FURLANI \& HANNA, 1984)

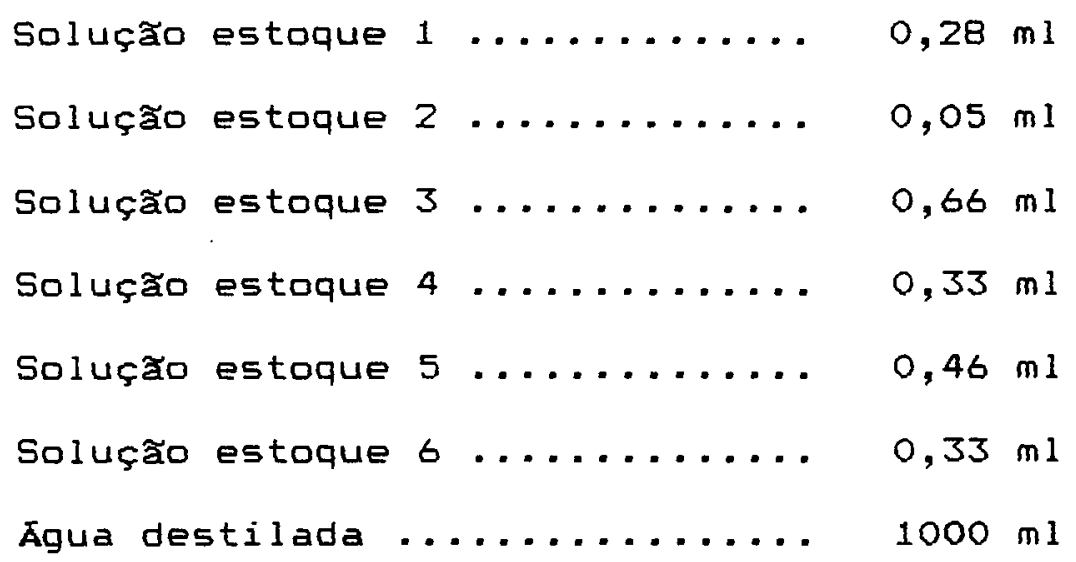


$0 \mathrm{pH}$ da solução foi ajustado a 4,0 com solução de ácido cloridrico $5 N$.

3.5. 29. Solução nutritiva 5 ppm de alumi nio

Preparado segundo o item 3.5.28, adicionandose $1,64 \mathrm{ml}$ da solução estoque de aluminio $3000 \mathrm{ppm}$. $0 \mathrm{pH}$ foi ajustado a 4,0 com solução de acido cloridrico 5N.

\subsubsection{Soluçăo nutritiva 10 ppm de aluminio}

Preparado segundo o item 3.5 .28 , adicionandose $3,32 \mathrm{ml}$ da solução estoque de aluminio $3000 \mathrm{ppm}$. $0 \mathrm{pH}$ foi ajustado a 4,0 com soluçăo de ácido cloridrico $5 N$.

3.5.31. Soluçăo nutritiva 15 ppm de alumi nio

Preparado segundo o item 3.5 .28 , adicionandose $5,0 \mathrm{ml}$ da solução estoque de aluminio $3000 \mathrm{ppm}$. O pH foi ajustado a 4,0 com solução de ácido cloridrico $5 \mathrm{~N}$.

3.5.32. Solução nutritiva 20 ppm de alumínio

Preparado segundo o item 3.5.28, adicionandose $6,64 \mathrm{ml}$ da solução estoque de aluminio. a pH foi ajustado a 4,0 com solução de ácido cloridrico 5N. 
3.5. 33. Soluçăo estaque de aluminio 3000 ppm

\author{
AlK(SO4)2.12 $\mathrm{H}_{2} \mathrm{O}, 52,77$ g. Completar com água \\ destilada para o volume de $1000 \mathrm{ml}$.
}

3.5.34. Solução nutritiva para fertilização de plantas de Eucalyptus de acordo com RUEHLE \& WELLS (1984)

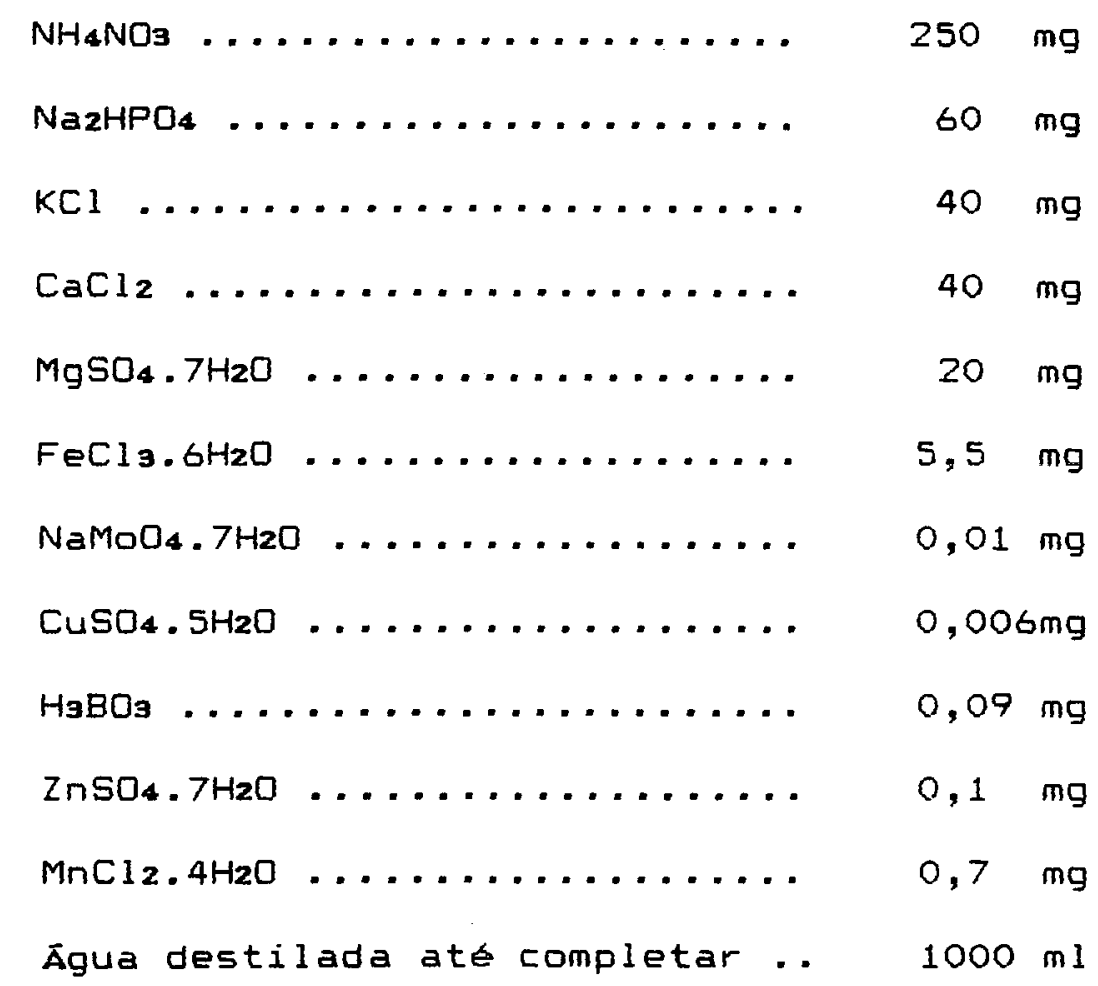

3.5.35. Sol ução de KOH $10 \%$

$\mathrm{KaH}, 100 \mathrm{~g}$. Completar o volume para $1000 \mathrm{ml}$ com água destilada. 
3. 5. 36. Sol ução de HCl $1 \%$

$\mathrm{HCl}, 10 \mathrm{ml}$. Completar a valume para $1000 \mathrm{ml}$ com água destilada.

3.5.37. Sol ução descorante

Glicerina, água destilada e ácido láctico $(1: 1: 1)$

3.5. 38. Sol ução corante Trypan-blue

Trypan-blue - $0,5 \mathrm{~g}$ para $1000 \mathrm{ml}$ de solução descorante (item 3.5.27).

3. 6. Substratos utilizados

3.6.1. Substrato Turfa-Vermiculita - Meio MNN para produção de inoculante

0 substrato foi preparado com uma mistura de Turfa-vermiculita - meio MNM 11quido na proporção de 1:28:14 e distribuido em frascos de $300 \mathrm{ml}$. 
3.6.2. Substrato Turfa-vermiculita - Meio BDA para produção de inoculante

o substrato foi preparado com uma mistura de turfa-vermiculita - meio BDA 11quido na proporção de 1:28:14 e distribuido em frascos de $300 \mathrm{ml}$.

3.6. 3. Substrato Turfa-vermiculita - Meio BDA-D para produção de inoculante

o substrato foi preparado com uma mistura de turfa-vermiculita - meio BDA-D liquido na proporção de 1:28: 14 e ditribuldo em frascos de $300 \mathrm{ml}$.

3.6. 4. Substrato Turfa-vermiculita - Meio BDMT para produção de inoculante

o substrato foi preparado com uma mistura de turfa-vermiculita - meio BDMT liquido na proporção de 1:28: 14 e distribuldo em frascos de $300 \mathrm{ml}$.

3.6.5. Substrato Turfa-vermiculita - Meio MNMB para produçăo de i noculante

o substrato foi preparado com uma mistura de turfa-vermiculita - meio MNMB liquido na proporção de 1:28: 14 e distribuido em frascos de $300 \mathrm{ml}$. 
3.6.6. Substrato Turfa-vermiculita para produção de mudas

o substrato foi preparado com uma mistura de turfa-vermiculita na proporção de $1: 1$.

\subsection{Sementes utilizadas}

Foram utilizadas sementes de Eucalyptus urophylla, Eucalyptus torelliana e Eucalyptus paniculata provenientes da Acesita energetica, pomar de Itamarandiba, MG.

3. 8. Caracterização do crescimento dos isolados de Pisolithus tinctorius em diferentes meios de cultura

Foram retirados discos de $4 \mathrm{~mm}$ de diâmetro das bordas das colónias crescidas em meio MNM por 15 dias a 26.C. A seguir, estes discos foram transferidos para placas de Petri com 9 centimetros de diámetro, contendo separadamente, $20 \mathrm{ml}$ de meio MNM, meio BDA, meio BDA-D, meio BDMT e meio MNMB. As placas foram incubadas a $26^{\circ} \mathrm{C}$ por 30 dias. 0 diámetro das colónias foram medidos em intervalos de 48 horas a partir do décimo dia.

Os tratamentos foram distribuidos segundo

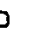


delineamento estatistico em blocos ao acaso com quatro repetiçбes, seguindo o esquema de parcelas sub-subdivididas onde os isolados constituiram os tratamentos primários, os meios os tratamentos secundários e os diametros os tratamentos terciários.

o quadro abaixo apresenta a análise de variancia proposta, bem como as causas de variaçăo e respectivos valores de $F$. Realizou-se comparações entre medias de isolados, de meios e diâmetros aplicando-se teste de Tukey através da seguintes formula: $\Delta=q \frac{5}{\sqrt{r}}$, onde: $q=$ valor da amplitude total estudentizada a nivel de $5 \%$ ou $1 \%$ de probabilidade; $r=$ número de repetiçóes, $s=$ estimativa do desvio padrão residual.

\begin{tabular}{|c|c|c|c|}
\hline Causas de Variação & GL & $Q M$ & Valor F \\
\hline $\begin{array}{l}\text { Blocos (B) } \\
\text { Isolados (I) } \\
\text { Residuo (a) }\end{array}$ & $\begin{array}{c}R-1 \\
I-1 \\
(I-1)(R-1)\end{array}$ & $\begin{array}{l}\text { QMB } \\
\text { QMI } \\
\operatorname{QMR}(a)\end{array}$ & $\begin{array}{l}\text { QMB/GMR (a) } \\
Q M I / Q M R(a)\end{array}$ \\
\hline $\begin{array}{l}\text { Parcelas } \\
\text { Meios (M) } \\
\text { Isolados } \times \text { meios } \\
\text { (I } \times \text { M) } \\
\text { Residuo (b) }\end{array}$ & $\begin{array}{l}(I R-1) \\
M-1 \\
(I-1)(M-1) \\
I(M-1)(R-1)\end{array}$ & $\begin{array}{l}\text { QMM } \\
\operatorname{QMI} \times M \\
\operatorname{GMR}(b)\end{array}$ & $\begin{array}{l}\text { GMM/QMR }(b) \\
\text { GMI } \times M / Q M R(b)\end{array}$ \\
\hline $\begin{array}{l}\text { Subparcelas } \\
\text { Diametros (D) } \\
\text { Isolados } \times \text { diame- } \\
\text { tros I } \times \text { D } \\
\text { Meios } \times \text { diametros } \\
\text { MxD } \\
\text { Isolados } \times \text { meios } \times \\
\text { diámetros I } \times \text { M } \times D \\
\text { Residuo }\end{array}$ & $\begin{array}{c}I M R-1 \\
D-1 \\
(I-1)(D-1) \\
(M-1)(D-1) \\
(I-1)(M-1)(D-1)\end{array}$ & $\begin{array}{l}Q M D \\
Q M I \times D \\
Q M M \times D \\
Q M I \times M \times D \\
Q M R(C)\end{array}$ & $\begin{array}{l}\text { QMD/QMR(c) } \\
\text { QMI XD/QMR(c) } \\
\text { QMM×D/QMR(c) } \\
\text { QMI } \times M \times D / Q M R(c)\end{array}$ \\
\hline
\end{tabular}


3.9. Produção de biomassa dos isolados de pisolithus tintctorius em diferentes meios de cultura

\begin{abstract}
Foram retirados discos de $4 \mathrm{~mm}$ das bordas das colonias crescidas em meio MNM por 20 dias a $26^{\circ} \mathrm{C}$. Em seguida, estes discos foram transferidos para frascos de 150 ml contendo separadamente, $25 \mathrm{ml}$ de meio MNM, meio BDA, meio BDA-D, meio BDMT e meio MNMB liquido.
\end{abstract}

Os discos foram colocados cuidadosamente nos meios, visto que os isolados apresentam o crescimento inibido quando submersos.

Os frascos foram incubados a $26^{\circ} \mathrm{C}$ por 30 dias. O micelio obtido ao fim deste períado foi filtrado em filtro Blüchner com auxilio de bomba de vácuo e lavado duas vezes com água destilada. O disco de meio de cultura que acompanhou o inóculo foi retirado e, a seguir, o micélio foi pesado e colocado em estufa a $60 \circ \mathrm{C}$ por 72 horas para medida de peso seco.

Os tratamentos foram distribuidos segundo a delineamento estatistico inteiramente casualizado com quatro repetiçōes, seguindo o esquema fatorial $13 \times 5$ cujos fatores foram: isolados e meios.

o quadro abaixo apresenta a análise de variância proposta com as causas de variação e respectivos valores de F.

Realizaram-se comparaçós entre medias de 
meios e isolados aplicando-se teste de Tukey atraves da seguintes formula: $\Delta=q \frac{s}{\sqrt{p}}$, onde, $q=$ valor da amplitude total estudentizada a nivel de $5 \%$ ou $1 \%$ de probabilidade, $r=$ número de repetições e $s=$ estimativa do desvio padrăo residual.

\begin{tabular}{lcll}
\hline Causa de Variação & GL & GM & Valor F \\
\hline Tratamentos (T) & $T-1$ & QMT & \\
Isolado (I) & $I-1$ & QMI & QMI/QMR \\
Meio (M) & $M-1$ & QMM & QMM/QMR \\
IsoladoxMeio I & $(I-1)(M-1)$ & QMI XM & QMIXM/QMR \\
Residuo (R) & $T(R-1)$ & QMR & \\
\end{tabular}

3.10. Técnica para coloração de núcleos (TANAKA Et alii, 1979)

Foram realizadas observaçöes citológicas do isolado TAEDA de Pisolithus tinctorius.

o micélio previamente crescido en meio MNM a $26 \circ C$ foi aderido sobre a laminula em presença de albumina 50\%. Para a fixação foi utilizada solução de álcool etilicoácido acetico $3: 1$ durante 30 minutos à temperatura ambiente. A hidrataçăo foi efetuada por tratamento sucessivo em álcool 95,0\% por dez minutos e álcool 70\% por trinta minutos, pro- 
cedendo-se, a seguir, à hidrolise em acido cloridrico $1 \mathrm{~N}$ em bantio-maria a $60 \circ \mathrm{C}$ por 8 minutos. 0 material foi corado por imersão em solução de Giemsa diluída de 1 para 5 com tampão fosfato $\mathrm{pH} 7,0$ durante 30 minutos. O excesso de corante foi retirado por lavagem com o mesmo tampão. As laminulas foram fixadas em lâminas com o uso de parafina e observadas ao microscópio.

3.10.1. Determinação do número de núcleos por célula somática micelial

O micelio proveniente de crescimento em meio MNM por 15 dias a $26^{\circ} \mathrm{C}$ foi preparado segundo a item 3.10 . Estes foram observados em microscópio alympus, modeo BHS, associado ao sistema fotomicrográfico alympus modelo $P M-1 O A D$.

3.10.2. Medida do tamanho de núcleos

o micelio proveniente de crescimento em meio MNM por 25 dias a $26^{\circ} \mathrm{C}$ foi preparado segundo o item 3.10. Fez-se a medida de 596 núcleos escolinidos aleatoriamente, utilizando-se ocular micrometrica adaptavel ao microscópio otico. 
3.10.3. Observaçōes da divisão nuclear em células somáticas do micelio

\begin{abstract}
O micelio proveniente de crescimento em meio MNM por 15 dias a $26^{\circ} \mathrm{C}$ foi preparado segundo o item 3.10 . Estes foram observados em microscopio alympus, modelo BHS, associado ao sistema fotomicrografico Olympus modelo PM-1OAD.
\end{abstract}

\title{
3.11. Caracterização el etroforetica (PACCOLA-MEIRELLES
} et alii, 1988)

\subsubsection{Preparação das amostras}

Foram retirados dos isolados a serem determinados eletroforeticamente, discos de $5 \mathrm{~mm}$ das bordas das colónias crescidas em meio MNM por 15 dias a $26 \circ \mathrm{C}$. Estes discos foram transferidos para frascos de $150 \mathrm{ml}$, contendo $25 \mathrm{ml}$ de meio MNM 11 quido e incubados a $26^{\circ} \mathrm{C}$ por 12 dias. 0 micelio obtido neste periodo foi filtrado em filtro Blúchner com auxilio de bomba de vácuo e lavado com água destilada. Em seguida, o micelio foi secado em papel de filtro e triturado com nitrogénio 11 quido. Para cada $500 \mathrm{mg}$ de micélio foi adicionado $1 \mathrm{ml}$ de tampão do gel empilhador $\mathrm{pH} 6,8$ (item 3.5.8). Este material foi deixado em banho de gelo durante uma noite e a final deste periodo foi centrifugado durante 
vinte minutos a 13.000 RPM em centrifuga refrigerada. 0 sobrenadante foi coletado e esta amostra foi mantida em "freezer".

\subsubsection{Placa de gel de acrilamida}

o gel separador preparado segundo o item 3.5.11. foi vertido em placa de $15 \mathrm{~cm} \times 16 \mathrm{~cm} \times 0,1 \mathrm{~cm}$ com uma seringa de vidro ate a altura de $1 \mathrm{~cm}$ abaixo do pente. Depois de polimerizada foi preparado o gel empilhador segundo o item 3.5 .12 e vertido na mesma placa até a borda. o pente foi colocado e retirado depois da polimerização do gel.

\subsubsection{Aplicaçăo das amostras e corrida da eletroforese}

No momento da aplicação foi retirado $50 \mu l$ da amostra (item 3.11.1) e colocado em tubo ependorf junto com $50 \mu l$ do tampão da amostra (item 3.5.10). Com o auxilio de micropipeta, colocou-se 50 Hl desta mistura na canaleta do gel. A placa foi colocada em cuba de eletroforese vertical. o tampão do eletrodo utilizado foi o tampão do tanque preparado segundo o item 3.5 .9$.

A corrida foi feita sob refrigeraçăo a $120 \mathrm{~V}$ até a amostra chegar no gel separador e depois colocado a $200 v$ ate o final da corrida. 


\title{
3.11.4. Revelação das esterases
}

\begin{abstract}
Após a corrida, o gel foi cuidadosamente retirado da placa e colocado em cuba de plástico com a solução reveladora (item 3.5 .16$)$.
\end{abstract}

\subsection{Obtenção de protoplastos}

\begin{abstract}
Foram realizados estudos de protoplastização com 0 isolado FEP3 de Pisolithus tinctorius.

Discos de cultura de $4 \mathrm{~mm}$ de diametro foram retirados das bordas das colónias crescidas em meio MNM e colocados cuidadosamente en frascos de $150 \mathrm{ml}$ com $25 \mathrm{ml}$ de meio MNM liquido. Os frascos foram incubados a $26^{\circ} \mathrm{C}$ por 10 dias. a disco de meio de cultura que acompanhou o inóculo foi retirado e o micelio crescido foi cortado com bisturi em pequenos fragmentos e colocados em frascos de $150 \mathrm{ml}$ com 50 $m l$ de meio MNM liquido, sendo em seguida incubados em agitador orbital (120 RPM) a $26^{\circ} \mathrm{C}$ por 7 dias. 0 micelio obtido foi coletado e triturado em liquidificador esterilizado com $150 \mathrm{ml}$ de meio MNM liquido, por 30 segundos em velocidade minima. $50 \mathrm{ml}$ deste homogeinizado foi colocado em frascos de $150 \mathrm{ml}$ e incubado a $26^{\circ} \mathrm{C}$ em agitador orbital a 120 RPM por 7 dias. Esta operação foi repetida reduzindo-se - tempo de incubação para 4 dias. Ao fim deste periodo o
\end{abstract}


micelio foi filtrado em filtro de Blüchner com auxilio de bomba de vácuo e lavado com solução manitol 0,6 M. A seguir, o micelio foi pesado e colocado em presença de solução 11 tica (preparada segundo o item 3.5 .19 ) na proporção de 50 mg de micelio: $1 \mathrm{ml}$ de solução litica.

Incubou-se novamente em agitador orbital a 100 rpm para que ocorresse a digestao litica. Foram retiradas amostras em intervalos de 60 minutos num periodo de 4 horas para verificar-se a presença de protoplastos.

\subsubsection{Avaliação da idade do micélio na liberação de protoplastos}

o micelio proveniente de crescimento em meio MNM por 15 dias a $26^{\circ} \mathrm{C}$ foi preparado segundo 0 item 3.12 , sendo que o tempo de incubação do micellio na última operação foi de 3,4 e 5 dias.

\section{12.2. Comparação de diferentes enzimas na}

\section{liberação de protoplastos}

0 micelio proveniente de crescimento em meio MNM por 15 dias a $26^{\circ} \mathrm{C}$ foi preparado segundo o item 3.12 , sendo testadas mais duas soluçశes 11 ticas preparadas segundo os 1 tens 3.5 .20 e 3.5 .21 . 


\subsubsection{Determinaçăo do número de protoplastos}

A contagem do número de protoplastos foi feita em intervalos de 60 minutos em camara de Neubauer com auxilio de microscópio otico até completar quatro horas de digestão 11 tica.

\subsubsection{Medida do tamanho dos protoplastos}

Foi feita a medida de 100 protoplastos produ$z i d o s$ de micelio de 4 e 5 dias de idade com 3 e 5 horas de digestão litica. Utilizou-se ocular micrometrica adaptável ao microscópio otico.

\subsubsection{Regeneração de protoplastos}

Após a período de incubação em agitador orbital com enzima litica, os protoplastos foram separados dos fragmentos maiores de hifas por filtração em algodão colocado no fim de uma seringa de vidro de $10 \mathrm{ml}$. O algodá foi lavado com $3 \mathrm{ml}$ de soluçăo manitol $0,6 M$ e os protoplastos foram peletizados por centrifugação por 15 minutos a 400 rpm (centrifuga Excelsa Baby). O sobrenadante foi eliminado e o "pellet" foi lavado duas vezes com soluçăo manitol 0,6M por centrifugação a $400 \mathrm{rpm}$ (centrifuga Excelsa Baby) por 5 minutos. a "pellet" final foi ressuspenso em $l \mathrm{ml}$ de 
solução manitol $0,6 M$ e o número de protoplastos contados em camara de Neubauer foram semeados pela técnica "pourplate" em meio $M N M+M$ semi-sólido $(37-40 \circ C)$ e incubados a $26 \cdot \mathrm{C}$. Em meio MNM+M liquido foram incubados em agitador orbital (100 $r p m)$ a $26^{\circ} \mathrm{C}$.

3.12.6. Coloração de núcleos dos protoplastos (BORGES, 1987)

Para a coloração de núcleos utilizou-se a suspensão de protoplastos obtida após a filtração em algodao do item 3.12 .6 .

Algumas gotas desta suspensão foram espalhadas em lâminas limpas, as quais foram mantidas a temperatura ambiente por 15 minutos. A fixaçăo foi feita em metanol absoluto por 5 minutos. Em seguida, as laminas foram parcialmente secas e imersas em solução de HCl IN por 2 minutos a $56^{\circ} \mathrm{C}$, sendo, a seguir, lavadas em agua corrente e água destilada. A coloração foi feita em solução corante Giemsatampão fosfato $0,02 M$ pH $5,8(1: 5)$ por 2 minutos.

Lavou-se em água corrente e depois das laminas estarem secas fez-se a montagen com laminulas. 
3.13. Sintese de ectomicorriza em Eucalyptus com isolados de Pisolithus tinctorius em diferentes niveis de al umi nnio em casa de vegetação

\subsubsection{Produção de inoculante}

0 método de produção de inoculante consistiu da transferencia de 8 discos de $0,5 \mathrm{~cm}$ de diametro retirados das bordas das colónias crescidas em meio MNM, para frascos de $300 \mathrm{ml}$ contendo $200 \mathrm{ml}$ de substrato turfa-vermiculitameio MNM (preparado segundo o item 3.6.1). Os frascos foram incubados a $26 \cdot \mathrm{C}$ por 3 meses.

\subsubsection{Inoculação do substrato}

A inoculação foi feita através de uma mistura manual do inoculante ao substrato turfa-vermiculita (preparado segundo o item 3.6 .6$)$ na concentração de $10 \%$.

o inoculante dos isolados ectomicorrizicos, antes de sua utilização, foi transferido para um tecido poroso e submetido a uma lavagem em água corrente por 2 minutos e, em seguida colocado em bandeja plástica para secagem à temperatura ambiente, ate eliminaçăo do excesso de umidade. 


\title{
3.13.3. Recipiente
}

\begin{abstract}
0 substrato turfa-vermiculita inoculado foi distribuido em tubetes do tipo "dibbing tube", fabricado em polietileno de alta densidade, de formato conico, na cor preta, com estrias internas para direcionamento das raizes, dispostas em bandejas de isopor.
\end{abstract}

\subsubsection{Semeadura}

Foram colocadas 3 a 5 sementes de Eucalyptus urophylla por tubete a $1 \mathrm{~cm}$ de profundidade.

3.13.5. Local da instal ação do experimento

o experimento foi instalado em casa de vegetação da Bioplanta Tecnologia de Plantas S.A. Situata em Paulinia-SP.

3.13.6. Delineamento estatistico

Os tratamentos foram distribuidos segundo o delineamento estatistico inteiramente casualizado com 16 repetiçós, seguindo o esquema fatorial $4 \times 5$ cujos fatores foram: isolados e concentraçöes de aluminio no substrato.

- quadro a seguir representa a analise de 
variância proposta, com as causas de variação e respectivos valores de $F$.

\begin{tabular}{lcll}
\hline Causa de variação & GL & QM & $F$ \\
\hline Tratamentos (T) & $T-1$ & QMT & \\
Isolados (I) & $I-1$ & QMI & QMI/QMR \\
Concentração Al (A) & A-1 & QMA & QMA/QMR \\
Isol. X Conc. Al & $(I-1)(A-1)$ & QMI $\times A$ & QMI $\times A / Q M R$ \\
Residuo (R) & $T(R-1)$ & QMR & \\
\end{tabular}

3.13.7. Desbaste

Aos 20 dias da inoculação foi feito um desbaste seletivo, eliminando as plantas menores ou mal localizadas, deixando-se somente uma por recipiente.

3.13.8. Adubação e aplicaçăo do aluminio no substrato

A adubação e o aluminio foram adicionados ao substrato atraves da aplicação de solução nutriente contendo diferentes concentraçช̋es de aluminio, preparada segundo os 1 tens $3.5 .28,3.5 .29,3.5 .30,3.5 .31$ e 3.5 .32 , diariamente, quantas vezes fosse necessário, até a drenagem. 
3.13.9. Avaliaçăo visual de colonização

Aos 90 dias da inoculação foi feita uma avaliação visual em escalas de notas de 0 a 5 do grau de colonizaçăo das rấzes.

\subsubsection{Coloraçăo de rázes para avaliação de colonização}

Foram retiradas pequenas amostras das ralzes lavadas de 8 plantas escolihidas ao acaso. As raizes foram colocadas em KOH $10 \%$ em banho-maria a $90 \circ \mathrm{C}$ por 1 hora, sendo em seguida lavadas trés vezes em áqua destilada e colocadas em HCl 1\% por 5 minutos. A coloração fai feita com o corante Trypan blue preparado segundo o item 3.5 .38 em banho-maria a $90 \circ \mathrm{C}$ por $10 \mathrm{minutos.} \mathrm{As} \mathrm{rázes} \mathrm{coloridas} \mathrm{foram} \mathrm{transferidas}$ para placas de Petri contendo solução descorante (preparado segundo item 3.5.37). A avaliação foi feita em Lupa em escalas de notas de 0 a 10.

\subsubsection{Análise química do substrato}

Foi feita uma análise química do substrato turfa-vermiculita (item 3.6.6) antes da inoculação. No final do experimento, amostras do mesmo substrato foram retiradas dos tubetes e analisadas separadamente para a dosagem da concentração de aluminio. As análises foram feitas no de- 
partamento de nutriçăo de plantas da Escola Superior de Agricultura "Luiz de Queiroz".

\subsection{Coleta e isolamento de Pisolithus tinctorius}

A coleta de corpos de frutificação de Pisolithus tinctorius foi feita na região de Atibaia-SP. Qs basidiocarpos jovens foram transportados para o laboratório em sacos de papel e submetidos a uma lavagem em água corrente. A seguir foram lavados tres vezes en álcool 70\% para uma esterilização superficial. Após secagem em toalha de papel esterilizada, os basidiocarpos foram cortados ao meio com um bisturi esteril e, da parte interna, retiraram-se pequenas partes do tecido, de 1 a $2 \mathrm{~mm}^{3}$. Estes foram colocados em placas contendo meio MNM e incubados a $26 \cdot \mathrm{C}$.

3.15. Seleção de isolados de Pisolithus tinctorius para trés espécies de Eucalyptus quanto à eficiência para formação de micorrizas

\subsubsection{Produção de inoculante}

A produção de inoculante consistiu da transferencia de 8 discos de $0,5 \mathrm{~cm}$ de diametro retirados das bordas das colónias crescidas em meio MNM, para frascos de $300 \mathrm{ml}$ contendo $200 \mathrm{ml}$ de substrato turfa-vermiculita-meio 
MNM (preparado segundo o item 3.6.1). Os frascos foram incubados a $26^{\circ} \mathrm{C}$ por 3 meses.

\subsubsection{Inoculação do substrato}

A inoculação foi feita atraves de uma mistura manual do inoculante ao substrato turfa-vermiculita (preparado segundo o item 3.6 .6$)$ na concentração de $10 \%$.

o inoculante dos isolados ectomicorrizicos, antes de sua utilização, foi transferido para um tecido poroso e submetido a uma lavagem em água corrente por 2 minutos e, em seguida colocada em bandeja plástica à temperatura ambiente para secagem, até eliminação do excesso de umidade.

\subsubsection{Recipiente}

o substrato inoculado foi distribuldo em tubetes do tipo "dibbing tube", fabricado em polietileno de alta densidade, de formato cónico, na cor preta, com estrias internas para direcionamento das ralzes, dispostos em bandejas de isopor.

\subsubsection{Semeadura}

Foram colocadas de 3 a 5 sementes de Eucalyptus urophylla, Eucalyptus torelliana e Eucalyptus paniculata nos tubetes a $1 \mathrm{~cm}$ de profundidade. 
3.15.5. Local de instalação do experimento

\begin{abstract}
o experimento foi instalado em casa de vegetação da Bioplanta Tecnologia de Plantas S.A., situada em Paulinia-SP.
\end{abstract}

3.15.6. Delineamento estatistico

Qs tratamentos foram distribuidos segundo o delineamento estatistico inteiramente casualizado com 24 repetiçơes.

3.15.7. Desbaste

Aos 30 dias da inoculaçå foi feito um des-
baste seletivo deixando-se somente uma planta por reci-
piente (a mais vigorosa).

3.15.8. Adubaçăo

A adubação consistiu da aplicação de solução nutriente (RUEHLE \& WELLS, 1984), preparado segundo o item 3.5.34, semanalmente, após o destaste. 
3.15.9. Araliação

Aos 90 dias da inoculação foi feita uma avaliaça visual em escalas de notas de 0 a 5 do grau de colonização das raizes e porcentagem de plantas micorrizadas.

3.16. Avaliação do grau de micorrizaçăo de mudas de Eucalyptus urophylla proveniente de semeio direto e plantulas, i noculadas com isolados de Pisolithus tinctorius

\subsubsection{Produção de inoculante}

A produção de inoculante consistiu da transferencia de 9 discos de $0,5 \mathrm{~cm}$ de dismetro retirados das bordas das colonias crescidas em meio MNM para frascos de $300 \mathrm{ml}$ contendo $200 \mathrm{ml}$ de substrato turfa-vermiculita-meio MNM (preparado segundo o item 3.6.1).

Os frascos foram incubados a $26^{\circ} \mathrm{C}$ por 3 meses.

3.16.2. Inoculação do substrato

A inoculaçåo foi feita atraves de uma mistura manual do inoculante ao substrato turfa-vermiculita (preparado segundo o item 3.6 .6$)$ na concentraçăo de $10 \%$. 
0 inoculante dos isolados ectomicorrizicos, antes de sua utilização, foi transferido para um tecido poroso e submetido a uma lavagem em água corrente por 2 minutos e, em seguida, colocada em bandeja plástica a temperatura ambiente para secagem, até eliminação do excesso de umidade.

\subsubsection{Recipiente}

a substrato inoculado foi distribuido em tubetes do tipo "dibbing tube", fabricado em polietileno de alta densidade, de formato cónico, na cor preta, com estrias internas para direcionamento das raizes, dispostos em bandejas de isopor.

3.16. 4. Semeadura

Foram colocadas de 3 a 5 sementes de Eucalyptus urophylla por tubete a $1 \mathrm{~cm}$ de profundidade.

3.16.5. Transplante de plántulas

Plântulas retiradas de sementeiras foram transplantadas para os tubetes com 20 dias de idade. 
3.16.6. Local de instalação do experimento

0 experimento foi instalado en casa de vegetação da Bioplanta Tecnologia de Plantas S.A. Situada em Paulinia-SP.

\subsubsection{Delineamento estatistico}

Os tratamentos foram distribufdos segundo 0 delineamento estatistico inteiramente casualizado com dezesseis repetiçôes, seguindo o esquema fatorial $7 \times 2$ cujos fatores foram: isolados e fases de inoculaçăo (plantulas ou sementes).

- quadro abaixo representa a análise de variancia proposta, com as causas de variação e respectivos valores de $F$.

\begin{tabular}{|c|c|c|c|}
\hline Causa de variação & GL & QM & $F$ \\
\hline Tratamentos (T) & $T-1$ & QMT & \\
\hline Isolados (I) & $I-1$ & QMI & QMI / QMR \\
\hline $\begin{array}{l}\text { Fases de inoculaça } \\
\text { (F) }\end{array}$ & $F-1$ & QMF & QMF / QMR \\
\hline $\begin{array}{l}\text { Isolado } \times \text { Fases } d e \\
\text { inoculação I } \times F\end{array}$ & $(I-1)(F-1)$ & $Q M I \times F$ & $Q M I \times F / Q M R$ \\
\hline Residuo (R) & $T(R-1)$ & QMR & \\
\hline
\end{tabular}


Realizaram-se comparaçós entre médias de isolados e fases de inoculaçăo aplicando-se teste de Tukey, atraves da seguinte formula: $\Delta=q \frac{s}{\sqrt{r}}$, onde, $q=$ valor da amplitude total estudentizada a nivel de $5 \%$ e $1 \%$ de probabilidade, $r=$ número de repetiçơes e $s=$ estimativa do desvio padrão residual.

\subsubsection{Desbaste}

Aos 30 dias da inoculação foi feito um desbaste seletivo, nos tubetes semeados, deixando-se somente uma planta por recipiente (a mais vigorosa).

\subsubsection{Adubação}

A adubaçå consistiu da aplicação de solução nutriente (RUEHLE \& WELLS, 1984), preparado segundo o item 3.5.34, semanalmente, apos desbaste.

\subsubsection{Avaliação}

Aos 60 dias da inoculaçăo foi feita uma avaliação visual do grau de colonização das ralzes. 
3.17. Produção de inoculante de um isolado de Pisolithus tinctorius em diferentes substratos

3.17.1. Preparo do substrato

$$
\text { Preparado segundo os } 1 \text { tens } 3.6 .1,3.6 .2 \text {, }
$$

$3.6 .3,3.6 .4$ e 3.6 .5$.

3.17.2. Produção de inoculante

o método de produção de inoculante consistiu da transferencia de 8 discos de $0,5 \mathrm{~cm}$ de diámetro retirados das bordas das colónias do isolado PI 314 crescidas em meio MNM, para frascos de $300 \mathrm{ml}$, contendo separadamente, $200 \mathrm{ml}$ de substrato turfa-vermiculita-meio MNM, turfa-vermiculitameio BDA, turfa-vermiculita-meio BDA-D, turfa-vermiculitameio BDMT e turfa-vermiculita-meio MNMB (preparado segundo os 1 tens $3.6 .1,3.6 .2,3.6 .3,3.6 .4$ e 3.6 .5$)$. Os fracas foram incubados a $26 \circ \mathrm{C}$ por 3 meses.

\subsubsection{Delineamento estatistico}

Os tratamentos foram distribuldos segundo 0 delineamento estatistico inteiramente casualizado com seis repetiçzes. 
3.17.4. Avaliação

Aos 90 dias da inoculaçăo do substrato foi feita uma avaliação visual do crescimento micelial nos substratos. 


\section{RESULTADOS E DISCUSSÃO}

4.1. Caracterização do crescimento dos isolados de Pisalithus tinctorius em diferentes meios de cultura

$$
\text { Os isolados do fungo Pisolithus tinctorius, }
$$

utilizados no presente trabalho, apresentam crescimento lento quando comparado a outros fungos. Segundo SASEK \& MUSILEK (1971), a crescimento de fungos basidiomicetos micorrizicos em laboratório é geralmente mais lento do que fungos basidiomicetos năo-micorrizicos. Do ponto de vista prático e interessante testarem-se outros meios de cultura, com vistas à aceleração do seu crescimento, a que muito ajudaria em estudos posteriores.

Seguindo-se a metodologia descrita no item 3.8, obtiveram-se os resultados dos diametros das colónias em placas contendo diferentes meios de cultura dos isolados $A C 1, A C 3, A C 6, A C 8, A C 12, P I 203, P I 312, P I 314, P I 316$, ITA6, ITA11, Pt 185 e Pt taeda de Pisolithus tinctorius 
Tabela 2. Comparação das medias (diâmetros de colónias em (m) de isolados pelo teste de Tukey.

\begin{tabular}{|c|c|c|c|}
\hline Isolados & Médias & $5 \%$ & $1 \%$ \\
\hline$A C 12$ & 6,4595 & $a$ & $A$ \\
\hline PI 314 & 6,0545 & b & $B$ \\
\hline PI 203 & 5,6170 & c & C \\
\hline ITA 6 & 5,5837 & c & C \\
\hline$A C 6$ & 5,3333 & c & C \\
\hline Pt 185 & 4,8137 & d & $D$ \\
\hline Pt. taeda & 4,8029 & de & $\mathrm{D}$ \\
\hline PI 312 & 4,7954 & $d e$ & D \\
\hline ITA 11 & 4,6104 & def & $\mathrm{D}$ \\
\hline PI 316 & 4,5441 & def & $D$ \\
\hline$A C 1$ & 4,5154 & ef & $D$ \\
\hline$A C 3$ & 4,5041 & $f$ & $\mathrm{D}$ \\
\hline$A C B$ & 3,7741 & 9 & $E$ \\
\hline
\end{tabular}

Medias seguidas por letras distintas diferem entre $5 i$ ao nivel de significancia indicado.

DMS $1 \%=0,3417 \quad$ DMS $5 \%=0,2903$

Tabela 3. Comparação das medias (diâmetros de colónias em cm) de meios pelo teste de Tukey.

\begin{tabular}{lccc}
\hline Meios & Medias & $5 \%$ & $1 \%$ \\
\hline MNM & 5,8104 & a & A \\
BDA-D & 5,0698 & $b$ & B \\
BDA & 5,0237 & $b$ & B \\
MNMB & 4,7945 & $c$ & $C$ \\
BDMT & 4,4586 & $d$ & D \\
\hline
\end{tabular}

Médias seguidas por letras distintas diferem entre $5 i$ ao nivel de significancia indicado.

DMS $1 \%=0,1447 \quad$ DMS $5 \%=0,1208$ 
Tabela 4. Comparação das medias de diametros das colónias dos isolados em funçăo da idade (dias) pelo teste de Tukey.

\begin{tabular}{|c|c|c|c|}
\hline Idade (dias) & Médias & $1 \%$ & $5 \%$ \\
\hline 25 & 7,0334 & $a$ & $A$ \\
\hline 22 & 6,3036 & $b$ & $B$ \\
\hline 19 & 5,6242 & $c$ & C \\
\hline 16 & 4,7157 & $d$ & $\mathrm{D}$ \\
\hline 13 & 3,7444 & e & $E$ \\
\hline 10 & 2,7671 & $f$ & $F$ \\
\hline
\end{tabular}

Medias seguidas por letras distintas diferem entre si ao nivel de significancia indicado.

DMS $1 \%=4,5894 \quad$ DMS $5 \%=4,0896$

Os isolados AC 12 e PI 314 cresceram bem em todos os meios testados, porém não superando o crescimento em meio MNM. Esta observação pode ser confirmada atraves da comparação das médias de isolados pelo teste de Tukey (Tabela 2). Nesta tabela pademos verificar que estes isolados apresentam as melhores médias e que eles diferem entre si e diferem dos demais a 5 e $1 \%$ de significáncia.

o isolado PI 203 também apresentou um bom crescimento nos meios testados e, na Tabela 2 podemos verificar que este isolado apresentou a terceira melhor media, 
apesar de não diferir estatisticamente dos isolados ITA 6 e AC 6.

Os outros isolados apresentaram modificaçăes no hábito de crescimento micelial nos meios testados. Com exceção para o meio MNM, eles apresentaram crescimento de colónias compactadas, aumentando a massa micelial (discutido a seguir) e, em alguns casos, apresentaram colónias rugosas.

Na Tabela 3 podemos observar que o meio BDA que contém $20 \mathrm{~g}$ de Dextrose não diferiu estatisticamente do meio BDA contendo $10 \mathrm{~g}$ de Dextrose. Isto mostra que reduzindo-se para a metade a quantidade de Dextrose podemos obter a mesmo crescimenta. Tadas as outros meios diferem entre si ao nivel de 5 e $1 \%$ de significáncia e o melhor meio foi o MNM, como pode ser verificado pela comparação das médias de meios pelo teste de Tukey.

Apesar de nentium meio ter sido melhor que o meio MNM para os isolados AC 12 e PI 314 , o crescimento nos meios MNMB, BDA, BDA-D e BDMT foi igual ao obtido no meio MNM.

Considerando-se os resultados obtidos, foi desenvolvido um outro ensaio para avaliar melhor os meios, visto que foi observado um aumento de massa micelial de alguns isolados. 



tinctorius em diferentes meios de cultura

No experimento anterior foi verificado, na maioria dos isolados, um aumento na massa micelial devido ao crescimento de colónias com micelio compacto nos meios BDA, BDA-D, BDMT e MNMB. Para avaliar este aumento, os isolados foram inoculados em meio liquido visando a avaliação da biomassa produzida por eles nestes meios.

Os resultados dos pesos secos de micelio, dos isolados AC1, AC3, AC6, AC8, AC12, PI 203, PI 312, PI 314, PI 316, ITA 6, ITA 11, Pt 185 e Pt taeda, inoculados em diferentes meios de cultura, após 30 dias foram tomados segundo o item 3.9 e estão apresentados na Tabela 2 do Apendice. A Tabela 5 apresenta os valores e significancias dos quadrados médios da análise de variancia. As Tabelas 6 e 7 mostram a comparação das médias de isolados e comparação das médias de isolados dentro de cada meio pelo teste de Tukey a nivel de 5 e $1 \%$ de significáncia, enquanto que a comparação das médias de meios e comparação das médias de meios dentro de cada linhagem pelo teste de Tukey a nivel de 5 e $1 \%$ de significância estão apresentados nas Tabelas 8 e 9.

A análise de variăncia mostra que houveram diferenças significativas a nivel de $1 \%$ tanto para o fator isolado como para o fator meio. 
Tabela 5. Valores e significancias dos quadrados médios da análise de variância dos dados das medidas de pesos secos de micélio de diferentes isolados em diferentes meios de cultura.

C.V.

GL

Q.M.

F

\begin{tabular}{lrrr}
\hline Isolado & 12 & 0,0162 & $44,2467 * *$ \\
Meio & 4 & 0,0350 & $95,5171 * *$ \\
Isol. x Meio & 48 & 0,0016 & $4,5080 * *$ \\
Residuo & 195 & 0,0003 & \\
\hline
\end{tabular}

Total

259

Média geral $=0,0866$

Coeficiente de Variação $=20,00 \%$

$n s=$ não significativo

** = significativo ao nível de $1 \%$ de probabilidade

Nå existe uma relaçăo direta entre diametro da colônia e seus respectivos pesos; os isolados que possuem as melhores médias de crescimento não são os que tem maior média de peso seco.

As médias de cada isolado indicam que os melhores foram Pt 185 e Pt taeda, os quais apresentaram $0,130 \mathrm{~g}$ e $0,118 \mathrm{~g}$ de peso seco de micelio respectivamente, como pode ser verificado na Tabela 6. Nesta tabela podemos verificar que o isolado Pt 185 difere dos demais, exceto do Pt taeda. No entanto, na Tabela 2 podemos verificar que estes dois isolados apresentaram as priores medias de crescimento. 
Tabela b. Comparação das médias (peso seco de micélio) de isolados inoculados em diferentes meios de cultura pelo teste de Tukey.

\begin{tabular}{|c|c|c|c|}
\hline Isolado & Medias & $5 \%$ & $1 \%$ \\
\hline Pt 185 & 0,1300 & $a$ & $A$ \\
\hline Pt taeda & 0,1180 & $a b$ & $A B$ \\
\hline ITA 6 & 0,1040 & $b c$ & $\mathrm{BC}$ \\
\hline$A C 8$ & 0,1025 & DC & $\mathrm{BC}$ \\
\hline$A C 3$ & 0,1020 & bc & $\mathrm{BC}$ \\
\hline$A C 1$ & 0,0925 & $c d$ & $C D$ \\
\hline ITA 11 & 0,0925 & $c d$ & $C D$ \\
\hline$A C 6$ & 0,0875 & cde & $C D$ \\
\hline AC 12 & 0,0850 & cde & $C D$ \\
\hline PI 316 & 0,0730 & de & $\mathrm{D}$ \\
\hline$P I 312$ & 0,0695 & e & $D$ \\
\hline PI 314 & 0,0450 & $f$ & $E$ \\
\hline PI 203 & 0,0250 & $f$ & $E$ \\
\hline
\end{tabular}

Médias seguidas por letras distintas diferem entre si ao nivel de significância indicado.

DMS $1 \%=2,3071 \quad$ DMS $5 \%=2,0181$

Dentro do meio MNM, que é o meio normalmente utilizado, os isolados não apresentaram diferenças estatisticamente significativas a nivel de $1 \%$ pelo teste de Tukey. Já nos outros meios testados ocorrem diferenças entre os isolados ao mesmo nivel de significancia (Tabela 7). No meio MNMB o isolado AC3 apresentou a maior média de peso seco. Neste meio, o AC 3 difere dos demais. 
Tabela 7. Comparação das medias (peso seco de micelio) dos isolados dentro de cada meio.

\begin{tabular}{|c|c|c|c|c|c|}
\hline \multirow{2}{*}{ I sol ados } & \multicolumn{5}{|c|}{ Medias dos pesos secos d } \\
\hline & MNM & MNMB & BDA & $B D A-D$ & BDMT \\
\hline$A C 1$ & $0,0425 A$ & $0,1350 \mathrm{BC}$ & $0,0950 \mathrm{~B}$ & $0,0850 A B$ & $0,1050 \mathrm{AB}$ \\
\hline$A C 3$ & $0,0450 A$ & $0,2000 A$ & $0,0950 \mathrm{~B}$ & $0,0825 \mathrm{AB}$ & $0,0875 \mathrm{AB}$ \\
\hline$A C 6$ & $0,0400 A$ & $0,1275 B C$ & $0,0900 \mathrm{BC}$ & $0,0850 A B$ & $0,0950 \mathrm{AB}$ \\
\hline$A C 8$ & $0,0550 A$ & $0,1300 \mathrm{BC}$ & $0,1175 \mathrm{~B}$ & $0,1000 A$ & $0,1100 \mathrm{AB}$ \\
\hline$A C \quad 12$ & $0,0475 A$ & $0,1100 \mathrm{BCD}$ & $0,0925 B C$ & $0,0825 \mathrm{AB}$ & $0,0925 \mathrm{AB}$ \\
\hline PI 203 & $0,0175 A$ & $0,0450 E$ & $0,0225 \mathrm{D}$ & $0,0200 C$ & 0,02000 \\
\hline PI 312 & $0,0325 A$ & $0,0850 C D E$ & $0,0800 B C$ & $0,0700 A B C$ & $0,08008 \mathrm{C}$ \\
\hline PI 314 & $0,0525 A$ & $0,0625 D E$ & $0,0425 \mathrm{CD}$ & $0,03508 \mathrm{C}$ & $0,0325 \mathrm{CD}$ \\
\hline PI 316 & $0,0450 A$ & $0,0950 B C D E$ & $0,0750 B C$ & $0,0750 A B$ & $0,0750 B C$ \\
\hline ITA 6 & $0,0525 A$ & $0,1300 \mathrm{BC}$ & $0,1125 \mathrm{~B}$ & $0,1100 \mathrm{~A}$ & $0,1150 \mathrm{AB}$ \\
\hline ITA 11 & $0,0475 A$ & $0,1225 B C$ & $0,0925 B C$ & $0,9250 A$ & $0,1075 \mathrm{AB}$ \\
\hline Pt 185 & $0,0675 A$ & 0,14008 & $0,1950 \mathrm{~A}$ & $0,1100 \mathrm{~A}$ & $0,1375 \mathrm{~A}$ \\
\hline Pt taeda & $0,0575 A$ & $0,1250 \mathrm{BC}$ & $0,1800 \mathrm{~A}$ & $0,1025 A$ & $0,1250 \mathrm{AB}$ \\
\hline
\end{tabular}

Médias seguidas da mesma letra não diferem entre si pelo teste de Tukey a $1 \%$ de probabilidade.

DMS $(1 \%)=5,1590$

No meio BDA, Pt 185 e Pt taeda nå diferem entre si, mas diferem dos demais, sendo estes os que produzem maiores médias de peso seco neste meio. Na mesma tabe1 a podemos verificar que dentro do meio BDA-D os isolados ITA 6, Pt 185, Pt taeda, AC8, ITA11, AC6, AC1, AC12, AC3, PI 
316 e PI 312 não apresentaram diferenças estatisticamente significativas, mas diferem de PI 314 e PI 203. Dentro do meio BDMT Pt 185 difere estatisticamente de PI 312, PI 316, PI 314 e PI 203, mas nå difere dos demais.

Comparando-se os valores das medias de meios, podemos verificar que o meio MNM-B foi o melhor para produção de biomassa; no entanto, no meio MNM que foi o melhor meio para o crescimento do fungo (Tabela 2) - foi obtida a menor media de peso seco. Em todos as outros meios a produção de massa micelial foi maior, como mostra a Tabela 8.

Tabela 8. Comparação das médias (peso seco de micélio) de meios pelo teste de Tukey.

\begin{tabular}{lccc}
\hline Meias & Medias & $5 \%$ & $1 \%$ \\
\hline MNMB & 0,1159 & $a$ & A \\
BDA & 0,0992 & $b$ & B \\
BDMT & 0,0909 & bc & BC \\
BDA-D & 0,0807 & $c$ & C \\
MNM & 0,0463 & $d$ & D \\
\hline
\end{tabular}

Medias seguidas por letras distintas diferem entre si ao nível de significância indicado.

DMS $1 \%=1,2290$

DMS $5 \%=1,0291$ 
Na Tabela 9 podemos verificar que para os isolados PI 203 e PI 314 năo houve diferença entre os meios a nivel de 5 e $1 \%$ de significáncia.

a comportamento destes isolados confirmam os resultados obtidos anteriormente (item 3.8 ) onde estes isolados mostraram o mesmo crescimento em todos as meios testados.

Tabela 9. Comparação das medias de meios (peso seco de micelio) dentro de cada isolado.

\begin{tabular}{|c|c|c|c|c|c|}
\hline \multirow{2}{*}{ Isolados } & \multicolumn{5}{|c|}{ Médias dos pesos secos } \\
\hline & MNM & MNMB & BDA & $B D A-D$ & BDMT \\
\hline$A C 1$ & $0,0425 C$ & $0,1350 A$ & $0,0950 A B$ & $0,0850 B C$ & $0,1050 A B$ \\
\hline$A C 3$ & 0,04500 & $0,2000 A$ & $0,0950 \mathrm{~B}$ & $0,0825 B C$ & $0,0875 B C$ \\
\hline AC6 & $0,0400 B$ & $0,1275 A$ & $0,0900 A$ & $0,0850 A$ & $0,0950 \mathrm{~A}$ \\
\hline ACB & $0,0550 \mathrm{~B}$ & $0,1300 A$ & $0,1175 A$ & $0,1000 \mathrm{~A}$ & $0,1100 \mathrm{~A}$ \\
\hline$A C 12$ & 0,04758 & $0,1100 \mathrm{~A}$ & $0,0925 A$ & $0,0825 A B$ & $0,0925 A$ \\
\hline PI 203 & $0,0175 A$ & $0,0450 A$ & $0,0225 A$ & $0,0200 A$ & $0,0200 A$ \\
\hline PIO 312 & $0,0325 B$ & $0,0850 A$ & $0,0800 A$ & $0,0700 \mathrm{AB}$ & $0,0800 \mathrm{~A}$ \\
\hline PI 314 & $0,0525 A$ & $0,0625 A$ & $0,0425 A$ & $0,0350 A$ & $0,0325 A$ \\
\hline PI 316 & $0,0450 B$ & $0,0950 A$ & $0,0750 A B$ & $0,0750 \mathrm{AB}$ & $0,0750 A B$ \\
\hline ITAG & $0,0525 B$ & $0,1300 A$ & $0,1125 A$ & $0,1100 \mathrm{~A}$ & $0,1150 A$ \\
\hline ITA 11 & 0,04758 & $0,1225 A$ & $0,0925 A$ & $0,0925 A$ & $0,1075 A$ \\
\hline Pt 185 & $0,0675 \mathrm{C}$ & $0,1400 \mathrm{~B}$ & $0,1950 \mathrm{~A}$ & $0,1100 B C$ & 0,13758 \\
\hline Pt taeda & $0,0575 \mathrm{C}$ & 0,12508 & $0,1800 A$ & 0,10258 & $0,1250 B$ \\
\hline
\end{tabular}

Médias seguidas da mesma letra não diferem entre si pelo teste de Tukey a $1 \%$ de probabilidade.

DMS $(1 \%)=4,4312$ 
Para o isolado AC12 não houve diferença estatisticamente significativa entre os meios MNMB, BDA, BDA-D e BDMT, mas estes diferem do meio MNM (Tabela 9). No entanto, o desenvolvimento das colónias também foram normais em todos os meios. Para os outros isolados houveram diferenças estatisticamente significativas entre as meios. desenvalvimento do fungo nos meios MNMB, BDA, BDA-D e BDMT não foi normal. As colónias cresceram rugosas, compactas, com coloração escura e ocorrendo também liberação de uma substancia escura (não identificada); isto poderia causar uma mudança no comportamento do fungo.

Os meios foram bons somente para os isolados PI 203, PI 314 e AC12 porque eles tiveram desenvalvimento de colónias normais em todos os meios. Nă foi constatado nenhum aumento na produção de massa micelial destes isolados. Contudo, deve-se salientar que os mesmos apresentam opç̧es de crescimento em diferentes meios de cultura. Para estes trés isolados, como já tinha sido observado anteriormente, o meio BDA que contém 209 de Dextrose não difere estatisticamente do meio BDA contendo 109 de Dextrose; reduzindo-se para a metade a quantidade de Dextrose obtemos - mesmo resultado. 


\title{
4. 3. Caracterização citológica
}

\begin{abstract}
Com a intuito de se iniciar um estudo genético nessa especie, fizeram-se inicialmente observações citológicas de hifas em diferentes estadios de desenvolvimento. Estes estudos citológicos såo necessários para se conhecer e compreender as fenómenos de variabilidade genetica natural já constatada nessa espécie.

Após a coloração pelo método descrito no item
\end{abstract} 3.10, foi possivel observar a desenvolvimento de hifas, determinar o número de núcleos por célula micelial (Figura 1) e fazer algumas observaçôes da divisão nuclear em células somáticas do micélio. As medidas dos núcleos foram feitas como descrito no item 3.10 .2 .

Os resultados mostram que as hifas possuem espessuras bem diversificadas. Cada celula micelial possui dois núcleos, sendo que estes apresentam um tamanho médio de $2,439 \mu$ (média de 596 núcleos). De uma célula para outra foram observadas as pontes de conexão e, raramente, foi observado a passagem de núcleos atraves destas pontes, talvez por este processo ser relativamente rápido. AIST \& WILSON (1967b) verificaram que em Ceratocystis fagacearum o processo de divisăo nuclear prolonga-se por 3 a 5 minutos.

A divisăo celular ocorre mais frequentemente em celulas de extremidades de hifas do que em hifas velhas. 




Figura 1. a - d) Desenvolvimento de hifas de Pisolithus tinctorius. Presença de dois núcleos por célula micelial $(a-c \times 1000, d \times 400)$. 
Há muitas teorias publicadas relacionadas à divisão nuclear assexual em fungos. Uma delas é a que a divisão corresponde à mitose clásica (SOMERS et alii, 1960; WARD \& CIURYSEK, 1961 e ICHIDA \& FULLER, 1968).

Alguns pesquisadores (BAKERSPIGEL, 1958 e 1959 e SAKSENA, 1961) năo encontraram fusos, placas metafásicas ou centriolos, como na mitose regular. 0 núcleo simplesmente se alonga, contrai ao meio e, então, se separa para formar núcleos filhos.

Apesar do número considerável de informaçỡes sobre mitose em hifas de fungos filamentosos, nenhum padrão de divisão fai sugerido. Alguns pesquisadores não revelaram nada além do conhecido; mas, muitos outros encontraram que a divisão ocorre por um processo que difere em vários aspectos da divisão de núcleos de organismos superiores.

A literatura nos deixa em dúvida se essas diferenças se devem ao pequeno tamantio dos núcleos dos fungos, às técnicas empregadas em seu estudo, a alguma peculiaridade do comportamento ou se são meras impressás.

As observaçốes da divisão nuclear em celulas somáticas do fungo Pisolithus tinctorius demonstraram ocorrer com alguma similaridade à de outros fungos, mas algumas estruturas não puderam ser observadas.

Os núcleos em divisă variam en forma e tamanho, dependendo, da fase de divisão que se encontra. Utilizando-se o criterio proposto por TANAKA (1976) para o 
fungo filamentoso Pyricularia oryzae e utilizado por RoDRIGUES ( 1987 ) para o fungo Humicola sp, o processo de divisăo foi classificado em cinco estágios de acordo com a forma e tamanho dos núcleos. No estágio de interfase os núcleos apresentavam-se esfericos ou subesféricos e corados uniformemente (Figura 2-h). Em muitos fungos a estágio de interface é caracterizado pela presença de um nucleolo proeminente como em Neurospora crassa (SOMERS et alii, 1960), Ceratobasidium praticolum (SAKSENA, 1961), Ceratocystis fagacearum (AIST \& WILSON, 1967b), FUsarium oxysporum (AIST \& WILSON, 1967a), Macrophomina phaseali (KNOX-DAVIES, 1967), Catenaria anguillulae (ICHIDA \& FULLER, 1968), foria monticola (BRUSHABER \& JENKINS, 1971); esta estruturanão foi observada em Pisolithus tinctorius. Na profase, os núcleos apresentavam-se menos corados do que na interfase, tintiam formato esférico ou, algumas vezes, alongados (Figura 2-a). Os cromossomos năo foram diferenciados neste estágio: Os núcleos em metáfase apresentavam corpos cromatinicos irregulares e não diferenciados em cromossomos individualizados (Figura 2-b e C). Placas metafásicas encontradas por alguns pesquisadores (WARD \& CIURYSEK, 1961 e SOMERS, 1960) não foram observados. Classificou-se como anafásicos, dois núcleos pareados, conectados por fios de cromatina. Com o prosseguimento da anáfase as cromatides irmás, tornaram-se igualmente distribuidas no núcleo. Na anáfase final ou telofase inicial, os cromossomos filhos agregaram-se em duas 
massas relativamente grandes, paralelas uma a outra e ao eixo lango da hifa, parecendo algumas vezes, uma configuração de "duplo trilho" (Figura 2d-e). Esta configuração cromossomal foi detectada em Aspergillus e Fusarium, utilizando-se o mesmo corante (BURNETT, 1976). Em Aspergillus nidulans os cromossomos se separam e o grupo compacto se transforma em duas ou mais cadeias de corpos cromatinicos parelalos uma a outra e a lacuna entre as cadeias paralelas e ocupada por um lango fuso (ROBINSON \& CATEN, 1969). A estrutura do fuso não foi observada em Pisalithus.

Os detalhes do processo pelo qual a estagio de "trilho" é alcançado permanece obscuro. Segundo FINCHAM et alii (1979) a aparência de "trilha" pode ser devido, parcialmente, a assincromia da disjunção cromossómica, alguns pares quase nos polos enquanto outros se encontram ainda pouco separados.

A formaçăo pareada, em Aspergillus, parece se quebrar transversalmente na região equatorial, ocorrendo movimento da cromatina em direçăo a ambas extremidades em cada cadeia (ROBINSON \& CATEN, 1969). Semelhante observação também foi feita por BURNETT (1976). No entanto, em Pisolithus tinctotius não foi abservado nentiuma quebra transversal. Neste fungo parece que há migração de uma cadeia para cada extremidade, como se cada cadeia fosse puxada para umpólo (Figura $2 f-g$ ). No final da telófase são formados dois núcleos filhos que assumem uma forma esférica (Figura $2 h$ ). 


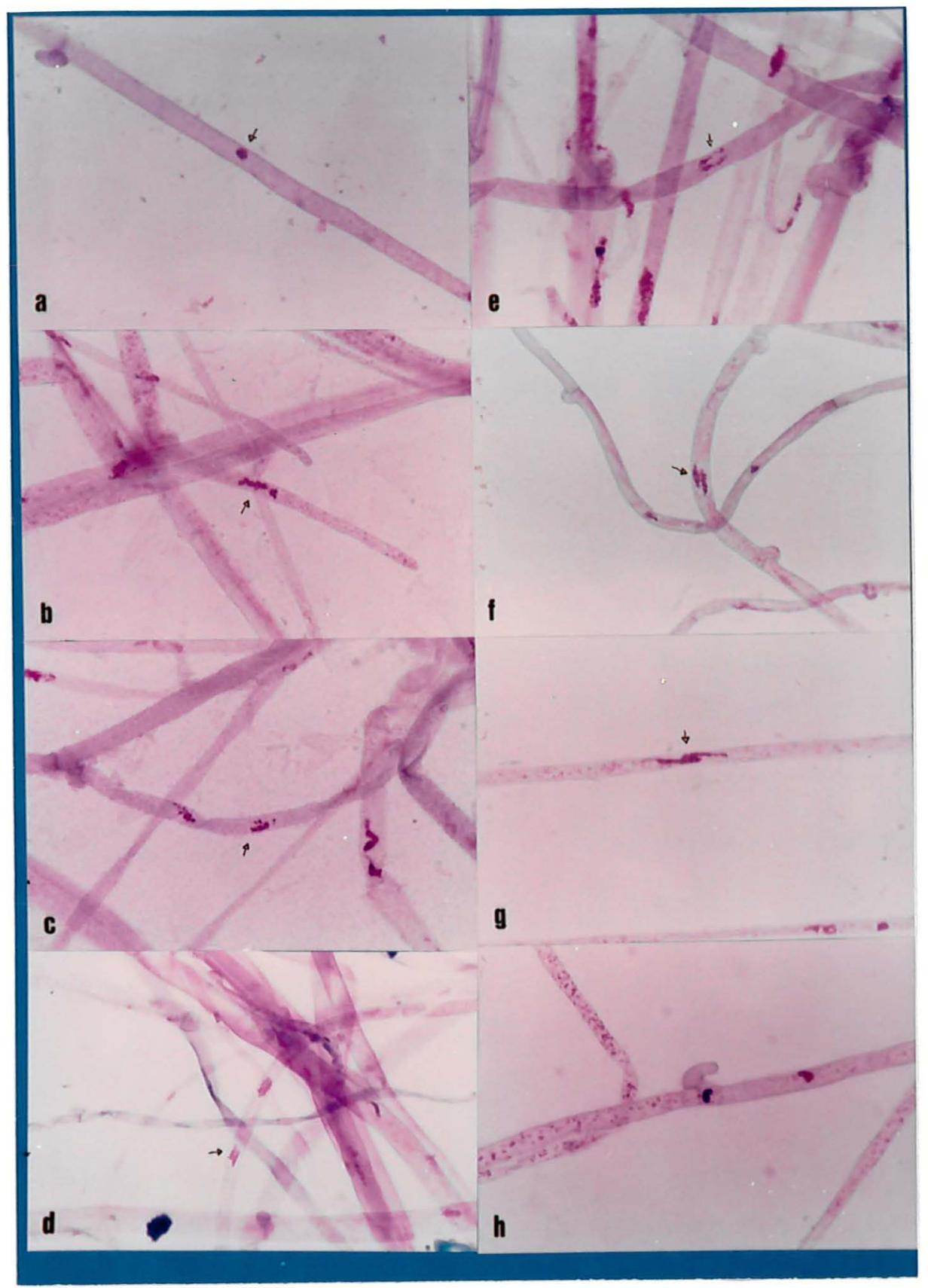

Figura 2. Fases da divisão mitótica em célula somática de micélio de Pisolithus tinctorius $(\times 1000)$. a) Prófase; b-c) metáfase; d-el anáfase; f-gl telófase; h) interfase. 
Segundo BURNETT (1976), este tipo de alinhamento duplo paralelo é extremamente difundido entre os fungos e esta forma de arranjo tem sido mais comumente vista em Basidiomicetos de todas as espécies.

As limitaçơes da resolução ótica não permitem maiores detalhes, contudo, a microscopia de contraste de fase ou microscopia eletrónica poderiam fornecer mais detaIhadamente o processo de divisão podendo elucidar melhor o comportamento cromossomal neste fungo.

\section{4. Padrão eletroforético de esterases}

Q perfil eletroforético para esterases em gel de poliacrilamida dos isolados Pt 185, FEP2, FEP3, Pt taeda e P5, obtido segundo o item 3.11 , está representado na figura 3

A idade da cultura, a metodologia para extração das enzimas e a concentração das amostras foram padronizadas para os isolados de Pinus (item 3.11 .1 ) e foram testados para os isolados de Eucalyptus, sendo que nestes não houve um resultado satisfatório.

Pelo padrão resultante, os isolados de Pinus não mostraram diferenças quando ao padrão de bandas para esterases, apresentando, todos eles, quatro bandas estreitas. O perfil eletroforetico de outras enzimas deve ser 
traçado para estes isolados com intenção de verificar se os mesmos apresentam diferenças no padrão de bandas de outras enzimas.

Para os isolados de Eucalyptus também devem ser padronizados a idade da cultura e uma metodologia para a extração das enzimas.

o desenvalvimento de uma metodologia para caracterização eletroforética dos isolados é de grande importáncia em estudos posteriores para demonstração de enzimas particulares presente no micélio e, também, para identificação de protelnas envolvidas na simbiose do fungo com o hospedeiro.



Figura 3. Padrão eletroforético de esterases de diferentes isolados de Pisolithus tinctotius. 1. Pt 185; 2. FEP2; 3. FEP3; 4. Pt taeda; 5 e 6. FEP5. 


\subsection{Obtenção de protoplastos}

Técnicas para produção e regeneração de protoplastos podem ser de grande beneficio para a pesquisa em organismos como as fungos micorrizicos, que são difíceis ou impossiveis de cultivar em laboratorio e sobre os quais pouco ou nada se conhece sobre seu sistema genético.

Foram avaliadas algumas condiçós para produção de protoplastos de um isolado selecionado de Pisolithis tinctorius.

A seleçåo do isolado foi feita atraves da avaliação do crescimento dos isolados em meio sólido e meio 11 quido.

Soluçđes liticas preparadas com manitol $0,6 M$ foram testadas para liberaçăo de protoplastos do isolado FEP3 de $P$. tinctorius. A preparação enzimatica mais eficiente foi Novozyme 234 , liberando $3,3 \times 10^{\circ}$ protoplastos/ml depois de 2 horas de incubação. Esta enzima tambem foi utilizada por BARRETT et alii (1989) para obtençao de protoplastos de Hebeloma circinans, Hebeloma cylindrosporum, Laccaria bicalor, Laccaria laccata, Pisalithus tinctorius, Suilus luteus e Telephara terrestris. Segundo KROPP \& FORTIN (1986) esta foi a enzima mais eficiente para Laccaria bicolar.

A combinação de Celulase Onozuka e Driselase com Zimaliase e Quitinase ou com ß-Glucuronidase produziu um 
número insignificante de protoplastos (Tabela 10). HeBRAUD \& FÉVRE (1988) testaram a mistura de Celulase Onazuka R10 e Driselase utilizando MgSO4 O,7M como estabilizador e não obtiveram protoplastos de micelio de Pisolithus tinctorius; segundo os autores foi devido a presença de pigmentos protetores na parede das hifas. Esta mesma mistura em combinação com ß-glucuronidase foi utilizada com sucesso em outros Basidiomicetos como Pleurotus ostreatus e Pleurotus salmoneo straminius (TOYOMASU et alii, 1986).

Tabela 10. Liberação de protoplastos de Pisolithus tinctorius usando diferentes preparaçăes enzimáticas.

\begin{tabular}{lc}
\hline Enzima litica & $\begin{array}{r}\text { Protoplastos liberados/ml depois } \\
\text { de } 4 \mathrm{~h} \text { de incubação* }\end{array}$ \\
\hline Novozyme 234 & $3,3 \pm 0,4 \times 10^{\circ}$ \\
Celulase Onozuka + Driselase & $0,09 \pm 0,05 \times 10^{\circ}$ \\
+ Zimoliase + quitinase & \\
Celulase Onozuka + Driselase & $0,03 \pm 0,02 \times 10^{\circ}$ \\
+ B-glucuronidase &
\end{tabular}

* média de 4 repetiç8es.

Os protoplastos são formados em tampão MMC utilizados para outros fungos basidiomicetos ectomicorrizicOS (KROPP \& FORTIN, 1986; BARRETT et alii, 1989). 
A idade da cultura afetou grandemente a digestão da parede celular por Novozyme 234 (Figura 4). A proporção de hifas jovens e veltas varia de acordo com a idade da cultura; consequentemente, isto afeta a produção de protoplastos, pois as hifas jovens sao mais sensiveis a digestão enzimatica. O maior número de protoplastos produzido foi observado apos quatro dias de crescimento dos fragmentos de hifas. Depois de cinco dias de crescimento, a nivel de protoplastos liberados declinou e, com tres dias, quase nada foi produzido.

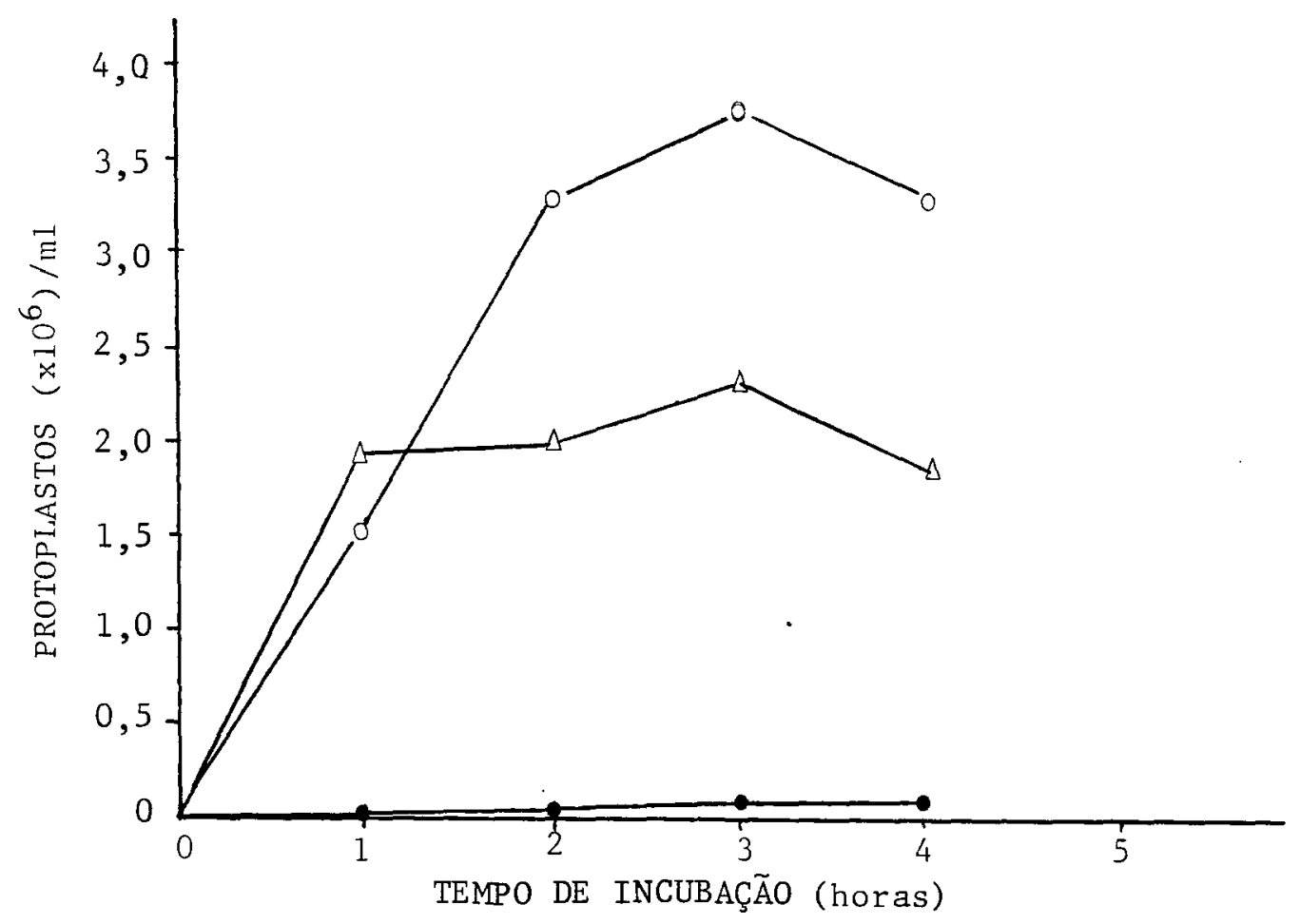

Figura 4. Influência da idade do micelio na liberação de protoplastos do isolado FEP3 de Pisolitus tinctorius em diferentes tempos de incubaçăo com Novozyme 234 (média de 4 repetiçzes); --0, 3 dias; 0--o, 4 dias; $\Delta^{--\Delta, 5}$ dias. 
HEBRAUD \& FEVRE (1988) consideraram a idade do micélio o principal parámetro para a produçåo de protoplastos de Hebeloma cylindrosporum. KROPP \& FORTIN (1985) observaram que em Laccaria bicolor a digestão da parece pela enzima foi grandemente afetada pela idade da cultura. Esta mesma observação foi feita por BARRETT et alii (1989) para oito fungos ectomicorrizicos.

Para se obter a produção adequada de protoplastos foi necessário homogeneizar o inóculo para que fossem produzidas numerosas pontas de hifas jovens susceptiveis à digestão.

Os protoplastos produzidos em diferentes tempos de incubação não mostraram variaçăo em tamanho. 0 tamanto médio foi de $5,3 \mu$, variando de $3,4 \mu$ a $8,6 \mu$ de diămetro. Com micélio de cinco dias, os protoplastos liberados eram relativamente menores - com um tamanho médio de $4,4 \mu-$, variando de $2,5 \mu$ a $6,8 \mu$.

Não foi obtida a regeneração dos protoplastos nos meios testados. BARRETT et alii (1989) também não obtiveram regeneração de protoplastos de $P$. tinctorius; os protoplastos corados mostraram ausencia de núcleos. Segundo os autores, o micelio deste fungo é composto predominantemente de hifas largas $(>3 \mu)$ com paredes celulares grossas e, freqüentemente, pigmentadas e/ou incrustadas. A minoria das celulas desse micelio são estreitas e com paredes finas. 
YANAGI et alii (1985) constataram que protoplastos liberados com Novozyme 234 de Coprinus macrortizus são pequenos e uma grande proporção são anucleados. Em Laccaria bicolor $62,9 \%$ dos protoplastos liberados eram anucleados (KROPP \& FORTIN, 1986).

A técnica de coloração de núcleos de protoplastos utilizada neste estudo (item 3.12.6) foi proposta por BORGES (1987) e foi utilizada com sucesso em Aspergillus nidulans (VIEIRA, 1988), Trichoderma pseudokoningii (FURLANETO, 1989) e Metarhizilum anisopliae (VALADARES, 1989). No entanto, não foi possivel a coloraçăo de núcleos de protoplastos de Pisolithus tinctarius com esta técnica, pois houve cristalização do manitol nas láminas.

As possibilidades para o uso de protoplastos de fungos ectomicorrizicas justifica a importância da continuidade no esforço para regenerar protoplastos neste fungo.

Os protoplastos de fungos ectomicorrizicos são fontes para desenvolver o melhoramento de isolados que poderiam afetar positivamente a produtividade de culturas florestais.

Mutantes de Hebeloma cylindrosporum resistentes a fungicidas como Benomil, Benodanil e Carboxine foram obtidos por HEBRAUD \& FEVRE (1988) através da irradiação de protoplastos com luz ultravioleta.

Recentes avanços no desenvolvimento de sistema de clonagem em vários grupos de fungos tornaram 
possivel considerar-se a aplicação e o potencial benéfico de tal sistema em fungos micorrizicos.

A aplicação de clonagem genica em fungos micorrizicos inclui a possibilidade de introduzirem-se novos genes, determinando produtos que seriam beneficos a planta hospedeira em associaçช̃es simbióticas. Outro aspecto inclui a possibilidade de conhecermos mais a biologia fundamental da associação micorrizica. Segundo Gilchrist \& Yoder, 1984 (citados por TRAPPE \& MOLINA, 1986) "um beneficio primário de ter genes isolados o potencial que eles oferecem para aumentar nosso conthecimento sobre os mecanismos moleculares que controlam a interação entre microrganismos e seus hospedeiros".

4.6. Avaliação da formação de ectomicorriza em Eucalyptus com isolados de Pisolithus tinctorius em diferentes concentraçžes de alumi nio

Este estudo foi realizado com o intuito de verificar o efeito de altas concentraçóses de Al na capacidade de infeção micorrizica dos isolados ACG, ACB, AC12 e PI 314 de $P$. tinctarius.

Ao fim de trés meses de permanencia em casa de vegetação, as plantas inoculadas preparadas, segundo a metodologia descrita no item 3.13, foram avaliadas quanto ao 
grau de micorrização. Os resultados da avaliação visual das ralzes eståo apresentados na Tabela 3 do Apendice. As plantas inoculadas apresentaram-se visualmente com baixo grau de infecção micorrizica. A presença de micorrizas no interior do substrato foi facilmente detectada devido à coloraçăo dourada das hifas que facilitam a visualizaçăo e determinação da quantidade de ectomicorrizas nas ralzes das mudas (Figura $5-2$ e 3 ).

- resultado da avaliação através da coloração das raizes (segundo item 3.13 .10 ) estao apresentados na Tabela 4 do Apendice. Estes dados foram avaliados estatisticamente. A Tabela 11 apresenta os valores e significáncias dos quadrados médios da análise de variância. Os resultados da análise química dos componentes do substrato estão indicados na Tabela 12, enquanto que a dosagem de aluminio no substrato no final do experimento está apresentada na Tabela 13. A Tabela 14 apresenta a concentração final da solução nutritiva (preparada segundo a item 3.5 .28 ) utilizada durante o experimento. 


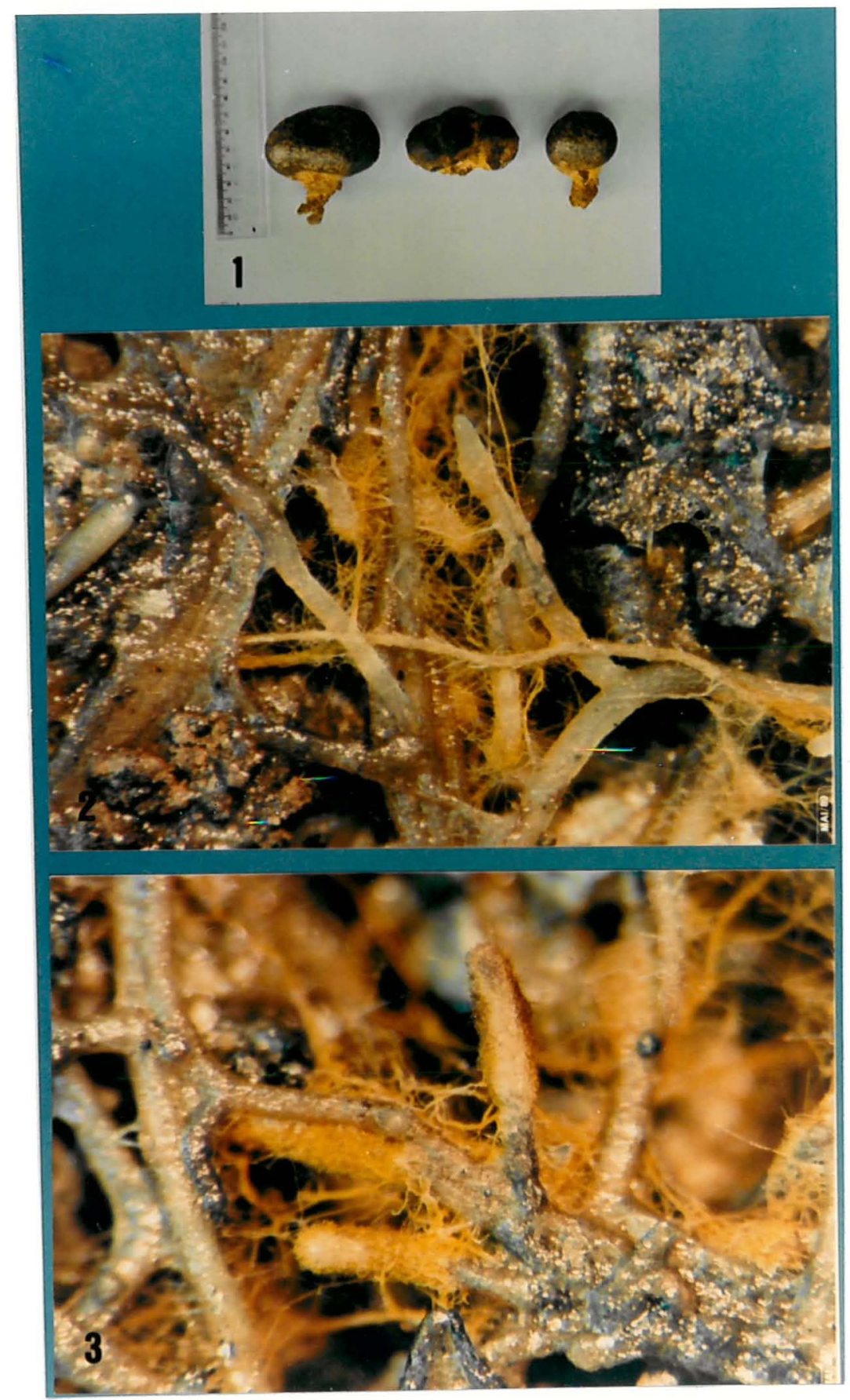

Figura 5. 1) Corpos de frutificação do fungo Pisolithus tinctorius; 2) Fase inicial da sintese de ectomicorriza em Eucalyptus urophylla (x40); 3) Ectomicorriza em Eucalyptus urophylla $(x 40)$. 
Tabela 11. Valores e significancias dos quadrados médios da análise de variância dos dados da avaliação da sintese de ectomicorriza em Eucalyptus em diferentes niveis de aluminio atraves de coloraçăo de raizes.

\begin{tabular}{lrrl}
\hline Causa de Variação & GL & QM & $F$ \\
\hline Isolados & 3 & 4,5833 & $0,78 n s$ \\
Concentração Al & 4 & 4,5406 & $0,77 n$ s \\
Isol. x Conc. Al & 12 & 5,9531 & $1,01 n$ s \\
Residuo & 140 & 5,8982 & \\
\hline Total & 159 & \\
\hline
\end{tabular}

Tabela 12. Resultado da análise química do substrato utilizado para o experimento da sintese de ectomicorriza em Eucalyptus em diferentes concentraçaes de aluminio.

\begin{tabular}{|c|c|c|c|c|c|}
\hline & & & $\%$ & & \\
\hline$N$ & $P$ & $k$ & $\mathrm{Ca}$ & Mg & $\mathrm{s}$ \\
\hline \multirow[t]{2}{*}{0,49} & 0,06 & 0,05 & 0,09 & 0,70 & 0,21 \\
\hline & & & ppm & & \\
\hline B & $\mathrm{Cu}$ & $\mathrm{Fe}$ & $M n$ & Mo & $Z n$ \\
\hline 30 & 17 & 4554 & 41 & - & 16 \\
\hline
\end{tabular}


Tabela 13. Dosagem de aluminio nos substratos no final do experimento.

Al

Substratos

\begin{tabular}{cc}
\hline meq/100 ml & ppm \\
0,65 & 58,5 \\
0,60 & 54,0 \\
0,95 & 85,5 \\
0,80 & 72,0 \\
1,40 & 126,0
\end{tabular}

Tabela 14. Concentração final da solução nutritiva.

\begin{tabular}{ll} 
Nutriente & Ppm \\
\hline $\mathrm{Ca}$ & 30 \\
$\mathrm{~K}$ & 18 \\
$\mathrm{Mg}$ & 3,8 \\
$\mathrm{~N}-\mathrm{NO}_{3}^{-}$ & 31 \\
$\mathrm{~N}_{\mathrm{P}}^{+} \mathrm{NH}^{+}$ & 4 \\
$\mathrm{P}$ & 0,2 \\
$\mathrm{~B}$ & 0,05 \\
$\mathrm{Fe}$ & 0,5 \\
$\mathrm{Mn}$ & 0,1 \\
$\mathrm{Mo}$ & 0,02 \\
$\mathrm{Zn}$ & 0,03 \\
$\mathrm{Cu}$ & 0,01
\end{tabular}


Os resultados mostram que não houve diferença entre os tratamentos a 10,5 e $1 \%$ de significancia pelo teste não paramétrico qui-quadrado. Pelo teste paramétrico seguindo-se o esquema fatorial, também não houve diferença significativa a nivel de 1 e $5 \%$ de probabilidade para o fator isolado e concentração de Al.

Nas condiçôs do experimento não foi possivel verificar o efeito de concentraçăo de Al na capacidade de infecçăo micorrizica. Houve falha na micorrização e a concentração final do aluminio no substrato não correspondeu a concentração aplicada, mas muito mais elevada (Tabela 13). 0 substrato da concentração 0 , apresentou 58,5 ppm de aluminio, sem que o mesmo fosse acrescentado. a nivel de aluminio pode variar no mesmo substrato, pois quando preparado com outro lote de turfa e vermiculita do mesmo lote, apresentou 40,5 ppm de aluminio.

Segundo DIXON \& BUSCHENA (1981), as metais pesados podem ser fungitóxicos e podem influenciar na formação de ectomicorrizas; no entanto, altos niveis de Al no substrato, provavelmente nå foram os fatores responsáveis pela falha na micorrização das plantas, pois algumas delas apresentaram raizes $100 \%$ micorrizadas, independente da concentraça de aluminio.

Segundo MULLETTE (1976), as falhas ocorrem na infecção micorrizica em Eucalyptus devido à condução dos testes em condições inadequadas ao estabelecimento da infeção. 
Alguns fatores já haviam sido avaliados anteriormente, como: as condiçơes ambientais da casa de vegetação, dose do inóculo empregado, a especie de Eucalyptus, substrato e tipo de recipiente.

Alta fertilidade que restringe ou impede o desenvolvimento micorrizico (MOLINA \& TRAPPE, 1982) provavelmente não foi a causa da falha na infecção, visto que a solução nutritiva utilizada continha baixa concentração de $P$ $(0,2$ ppm) para evitar a precipitaçăo do aluminio.

Outros fatores não avaliados neste trabalino săo, portanto, fundamentais para a formaçăo de micorrizas e precisam ser estudados separadamente.

4.7. Coleta e isolamento de Pisolithus tinstorius

A busca de basidiocarpos de Pisolithus tinctorius é de grande importancia para introdução e seleçăo de novos isolados.

A presença de basidiocarpos parece depender da idade do talhăo, da quantidade de insolação e da interdependência entre ambos (YOKOMIZO \& KRÜGNER, 1983/ 85).

Os basidiocarpos foram coletados segundo o item 3.14. A idade e a especie de Eucalyptus não foram identificadas. As formas dos basidiocarpos eram 
variáveis; de um modo geral eram irregularmente globosas com a cor amarela predominante, apresentando manchas rajadas de preto (Figura 5-1). O isolamento de Pisolithus tinctorius a partir de basidiocarpos, em meio de cultura (item 3.14 ), começa a se caracterizar aos cinco dias com um tênue crescimento micelial a partir do tecido implantado. A cor do micélio em meio de cultura não e uniforme para todos os isolados obtidos. Alguns isolados do fungo apresentavam setores de contorno irregular, geralmente com um micélio mais denso e coloraçăo mais escura que o normal. As dez culturas obtidas foram repicadas várias vezes até se conseguir um crescimento homogeneo das colónias. Os isolados foram denominados de AT 501, AT 502, AT 503, AT 504, AT 505, AT 506, AT 507, AT 508, AT 509 e AT 510.

Há necessidade de estudos posteriores para avaliar-se a capacidade de micorrização dos isolados.

4.8. Avaliação da seleção de isolados de Pisolithus tinctorius para tres especies de Eucalyptus quanto à eficiéncia para formaçăo de micorrizas

Este estudo foi realizado com o intuito de selecionar a eficiencia de diferentes isolados de $P$. tinctorius coletados, para formação de micorriza em tres espécies de Eucalyptus. 
Os isolados obtidos segundo o item 3.14 foram selecionados para trés espécies de Eucalyptus seguindo-se a metodologia descrita no item 3.15. O isolado AT 506 foi eliminado do experimento porque houve contaminaçăo do inoculante. A Tabela 15 apresenta a porcentagem de plantas micorrizadas e a media do grau de micorrização em escalas de notas de O a 5 para Eucalyptus urophylla, E. torelliana e E. paniculata inoculadas com nove isolados coletados. Considerando-se um bom isolado aquele com capacidade de micorrizar mais de $80 \%$ das plantas e com um grau de micorrização acima de 3,0, foram selecionados para Eucalyptus urophylla e E. paniculata os isolados AT 501 e AT 502 e para E. torelliana os isolados AT 502 e AT 508.

Tabela 15. Avaliação do grau de micorrização de tres espécies de Eucalyptus, inoculadas com 9 isolados de Pisolithus tinctorius.

\begin{tabular}{|c|c|c|c|c|c|c|c|}
\hline & & \multicolumn{6}{|c|}{ Especies de Eucalyptus } \\
\hline & & \multicolumn{2}{|c|}{ E. urophylla } & \multicolumn{2}{|c|}{ E. torelliana } & \multicolumn{2}{|c|}{ E. paniculata } \\
\hline & & $\begin{array}{l}\% \text { de } \\
\text { plantas } \\
\text { micor. }\end{array}$ & $\begin{array}{l}\text { Grau } \\
\text { micor- } \\
\text { riz.* }\end{array}$ & $\begin{array}{l}\% \text { de } \\
\text { plantas } \\
\text { micor. }\end{array}$ & $\begin{array}{l}\text { Grau } \\
\text { micor- } \\
\text { riz.* }\end{array}$ & $\begin{array}{l}\% \text { de } \\
\text { plantas } \\
\text { micor. }\end{array}$ & $\begin{array}{l}\text { Grau } \\
\text { micor- } \\
\text { riz.* }\end{array}$ \\
\hline AT & 501 & 91,67 & 3,5 & 72,73 & 3,06 & 100 & 3,36 \\
\hline AT & 502 & 91,67 & 3,5 & 95,65 & 3,27 & 82,60 & 3,05 \\
\hline AT & 503 & 75,00 & 2,83 & $6 \theta, 18$ & 2,00 & 33,33 & 2,00 \\
\hline AT & 504 & 29,16 & 2,28 & 29,16 & 1,71 & 27,27 & 1,66 \\
\hline AT & 505 & 47,82 & 2,63 & 31,82 & 1,42 & 45,83 & 1,63 \\
\hline AT & 507 & 62,50 & 2,6 & 65,21 & 2,60 & 78,26 & 3,00 \\
\hline AT & 508 & 87,50 & 2,78 & 86,66 & 3,38 & 68,75 & 2,18 \\
\hline AT & 509 & 58,33 & 2,5 & 60,86 & 2,21 & 58,33 & 2,07 \\
\hline AT & 510 & 41,66 & 2,10 & 45,83 & 2,36 & 45,83 & 1,54 \\
\hline
\end{tabular}

* Media de 24 plantas 
Para os isolados AT 504, AT 505 a AT 510 houve grande falha na micorrização - mais de 50\% das plantas não apresentavam micorrizas.

E provável que o insucesso foi devido a inadequabilidade da metodologia empregada.

A formaçăo de micorriza pode ter sido afetada por inúmeros fatores não testados anteriormente, incluindo a qualidade do inóculo.

E preciso que o inoculo vegetativo de um fungo sobreviva às manipulaçôes, como: lavagem, secagem e sua incorporação no substrato. Além disso, o inóculo deve sobreviver de 4 a 6 semanas entre a inoculação e a produção de raizes curtas pelas plantas.

Torna-se necessário conduzir novas ensaios para testar a qualidade do inóculo e influencia de fatores externos que possam estar afetando a eficiencia dos isolados.

4. 9. Avaliação do grau de micorrização de mudas de Eucalyptus urophylla provenientes de semeio direto e plántulas, inoculadas com isolados de Pisolithus tinctorius

Com o intuito de solucionar o problema de falha na micorrização de mudas produzidas a partir de sementes, foram testadas a inoculaçăo de plântulas para produçăo de mudas micorrizadas, seguindo-se a metodologia des- 
crita no item 3.16. A Tabela 5 do Apendice apresenta a avaliação em escala de notas de 0 a 5 do grau de micorrização de mudas provenientes de sementes e de plantulas inoculadas com os isolados AT 502, AT 503, AT 505, AT 507, AT 509 e AT 510. Os valores e significancias dos quadrados médios da análise de variância, estão apresentados na Tabela 16. As Tabelas 17 e 18 mostram a comparação das medias pelo teste de Tukey a 5 e $1 \%$ de significancia de isolados e comparação das medias de isolados dentro de sementes e plantulas do fator "fases de inoculaçăo" respectivamente, enquanto que a comparação das medias pelo teste de Tukey a nivel de 5 e $1 \%$ de significancia de fases de inoculaçăo e comparação das médias de fases de inoculaçăo dentro de cada isolado estå apresentados nas Tabelas 19 e 20.

Tabela 16. Valores e significáncias dos quadrados medios da análise de variância dos dados do grau de micorrizaçăo de mudas de Eucalyptus provenientes de semeio direto e plântulas com isolados de $P$. tinctorius.

\begin{tabular}{lrrr}
\hline C.V. & GL & Q.M. & \multicolumn{1}{c}{$F$} \\
\hline Isolados & 6 & 3,8640 & $5,7689 * *$ \\
Fases de inoc. & 1 & 91,8304 & $137,0981 * *$ \\
Isol. x Fases inor. & 6 & 3,7330 & $5,5732 * *$ \\
Residuo & 210 & 0,6698 & \\
\hline Total & 223 & & \\
\hline
\end{tabular}

Média geral $=1,7661$

Coeficiente de Variação $=46,340 \%$ 
Tabela 17. Comparação das medias (grau de micorrização) de isolados de Pisolithus tinctarius pelo teste de Tukey.

\begin{tabular}{lccc}
\hline Isolados & Médias & $5 \%$ & $1 \%$ \\
\hline AT 502 & 2,4163 & $a$ & $A$ \\
AT 503 & 1,9723 & ab & AB \\
AT 505 & 1,7409 & bc & AB \\
AT 507 & 1,7145 & bc & AB \\
AT 509 & 1,6033 & bc & B \\
AT 510 & 1,5978 & bc & B \\
AT 504 & 1,3176 & $c$ & B \\
\hline Medias seguidas por letras distintas diferem entre & ai \\
nivel de significancia indicado. & DMS $1 \%=0,7077$ & \\
DMS $5 \%=0,6043$ &
\end{tabular}

Tabela 18. Comparação das médias (grau de micorrização) de isolados dentro de sementes e plantulas do fator fases de inoculação.

\begin{tabular}{lll}
\hline & \multicolumn{2}{c}{ Fases de inoculaçăo } \\
\cline { 2 - 4 } Isolados & Sementes & Plăntulas \\
\hline AT 502 & $2,3167 \mathrm{~A}$ & $2,5158 \mathrm{~A}$ \\
AT 503 & $1,4697 \mathrm{AB}$ & $2,4748 \mathrm{~A}$ \\
AT 504 & $0,1250 \mathrm{C}$ & $1,5102 \mathrm{~A}$ \\
AT 505 & $0,9424 \mathrm{BC}$ & $2,5394 \mathrm{~A}$ \\
AT 507 & $1,2817 \mathrm{~B}$ & $2,1472 \mathrm{~A}$ \\
AT 509 & $0,8738 \mathrm{BC}$ & $2,3329 \mathrm{~A}$ \\
AT 510 & $0,8713 \mathrm{BC}$ & $2,3243 \mathrm{~A}$ \\
\hline Médias seguidas da mesma letra não diferrem entre & \\
teste de Tukey a $1 \%$ de probabilidade. &
\end{tabular}


Tabela 19. Comparação das médias (grau de micorrização) de fases de inoculação pelo teste de Tukey.

\begin{tabular}{lccc}
\hline $\begin{array}{l}\text { Fases de } \\
\text { inoculação }\end{array}$ & Medias & $5 \%$ & $1 \%$ \\
\hline Plântulas & 2,4064 & a & A \\
Semente & 1,1258 & b & B \\
\hline
\end{tabular}

Médias seguidas por letras distintas diferem entre $5 i$ ao nivel de significância indicado.

DMS $5 \%=0,2144 \quad$ DMS $1 \%=0,2819$

Tabela 20. Comparação das médias (grau de micorrização) de sementes e plantulas do fator fases de inoculação dentro de cada isolado.

\begin{tabular}{lcc}
\hline & \multicolumn{2}{c}{ Fases de inoculação } \\
\cline { 2 - 3 } Isolados & Sementes & Plántulas \\
& $2,3167 \mathrm{~A}$ & $2,5158 \mathrm{~A}$ \\
AT 502 & $1,4697 \mathrm{~B}$ & $2,4748 \mathrm{~A}$ \\
AT 503 & $0,1250 \mathrm{~B}$ & $2,5102 \mathrm{~A}$ \\
AT 504 & $0,9424 \mathrm{~B}$ & $2,5394 \mathrm{~A}$ \\
AT 505 & $1,2817 \mathrm{~B}$ & $2,1472 \mathrm{~A}$ \\
AT 507 & $0,8738 \mathrm{~B}$ & $2,3229 \mathrm{~A}$ \\
AT 509 & $0,8713 \mathrm{~B}$ & $2,3243 \mathrm{~A}$ \\
AT 510 & & \\
\hline
\end{tabular}

Médias sequidas da mesma letra não diferem entre $s i$ pelo teste de Tukey a $1 \%$ de probabilidade.

$\operatorname{DMS}(1 \%)=0,7459$ 
Os resultados mostram que as plantas de $E$. urophylla provenientes de plântulas, praticamente não apresentaram falhas na micorrização, além de apresentarem um grau de micorrização maior do que as provenientes de semeio direto para todos os isolados testados (Tabela 5 do Apendice). Para alguns isolados essa diferença foi mais evidente, como e caso do isolado AT 504, pois somente duas das dezesseis plantas formaram micorrizas quando proveniente de semeio direto.

A análise de variância (Tabela 16) mostra que houveram diferenças significativas (a nivel de $1 \%$ e $5 \%$ de probabilidade) para o fator isolado e para as fases de inoculação quanto ao grau de micorrização.

Um aspecto que se destaca foi o alto coeficiente de variação $46,34 \%$ encontrado na análise estatística dos resultados. Esse problema resultou da grande variaça do grau de micorrizaçåo verificado entre as repetiçơes de um mesmo tratamento.

Pelo teste de Tukey para comparação de médias dos isolados podemos verificar que o isolado AT 502 apresentou a maior média quanto ao grau de micorrização, embora não diferisse de AT 503, AT 505 e AT 507, como mostra a Tabela 17 .

Quando a fase de inoculação é semente, verificamos pelo teste de Tukey, que há diferença estatisticamente significativa entre os isolados. A Tabela 19 mostra 
novamente que os isolados AT 502 e AT 503 foram os melhores com 2,31 e 1,46 de média de grau de micorrização respectivamente. Os isolados AT 503 e AT 507 diferem de AT 504 que foi o pior isolado, embora não diferisse de AT 510, AT 509 e AT 505 a $1 \%$ de significancia. Quando a fase de inoculação é plântula, todos os isolados apresentaram médias altas quanto ao grau de micorrizaça e não apresentaram diferenças estatisticamente significativas a nivel de $1 \%$ (Tabela 18).

A Tabela 19 mostra a comparaça das medias pelo teste de Tukey das duas fases de inoculação testadas: sementes e plántulas. Podemos verificar que há diferença estatisticamente significativa a nivel de 5 e $1 \%$ entre as duas fases. Notadamente a fase de plantulas foi a melhor, apresentando cerca do dobro da média de grau de micorrização $(2,40)$ em relação a sementes $(1,12)$.

Todos os isolados, com exceção ao AT 502, apresentaram diferenças significativas ao nivel de 5 e $1 \%$ para as fases de inoculação (Tabela 20). A fase de plântulas do fator "fases de inoculação" para todos os isolados * a que apresentou maior media quanto ao grau de micorrização. Somente para o isolado AT 502 o teste de Tukey para comparação de médias não apresentou diferença significativa ao nivel de 5 e $1 \%$ entre as duas fases testadas (Tabela 20).

Podemos verificar que com a utilização de 
plántulas obtemos um resultado melfor, praticamente eliminando o problema de falha na micorrização de mudas.

Segundo LAPEYRIE \& BRUCHET (1985) o primeiro requerimento para a inoculação artificial e um inóculo bem crescido de uma forma que possa ser usado para dispersar o fungo ativo inteiramente no novo meio e realizar contato com - sistema radicular da planta. No inoculante preparado segundo o item 3.16.1, as hifas cobriam as particuclas de vermiculita; no entanto, nos tubetes as hifas externas expostas ao substrato, talvez não tenham sobrevivido o periodo entre a inoculaçãa e a desenvolvimento de raizes curtas. Durante este periodo as particulas de vermiculita provem um nicho protetor para o micelio desprotegido (MOLINA \& TRAPPE, 1982). Segundo MARX et alii (1982), as hifas internas as particulas de vermiculita protegidas é que são responsáveis pela efetividade do inóculo.

Isto pode explicar o maior grau de micorrização quando utilizamos plăntulas para produção de mudas. As hifas externas colonizaram as ralzes curtas já pré-formadas das plântulas.

Para a utilização de sementes, as particulas de vermiculitas devem estar internamente tomadas pelas hifas que ficam protegidas até a formação de raízes curtas. No inoculante utilizado, talvez poucas particulas de vermicuIita estivessem internamente tomadas pelas hifas; por essa 
razão ocorreram falhas na micorrizaça das plantas provenientes de sementes.

O isolado AT 502 mostrou-se mais resistente, pois năo houveram diferenças na micorrizaçăo de plantas provenientes de sementes e plántulas, confirmando os resultados anteriormente obtidos com trss especies de Eucalyptus, onde obtivemos altas percentagens de plantas micorrizadas com este isolado (Tabela 15).

A desvantagem do uso de plântulas para obtençă de plantas micorrizadas é que estas exigem um maior cuidado durante os primeiros sete dias após a transplante. Durante este periodo as plantulas săo muito sensiveis e exigem cuidados especiais, como um rigoroso controle de umidade e temperatura. Para fins praticos isto não seria viável. Segundo MoRo et alii (1988) a produção de mudas de Eucalyptus vém sofrendo grandes avanços técnicos nos últimos anos, visando automatização de todas as etapas, inclusive do semeio; sendo assim, sugere-se para futuros trabalhos, a utilização de particulas de vermiculitas maiores para que as hifas cresçam internamente às particulas ou o desenvolvimento de outras técnicas para produção de inoculante em que as hifas fiquem protegidas.

4. 10. Avaliação da produção de inoculante de un isolado de Pisolithus tinctorius em diferentes substratos

Após os isolados serem testados em diferentes 
meios de cultura quanto ao crescimento e produção de biomassa (segundo os 1 tens 3.8 e 3.9 respectivamente), foi selecionado o isolado PI 314 que apresentou um desenvolvimento normal das colónias em todos os meios e não apresentou diferença estatisticamente significativa entre os meios, quanto à produção de massa micelial (Tabela 22). Este isolado foi testado quanto à produção de inoculante em substratos preparados com os diferentes meios anteriormente testados, segundo o item 3.17. Os resultados do crescimento do fungo nestes substratos estão apresentados na Tabela 21.

Tabela 21. Crescimento do isolado PI 314 em diferentes substratos.

PI 314

Substratos

RI RII RIII RIV RV RVI

\begin{tabular}{lllllll}
\hline Subst. MMN & +++ & +++ & +++ & +++ & +++ & +++ \\
Subst. BDA & +++ & +++ & +++ & +++ & +++ & +++ \\
Subst. BDA-D & +++ & +++ & +++ & +++ & +++ & +++ \\
Subst. BDMT & +++ & +++ & +++ & +++ & +++ & +++ \\
Subst. MMNB & +++ & +++ & +++ & +++ & +++ & +++ \\
\hline
\end{tabular}

Legenda: +++ abundante; ++ regular; + escassa; - ausencia

0 isolado PI 314 cresceu bem em todos os substratos, podendo o inoculante deste isolado ser produzido em qualquer um destes substratos testados. 
Propöe-se que seja realizado outro ensaio para testar a efetividade destes inoculantes visto que os meios utilizados talvez afetem a qualidade do inoculo. 


\section{CONCLUSð̄ES}

Os resultados obtidos no presente trabaliho permitiram concluir que:

a) Nentum meio testado se apresentou melhor que o meio MNM para o cultivo do fungo, mas para os isolados AC12, PI314 e PI203 o crescimento nos meios MNMB, BDA, BDA-D e BDMT foi igual ao obtido no meio MNM.

b) Os isolados PI 203 e PI 314 não apresentaram diferenças entre os meios testados para a produçắ de biomassa.

c) Cada célula micelial possui dois núcleos com um tamanto médio de $2,439 \mu$.

d) Os eventos da divisão mitótica em cêlulas miceliais se mostraram similares a de alguns fungos filamentosos em que ocorrem agregação dos cromossomos formando barras paralelas. Q número de cromossomos nåo pode ser determinado.

e) Os isolados Pt 185, FEP 2, FEP 3, Pt taeda, FEP 5, obtidos de Pinus apresentaram a mesmo perfil eletroforetico para esterases. 
f) A melhor produção de protoplastos do isolado FEP3 de Pisolithus tinctorius e obtida utilizando-se micelio de quatro dias de idade, com a enzima litica Novozyme 234 e manitol 0,6 M como estabilizador osmótico.

9) Das isolados coletados, a AT 501 e AT 502 são os melhores para a sintese de micorriza em Eucalyptus urophylla e E. paniculata. Já para E. torelliana os melhores isolados foram AT 502 e AT 508 .

h) o problema de falna na micorrização de plantas provenientes de sementes pode ser solucionado se utilizarmos plántulas no lugar de sementes. 


\section{REFERÊNCIAS BIBLIOGRÁFICAS}

AIST, J.R. \& C.L. WILSON. A study of asemual nuflear division in Ceratocystis fagacearum with phase-contrast microscopy. Phytopathology. Lancaster, 50: 869, 1966.

AIST, J.R. \& C.L. WILSON. Chromosome behavior during vegetative nuclear division in Fusarium oxysporum. Phytopathology. Lancaster, 57: 801, 1967a.

AIST, J.,R. \& C.L. WILSON. Nuclear behavior in the vegetative hyphae of Ceratocystis fagacearum. American Journal Botany, New York, 54(1): 99-104, 1967b.

BARROS, N.F.; R.M. BRANDI; M.S. REIS. Micorriza em eucalipto. Revista Arvore, Viçosa, $2(2): 130-40,1978$.

BACHMANN, B.J. \& D.M. BONNER. Protoplasts from Neurospora crassa. Journal of Bacteriology. Baltimore, 78: 5506, 1959 .

BAKERSPIGEL, A. The structure and mode of division of the nuclei in the vegetative spores and hyphae of Endogone sphagnophila ATK. American Journal of Botany. New York, 45: 404-10, 1958 . 
BAKERSPIGEL, A. The structure and manner of division of the nuclei in the vegetative mycelium of the basidiomycete Schizophyllum commune. Canadian Journal of Botany, Ottawa, 37: 835-47, 1959.

BARRET, V.; P.A. LEMKE; R.K. DIXON. Protoplast formation from selected species of ectomycorrhizal fungi. Applied Microbiology and Biotechnology, Berlin, 30: 381-87, 1989.

BORGES, M.I. Técnicas de protoplastização e isolamento de DNA de alto peso molecular de Aspergillus niger. Campinas, 1987. 112p. (Mestrado - Universidade Estadual de Campinas).

BRADLEY, R.; A.J. BURT; D.J. READ. Mycorrhizal infection and resistance to heavy metal toxicity in Calluna vulgari5. Nature, London, 292: 335-7, 1981.

BRADLEY, R.; A.J. BURT; D.J. READ. The biology of mycorrhiza in the ericaceae. VIII. The role of mycorrhizal infection in heavy metal resistance. New Phytopathologist, London, 91 : 197-209, 1982.

BRUSHABER, J.A. \& S.F. JENKINS JUNIOR. Mitosis and clamp formation in the fungus poris monticola. American Journal of Botany, New York, 58(1): 273-80, 1971.

BURNETT, J.H. Fundamentals of Mycology. London, Edward Arnold Publishers Limited, 1976. 673p.

DAVIS, B. Factors influencing protoplast isolation. In: Fungal Protoplasts. J.F. PEBERDY e L. FERENCZY (Eds.). New York, 1985. p.45-71. 
DIXON, R.K. \& C.A. BUSCHENA. Response of ectomycorrhizal Pinus banksiana e Picea glauca to heavy metals in soil. Plant and Soil, Hague, 105: 265-71, 1981.

EMERSON, S. \& M.R. EMERSON. Production, reproduction and reversion of protoplasts-like structures in the osmotic strain of Neurospora crassa. Proceedings of National Academy of Science, Washington, 44: 663-71, 1958.

FINCHAM, J.R.S.; P.R. DAY; A. RADFORD. Fungal genetics. Blackwell Scientific Publication, oxford, 1979. 636P.

FULLER, M.S. Mitosis in fungi. International Review of Cytology. New York, 45: 113-53, 1976.

FURLANETO, M.C. Recombinação genetica e produção de celulases em Trichoderma pseudokoningii var. rifai. Piracicaba, 1989. 152p. (Mestrado - Escola Superior de Agricultura "Luiz de Queiraz"/USP).

FURLANI, P.R. \& L.G. HANNA. Avaliação da tolerancia de plantas de arroz e milho ao aluminio em soluçăo nutritiva. Revista Brasileira de Ciéncia do Solo. Campinas, $8(2): 205-8,1984$.

GILDON, A. \& P.B. TINKER. Interactions of vesicular-arbuscular mycorrhizal infection and heavy metals in plants. I. The effects of heavy metals on the development of vesicular-arbuscular mycorrtizas. New Phytologist, London, 95: $247-61,1983$.

GILES, K.L. \& H. WHITEHEAD. Uptake and continued activity of Azatabacter within fungal protoplasts. Science, Washington, 193: 1125-6, 1976 . 
GOLD, M.H.; T.M. CHENG; M. ALIC. Formation, fusion, and regeneration of protoplasts from wild-type and auxotrophic strains of the white rot basidiomycete Phanerochaete chrysosporium. Applied Environmental Microbiology, Baltimore, 46: 260-3, 1983.

HACSKAYLO, E. Pure culture syntesis of pine mycorrhizae in terra-1ite. Mycologia, Lancaster, 45: 971-5, 1953.

HACSKAYLO, E. Mycorrhizae. Superintendent of Documents, U.S. Government Printing Office, 1971. 255p.

HAMLYN, P.F.; R.E. BRADSHAW; F.M. MELLON; C.M. SANTIAGO; J.M. WILSON; J.F. PEBERDY. Efficient protoplast isolation from fungi using comercial enzymes. Enzyme and Microbial Tecnology, Guildford, 3: 321-5, 1981.

HEATH, I.B. Fungal mitosis, the significance of variations on a theme. Mycologia. New York, 72: 229-250, 1980a.

HEATH, I.B. Variant mitosis in lower eukaryotes: indicators of the evolution of mitosis? International Review Cytology. New York, 64: 1-80, 1980b.

HEBRAUD, M. \& M. FEVRE. Protoplast production and regenetion from mycorrhizal fungi and their use for isolation of mutants. Canadian Journal Microbiology, ottawa, 34: $157-61,1988$.

HOGBERG, P. Mycorrhizal association in some woodland and forest trees and shrubs in Tanzania. New Phytologist, London, 92: 407-15, 1982. 
HUNG, L.L. \& R. MOLINA. Temperature and time in storage influence the efficacy of selected isolates of fungi in commercially produced ectomycorrhizal inoculum. Forest Science, Washington, 32(2): 534-45, 1979.

ICHIDA, A.A. \& M.S. FULLER. Ultrastucture of mitosis in the aquatic fungus Catenaria anguillulae. Mycologia. New York, 60: 141-55, 1968 .

JACKSON, R.M. \& P.A. MASON. Mycorrhiza. London, Edward Arnold, 1984. 59p.

KIGUCHI, T. \& S.Q. YANAGI. Intraspecific heterokoryon and fruit body formation in Coprinus macrorhizus by protoplast fusion of auxotrophic mutants. Applied Microbiol. Biotechnology, Berlin, 22: 121-27, 1985.

KILLHAN, K. \& M.K. FIRESTONE. Vesicular arbuscular mycorrhizal mediation of grass response to acidic and heavy metal depositions. Plant and Soil, Hague,. 72: 39-48, 1983.

KNOX-DAVIES, P.S. Mitosis and aneuploidy in the vegetative hyphae of Macrophomina phaseoli. American Journal of Botany. New York, 54(10): 1290, 1967.

KROPP, B.R. \& J.A. FORTIN. Formation and regeneration of protoplasts from the ectomycorrhizal basidiomycete Laccaria bicolor. Canadian Journal Botany, Ottawa, 64: $1224-6,1986$.

KRÜGNER, T.L. \& M. TOMAZELLO FILHO. Tecnologia de inoculação micorrizica em viveiro de Pinus sp. Circular Técnica, 6. Piracicaba, IPEF, 1979. 6P. 
LAPEYRIE, F.F. \& G. BRUCHET. Some factors influencing viability of ectomycorrhizal fungal inoculum. New Phytologist, London, 100: 585-93, 1985.

MAGAE, Y.; Y. KASHIWAGI; M. SENDA; T. SASAKI. Eletrofusion of giant protoplasts of Pleurotus cornucopiae. Applied Microbiology and Biotechnology, Berlin, 24: 509-11, 1986.

MARTIN JUNIOR, R.W. \& C.W. MILLER. Ultrastructure of mitosis in the endoparasite olpidiopsis varians. Mycologia. New York, $78(1): 11-21,1986$.

MARX, D.H. The influence of ectotrophic mycorrhizal fungi on the resistance of pine roots to pathogenic infection. 1. Antagonism of mycorrhizal fungi to root pathogenic fungi and soil bacteria. Phytopathology, Saint Paul, 59 $153-63,1969$.

MARX, D.H. Three host rang and wored distribution of the

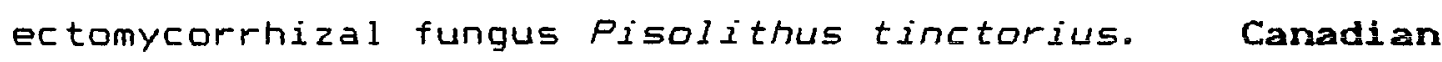
Journal of Microbiology, Ottawa, 23: 217-23, 1977.

MARX, D.H. \& W.C. BRYAN. Pure culture synthesis of ectomycorrhizae by Thelephora terrestris and pisolithus tinctorius on different conifer hosts. Canadian Journal of Botany, ottawa, 48: 639-43, 1969.

MARX, D.H.; J.L. RUEHLE; D.S. KENNEY; C.E. CORDELL; J.W. RIFFLE; R.J. MOLINA; W.H. PAWUK; S. NAVRATIL; R.W. TINUS; D.C. GOODWIN. Comercial vegetative inoculum of pisolithus tinctorius and inoculation techniques for develoment of ectomycorrhizae on container-grown tree seedlings. Forest Science, Washington, 28: 373-400, 1982. 
MEQUATTIER, C.J. \& SCHIER, G.A. Response of red spruce seedlings to aluminum toxicity in nutrient solution: alterations in root anatomy. Canadian Journal of Forest Research, Ottawa, 20(7): 1001-11, 1990.

MELO, I.S.; A.P.D. SILVEIRA; A.M. MALUF. Efeito do aluminio e de Glamus leptotichum Schenk e Smith no desenvolvimento de cultivares de Leucaena leucocephala (Lam.) de Wit tolerante e intolerantes ao aluminio. Anais da ESALQ, Piracicaba, XLIV: 1365-80, 1987.

MIKOLA, P. Application of mycorrhizal symbiosis in forestry practice. In: MARX, G.C. \& KOZLOWSKY, T.T. Ectomycorrhizae: their ecology and physiology. New York. Academic Press, 1973. p.383-411.

MOLINA, R. \& J.G. PALMER. Isolation, maintenance and pure culture manipulation of ectomycorrhizal fungi. In: SCHENK, N.C. Methods and Principles of Mycorrhizae Research. The American Phytopathological Society, Minnesota, 1982. p.115-29.

MOLINA, R. \& J.M. TRAPPE. Applied aspects of ectomocorrhizae. In: RAO, N.N.S., ed. Advances in Agricultural Microbiology. London, Butterworth Scientific, 1982. p. $305-26$.

MORINAGA, T.; M. KIKUCHI; R. NOMI. Formation and regeneration of protoplasts in Coprinus pellucidus and Coprinus cinereus. Agricultural Biological Chemistry, Tokyo, 49(2): 523-4, 1985. 
MORO, L.; C. BRESSAM; R.A. CANEVA; G. COLLI JUNIOR; P.A. NEGRI. Viveiro continuo de Eucalyptus da Champion Papel e Celulose Ltda. Circular Técnica no 160. Piracicaba, 1988. 5p.

MUKHERJEE, M. \& S. SENGUPTA. Mutagenesis of protoplasts and regeneration of mycelium in the mushroom Volvariella valvacea. Applied Environmental Microbiology, Baltimore, 52: $1412-14,1986$.

MULLETTE, K.J. Studies of eucalypt micorrhizas. I. A method of mycorrhizae induction in Eucalyptus gummifera (Gaertn \& Hochr.) by Pisolithus tinctorius (Pers.) Coker \& Couch. Australian Journal of Botany. Melbourne, 24: 193-200, 1976.

NAMBOODIRI, A.N. \& R.J. LOWRY. Vegetative nuclear division in Neuraspora. American Journal of Botany. New York, 54 (6): $735-48,1967$.

NEVES, J.C.L.; N.F. BARROS; R.F. NOVAIS; J.L. ANJOS. EfEito do aluminio em amostras de dois latossolos sob cerrado sobre o crescimento e a absorção de nutrientes de mudas de Eucalyptus spp. Revista Arvore, Viçosa, 6(1): 17-28, 1982 .

PACCOLA-MEIRELLES, L.D.; VALARINI, M.J.; AZEVEDO, J.L.; ALFENAS, A.C. Manual de técnicas eletroforéticas em microrganismos. Piracicaba, FEALQ, 1988. 54p.

PEBERDY, J.F. Fungal protoplasts: isolation, reversion and fusion. Annual Review of Microbiology. Palo ALto, 33: $21-39,1979$. 
PEBERDY, J.F. \& L. FERENCZY. Fungal protoplasts; applications in biochemistry and genetics. New York. Marcel Dekker, 1985. v.6, 353p.

PIMENTEL GOMES, F. Estatistica Experimental. 11a.ed. Să Paulo, Nobel, 1985. 466P.

QUEIRQZ, M.V. o efeito da protoplastização na instabilidade mitótica de Aspergillus nidulans. Piracicaba, 1988. 1360. (Mestrado - Escola Superior de Agricultura "Luiz de Queiroz"/USP).

RIFFLE, J.W. \& D.M. MARONEK. Ectomycorrhizal inoculations procedures for greenhouse and nursery studies. In: SCHENCK, N.C. Methods and Principles of Mycorrhizae Research. The American Phytopathological Society, Minnesota, $0.115-29,1982$.

ROBINOW, C.F. \& A. BAKERSPIGEL. Somatic nuclei and forms of mitosis in fungi. In: AINSWORTH, G.C. \& A.S. SUSSMAN, Eds. The Fungi: an advanced treatise. New York, Academic Press, 1965. p.119-42.

ROBINOW, C.F. \& C.E. CATEN. Mitosis in Aspergillus nidulans. Journal Cell Science, London, 5: 403-31, 1969.

RODRIGUES, E.C. Caracterizaçăo citogenética e bioquímica do fungo celulalitico Humicola sp. Piracicaba, 1987. 152p. (Mestrado - Escola Superior de Agricultura "Luiz de Queiroz" (USP).

RUEHLE, J.L. \& WELLS, C.G. Development of Pisolihus tinctorius ectomycorrhizae on container-grown pine seedlings as affected by fertility. Forest science, wastington, 30(4): 1010-16, 1984 . 
SAKSENA, H.K. Nuclear structure and division in the mycelium and basidiospores of Ceratobasidium praticalum. Canadian Journal of Botany, Ottawa, 39: 749-55, 1961.

SASEK, $V$. \& $V$. MUSILEK. Growth promotion of slowly growing mycorrhizal basidiomycetes in submerged culture. In: HACSKAYLO, E. Mycorrhizae. Washington, Superintendent of Document N.S. Government Printing Office, 1971. 255p.

SHENCK, N.C. Methods and principles of mycorrhizal research. The American Phytopathological Society, Minnesota, 1982. 244p.

SOMERS, C.E.; R.P. WAGNER; T.C. HSU. Mitosis in vegetative nuclei of Neurospora crassa. Genetics, Princetan, 45: $801-10,1960$.

TANAKA, Y. Karyological studies on variation of the rice blast fungus, Pyricularia oryzae Cav. Tokyo, 1976. $218 p$. (Ph.D - Univ. Nihon).

TANAKA, Y.; N. MURATA; H. KATO. BEhavior of nuclei and chromosomes during ascus development in the matting between either rice-strain or weeping lovegrass-strain and ragi-strain of Pyricularia. Annual Phytopathology Society Japan, Tokyo, 45: 182-91, 1979.

TOYOMASU, T.; T. MATSUMOTO; K. MORI. Interespecific protoplast fusion between Pleurotes ostriatus and Pleurotus salmoneo-straminus. Agricultural Biological Chemistry, Tokyo, $50(1)$ : 223-5, 1986.

TRAPPE, J.M. Fungus associates of ectotrophic mycorrhizae. Botanical Review, Lancaster, 28: 538-606, 1962. 
TRAPPE, J.M. Selection of fungi ectomycorrhizal inoculation in nurseries. Annual Review Phytopathology, Palo Alto, 15: $203-22,1977$.

TRAPPE, J.M. \& MOLINA, R. Taxonomy and genetics of mycorrhizal fungi: their interactions and relevance. In: EUROPEAN SYMPOSIUM ON MYCORRHIZAE, 1., DijOn, 1985. Physiological and genetical aspects of mycorrhizal; proceedings. Paris, Institut National de la Recherche Agronomic, 1986 . P.133-45.

TURIAN, G. \& E.C. CANTINO. A study of mitosis in the mold Blastocladiella with a ribonuclease acetoorcein staining technique. Cytologia, Tokyo, 25: 101-7, 1960.

VALADARES, M.C.C. Genética e produção de exoenzimas em linhagens de Metarhizium anisopliae var. anisopliae (Metsch.) Sorokin. Piracicaba, 1989. 160p. (Mestrado Escala Superior de Agricultura "Luiz de Queiraz"/USP).

VIEIRA, R.F. Efeito de fatores edáficos associados ao cerrado no crescimento de Pisolithus tinctorius (Pers.) Coker e Couch em meio de cultura e na infecça micorrizica de Eucalyptus grandis W. Hill ex. Maiden em condiçôes controladas. Viçosa, 1984. 84p. (Mestrado - Universidade Federal de Viçasa).

URIES, O.M.H. \& J.G.H. WESSELS. Release of protoplasts from Schizophyllum commune by a lytic enzyme preparation from Trichoderma viride. Journal of General Microbiology, Great Britain, 73: 13-22, 1972a. 
VRIES, O.M.H. \& J.G.H. WESSELS. Release of protoplasts from Schizophyllum commune by combined action of purified a1,3-glucanase and chitinase derived from Trichoderma viride. Journal of General Microbiology, Great Britain, 76: $319-30,1972 \mathrm{~b}$.

WAKABAYASHI, S.; Y. MAGAE; Y. KASHIWAGI; T. SASAKI. FOrmation of giant protoplasts from protoplasts of pleurotus cornucopiae by the cell wall lytic enzyme. Applied Microbiology and Biotechnology, Berlin, 21 : 32830,1985 .

WARD, E.W.B. \& K.W. CIURYSEK. Somatic mitosis in a basidiomycete. Canadian Journal of Botany, Ottawa, 39: 1497$1503,1961$.

YANAGI, S.O.; M. MONMA; T. KAWASUMI; A. HINO; M. KITO; I. TAKEBE. Conditions for isolation of and colony formation by mycelial protoplasts of Coprinus macrorhizus. Agricultural Biological Chemistry, Tokyo, 49(1): 171-9, 1985.

YANAGI, S.0. \& I. TAKEBE. An efficient method for the isolation of mycelial protoplasts from Coprinus macrorhizus and other basidiomycetes. Applied Microbiology Biotechnology, Berlin, 19: 58-60, 1984.

YOKOMIZO, N.K.S. \& T.L. KRÜGNER. Pisolithus tinctorius Coker et Couch e ectomicorrizas em especies de Eucalyptus L'Heritier. Silvicultura em São Paulo, 17/19: 1-8, 1983/ 85 .

ZAK, B. \& D.H. MARX. Isolation of mycorrhizal fungi from roots of individual slash pines. Forest Science, Washington, 2 : 214-22, 1964 . 
ZAMBOLIM, L. \& J.Q. SIQUEIRA. Associações micorrizicas das plantas superiores. Informe Agropecuário. Belo Horizonte, $11(122)$ : 77-81, 1985 .

ZAMBOLIM, L. \& SIQUEIRA, I.O. Importância e potencial das associaçớes micorrizicas para a agricultura. Belo Horizonte. EPAMIG, 1985. 36p. (EPAMIG. Serie Documentos, 26). 
APÊNDICE 
Tabela 1. Medidas ( $c m$ ) de diámetros das colónias em placas contendo diferentes meios de cultura, dos isolados $A C 1, A C 3, A C 6, A C 8, A C 12$, PI203, PI312, PI314, PI316, ITAG, ITA11, Pt 185 e Pt taeda.

\begin{tabular}{|c|c|c|c|c|c|c|}
\hline & & & R I & RII & RIII & RIV \\
\hline & MNM & $\begin{array}{l}\text { D1 } \\
\text { D2 } \\
\text { D3 } \\
\text { D4 } \\
\text { D5 } \\
\text { D6 }\end{array}$ & $\begin{array}{l}2,45 \\
4,00 \\
5,45 \\
6,75 \\
7,50 \\
8,25\end{array}$ & $\begin{array}{l}1,95 \\
3,90 \\
5,20 \\
6,45 \\
7,20 \\
7,80\end{array}$ & $\begin{array}{l}2,50 \\
3,90 \\
5,10 \\
6,45 \\
7,15 \\
7,90\end{array}$ & $\begin{array}{l}2,15 \\
3,65 \\
5,05 \\
6,30 \\
7,00 \\
7,70\end{array}$ \\
\hline & MNMB & $\begin{array}{l}\text { D1 } \\
\text { D2 } \\
\text { D3 } \\
\text { D4 } \\
\text { D5 } \\
\text { D6 }\end{array}$ & $\begin{array}{l}2,10 \\
3,35 \\
4,35 \\
5,45 \\
6,35 \\
6,85\end{array}$ & $\begin{array}{l}2,10 \\
3,40 \\
4,00 \\
4,65 \\
5,20 \\
5,60\end{array}$ & $\begin{array}{l}2,15 \\
3,40 \\
4,10 \\
4,65 \\
5,10 \\
5,60\end{array}$ & $\begin{array}{l}1,60 \\
2,90 \\
3,85 \\
4,85 \\
5,35 \\
5,85\end{array}$ \\
\hline$A C 1$ & $B D A$ & $\begin{array}{l}\text { D1 } \\
\text { D2 } \\
\text { D3 } \\
\text { D4 } \\
\text { D5 } \\
\text { D6 }\end{array}$ & $\begin{array}{l}2,05 \\
3,10 \\
3,50 \\
4,35 \\
4,85 \\
5,35\end{array}$ & $\begin{array}{l}2,15 \\
3,25 \\
3,80 \\
4,65 \\
5,20 \\
5,65\end{array}$ & $\begin{array}{l}2,05 \\
3,10 \\
3,70 \\
4,55 \\
5,15 \\
5,60\end{array}$ & $\begin{array}{l}2,10 \\
3,15 \\
3,75 \\
4,60 \\
5,10 \\
5,60\end{array}$ \\
\hline & $B D A-D$ & $\begin{array}{l}\text { D1 } \\
\text { D2 } \\
\text { D3 } \\
\text { D4 } \\
\text { D5 } \\
\text { D6 }\end{array}$ & $\begin{array}{l}2,65 \\
3,60 \\
4,30 \\
5,00 \\
5,60 \\
6,10\end{array}$ & $\begin{array}{l}2,40 \\
3,25 \\
3,95 \\
4,60 \\
5,20 \\
5,70\end{array}$ & $\begin{array}{l}2,35 \\
3,25 \\
3,90 \\
4,75 \\
5,25 \\
5,75\end{array}$ & $\begin{array}{l}2,85 \\
3,75 \\
4,40 \\
5,20 \\
5,70 \\
6,15\end{array}$ \\
\hline & BDMT & $\begin{array}{l}\text { D1 } \\
\text { D2 } \\
\text { D3 } \\
\text { D4 } \\
\text { D5 } \\
\text { D6 }\end{array}$ & $\begin{array}{l}2,30 \\
3,60 \\
4,20 \\
5,00 \\
5,50 \\
6,00\end{array}$ & $\begin{array}{l}1,80 \\
2,90 \\
3,75 \\
4,80 \\
5,50 \\
6,10\end{array}$ & $\begin{array}{l}1,95 \\
3,05 \\
4,05 \\
5,10 \\
5,80 \\
6,40\end{array}$ & $\begin{array}{l}2,20 \\
3,35 \\
4,25 \\
5,20 \\
6,00 \\
6,50\end{array}$ \\
\hline
\end{tabular}


Tabela 1. Continução.

\begin{tabular}{|c|c|c|c|c|c|c|}
\hline & & & RI & RI I & RI I I & RIV \\
\hline & MNM & $\begin{array}{l}\text { D1 } \\
\text { D2 } \\
\text { D3 } \\
\text { D4 } \\
\text { D5 } \\
\text { D6 }\end{array}$ & $\begin{array}{l}3,30 \\
4,30 \\
5,30 \\
5,90 \\
6,30 \\
6,50\end{array}$ & $\begin{array}{l}3,10 \\
4,20 \\
5,25 \\
6,20 \\
6,65 \\
6,90\end{array}$ & $\begin{array}{l}2,90 \\
3,90 \\
5,00 \\
5,95 \\
6,30 \\
6,55\end{array}$ & $\begin{array}{l}2,75 \\
4,00 \\
5,20 \\
5,90 \\
6,25 \\
6,50\end{array}$ \\
\hline & MNMB & $\begin{array}{l}\text { D1 } \\
\text { D2 } \\
\text { D3 } \\
\text { D4 } \\
\text { D5 } \\
\text { D6 }\end{array}$ & $\begin{array}{l}2,80 \\
3,40 \\
4,10 \\
4,75 \\
5,30 \\
5,50\end{array}$ & $\begin{array}{l}2,40 \\
2,90 \\
3,50 \\
4,20 \\
4,65 \\
5,00\end{array}$ & $\begin{array}{l}2,35 \\
3,00 \\
3,60 \\
4,15 \\
4,75 \\
5,05\end{array}$ & $\begin{array}{l}2,70 \\
3,45 \\
4,05 \\
4,70 \\
5,20 \\
5,55\end{array}$ \\
\hline$A C 3$ & $B D A$ & $\begin{array}{l}\text { D1 } \\
\text { D2 } \\
\text { D3 } \\
\text { D4 } \\
\text { D5 } \\
\text { D6 }\end{array}$ & $\begin{array}{l}2,90 \\
3,70 \\
4,50 \\
5,20 \\
5,80 \\
6,10\end{array}$ & $\begin{array}{l}2,80 \\
3,60 \\
4,40 \\
5,10 \\
5,55 \\
6,00\end{array}$ & $\begin{array}{l}2,85 \\
3,70 \\
4,70 \\
6,00 \\
6,75 \\
7,35\end{array}$ & $\begin{array}{l}2,70 \\
3,50 \\
4,30 \\
5,00 \\
5,50 \\
5,95\end{array}$ \\
\hline & $B D A-D$ & $\begin{array}{l}\text { D1 } \\
\text { D2 } \\
\text { D3 } \\
\text { D4 } \\
\text { D5 } \\
\text { D6 }\end{array}$ & $\begin{array}{l}2,85 \\
3,60 \\
4,35 \\
5,10 \\
5,60 \\
5,90\end{array}$ & $\begin{array}{l}2,75 \\
3,60 \\
4,35 \\
5,10 \\
5,60 \\
6,00\end{array}$ & $\begin{array}{l}2,85 \\
3,60 \\
4,45 \\
5,25 \\
5,75 \\
6,15\end{array}$ & $\begin{array}{l}2,80 \\
3,60 \\
4,20 \\
4,95 \\
5,45 \\
5,80\end{array}$ \\
\hline & BDMT & $\begin{array}{l}\text { D1 } \\
\text { D2 } \\
\text { D3 } \\
\text { D4 } \\
\text { D5 } \\
\text { D6 }\end{array}$ & $\begin{array}{l}2,60 \\
3,30 \\
4,00 \\
4,65 \\
5,15 \\
5,50\end{array}$ & $\begin{array}{l}2,50 \\
3,25 \\
4,05 \\
4,70 \\
5,20 \\
5,50\end{array}$ & $\begin{array}{l}2,25 \\
2,95 \\
3,60 \\
4,25 \\
4,65 \\
4,95\end{array}$ & $\begin{array}{l}2,10 \\
2,75 \\
3,40 \\
4,10 \\
4,50 \\
4,85\end{array}$ \\
\hline
\end{tabular}


Tabela 1. Continuação.

\begin{tabular}{|c|c|c|c|c|c|c|}
\hline & & & RI & R I I & RII & RIV \\
\hline & MNM & $\begin{array}{l}\text { D1 } \\
\text { D2 } \\
\text { D3 } \\
\text { D4 } \\
\text { D5 } \\
\text { D6 }\end{array}$ & $\begin{array}{l}3,05 \\
3,95 \\
4,65 \\
5,95 \\
6,80 \\
7,50\end{array}$ & $\begin{array}{l}3,10 \\
4,00 \\
4,70 \\
6,05 \\
7,00 \\
7,55\end{array}$ & $\begin{array}{l}3,10 \\
4,00 \\
4,70 \\
6,00 \\
7,10 \\
7,70\end{array}$ & $\begin{array}{l}3,30 \\
4,20 \\
4,90 \\
6,15 \\
7,10 \\
7,70\end{array}$ \\
\hline & MNMB & $\begin{array}{l}\text { D1 } \\
\text { D2 } \\
\text { D3 } \\
\text { D4 } \\
\text { D5 } \\
\text { D6 }\end{array}$ & $\begin{array}{l}3,05 \\
3,85 \\
4,30 \\
5,20 \\
6,00 \\
6,65\end{array}$ & $\begin{array}{l}3,25 \\
4,00 \\
4,50 \\
5,35 \\
6,05 \\
6,70\end{array}$ & $\begin{array}{l}3,25 \\
4,05 \\
4,60 \\
5,50 \\
6,35 \\
7,00\end{array}$ & $\begin{array}{l}3,00 \\
3,80 \\
4,25 \\
5,10 \\
5,85 \\
6,50\end{array}$ \\
\hline ACS & $B D A$ & $\begin{array}{l}\text { D1 } \\
\text { D2 } \\
\text { D3 } \\
\text { D4 } \\
\text { D5 } \\
\text { D6 }\end{array}$ & $\begin{array}{l}3,80 \\
4,50 \\
5,20 \\
6,05 \\
6,80 \\
7,40\end{array}$ & $\begin{array}{l}3,75 \\
4,50 \\
5,40 \\
6,55 \\
7,40 \\
8,00\end{array}$ & $\begin{array}{l}3,95 \\
4,65 \\
5,15 \\
6,05 \\
6,80 \\
7,45\end{array}$ & $\begin{array}{l}4,05 \\
4,75 \\
5,35 \\
6,40 \\
7,15 \\
7,85\end{array}$ \\
\hline & $B D A-D$ & $\begin{array}{l}\text { D1 } \\
\text { D2 } \\
\text { D3 } \\
\text { D4 } \\
\text { D5 } \\
\text { D6 }\end{array}$ & $\begin{array}{l}3,90 \\
4,60 \\
5,15 \\
6,00 \\
6,65 \\
7,25\end{array}$ & $\begin{array}{l}3,80 \\
4,50 \\
5,10 \\
6,05 \\
6,70 \\
7,45\end{array}$ & $\begin{array}{l}4,10 \\
4,80 \\
5,50 \\
6,50 \\
7,30 \\
8,10\end{array}$ & $\begin{array}{l}3,75 \\
4,45 \\
4,95 \\
6,00 \\
6,65 \\
7,35\end{array}$ \\
\hline & BDMT & $\begin{array}{l}\text { D1 } \\
\text { D2 } \\
\text { D3 } \\
\text { D4 } \\
\text { D5 } \\
\text { D6 }\end{array}$ & $\begin{array}{l}3,15 \\
3,95 \\
4,45 \\
5,40 \\
6,10 \\
6,90\end{array}$ & $\begin{array}{l}2,80 \\
3,60 \\
4,10 \\
5,05 \\
5,85 \\
6,55\end{array}$ & $\begin{array}{l}2,90 \\
3,70 \\
4,20 \\
5,05 \\
6,85 \\
6,40\end{array}$ & $\begin{array}{l}3,05 \\
3,85 \\
4,35 \\
5,20 \\
6,00 \\
6,60\end{array}$ \\
\hline
\end{tabular}

Continua 
Tabela 1. Continuação.

\begin{tabular}{|c|c|c|c|c|c|c|}
\hline & & & RI & RII & RI I I & RIV \\
\hline & MNM & $\begin{array}{l}\text { D1 } \\
\text { D2 } \\
\text { D3 } \\
\text { D4 } \\
\text { D5 } \\
\text { D6 }\end{array}$ & $\begin{array}{l}2,95 \\
3,55 \\
3,95 \\
4,80 \\
5,35 \\
5,80\end{array}$ & $\begin{array}{l}2,75 \\
3,35 \\
3,70 \\
4,30 \\
5,00 \\
5,45\end{array}$ & $\begin{array}{l}2,75 \\
3,35 \\
3,90 \\
4,90 \\
5,50 \\
6,00\end{array}$ & $\begin{array}{l}2,75 \\
3,35 \\
3,80 \\
4,60 \\
5,10 \\
5,70\end{array}$ \\
\hline & MNMB & $\begin{array}{l}\text { D1 } \\
\text { D2 } \\
\text { D3 } \\
\text { D4 } \\
\text { D5 } \\
\text { D6 }\end{array}$ & $\begin{array}{l}2,40 \\
3,00 \\
3,40 \\
4,05 \\
4,60 \\
5,15\end{array}$ & $\begin{array}{l}2,50 \\
3,10 \\
3,40 \\
4,10 \\
4,55 \\
5,00\end{array}$ & $\begin{array}{l}2,35 \\
2,95 \\
3,35 \\
4,05 \\
4,45 \\
4,95\end{array}$ & $\begin{array}{l}2,15 \\
2,75 \\
3,15 \\
4,05 \\
4,85 \\
5,40\end{array}$ \\
\hline$A C B$ & $B D A$ & $\begin{array}{l}\text { D1 } \\
\text { D2 } \\
\text { D3 } \\
\text { D4 } \\
\text { D5 } \\
\text { D6 }\end{array}$ & $\begin{array}{l}2,30 \\
3,00 \\
3,20 \\
3,90 \\
4,55 \\
5,40\end{array}$ & $\begin{array}{l}2,35 \\
3,05 \\
3,40 \\
4,20 \\
4,95 \\
5,65\end{array}$ & $\begin{array}{l}2,20 \\
2,90 \\
3,20 \\
4,00 \\
4,70 \\
5,35\end{array}$ & $\begin{array}{l}2,50 \\
3,20 \\
3,60 \\
4,20 \\
4,90 \\
5,75\end{array}$ \\
\hline & $B D A-D$ & $\begin{array}{l}\text { D1 } \\
\text { D2 } \\
\text { D3 } \\
\text { D4 } \\
\text { D5 } \\
\text { D6 }\end{array}$ & $\begin{array}{l}2,20 \\
2,90 \\
3,30 \\
4,20 \\
4,95 \\
5,40\end{array}$ & $\begin{array}{l}2,10 \\
2,80 \\
3,20 \\
4,00 \\
4,70 \\
5,30\end{array}$ & $\begin{array}{l}2,10 \\
2,80 \\
3,20 \\
4,00 \\
4,70 \\
5,30\end{array}$ & $\begin{array}{l}2,10 \\
2,80 \\
3,20 \\
4,00 \\
4,70 \\
5,40\end{array}$ \\
\hline & BDMT & $\begin{array}{l}\text { D1 } \\
\text { D2 } \\
\text { D3 } \\
\text { D4 } \\
\text { D5 } \\
\text { D6 }\end{array}$ & $\begin{array}{l}2,00 \\
2,60 \\
2,80 \\
3,35 \\
3,80 \\
4,40\end{array}$ & $\begin{array}{l}2,00 \\
2,60 \\
2,95 \\
3,70 \\
4,35 \\
4,90\end{array}$ & $\begin{array}{l}1,95 \\
2,55 \\
2,80 \\
3,55 \\
4,15 \\
4,75\end{array}$ & $\begin{array}{l}1,80 \\
2,40 \\
2,80 \\
3,50 \\
4,20 \\
4,85\end{array}$ \\
\hline
\end{tabular}

Continua 
Tabela 1. Continuação.

\begin{tabular}{|c|c|c|c|c|c|c|}
\hline & & & $R I$ & RI I & R I I I & RIV \\
\hline & MNM & $\begin{array}{l}\text { D1 } \\
\text { D2 } \\
\text { D3 } \\
\text { D4 } \\
\text { D5 } \\
\text { D6 }\end{array}$ & $\begin{array}{l}3,00 \\
4,05 \\
5,05 \\
6,40 \\
7,55 \\
8,35\end{array}$ & $\begin{array}{l}3,00 \\
4,00 \\
5,10 \\
6,45 \\
7,55 \\
8,15\end{array}$ & $\begin{array}{l}3,05 \\
3,80 \\
4,55 \\
5,80 \\
6,70 \\
7,50\end{array}$ & $\begin{array}{l}3,30 \\
4,20 \\
5,15 \\
6,75 \\
7,80 \\
8,55\end{array}$ \\
\hline & MNMB & $\begin{array}{l}\text { D1 } \\
\text { D2 } \\
\text { D3 } \\
\text { D4 } \\
\text { D5 } \\
\text { D6 }\end{array}$ & $\begin{array}{l}3,60 \\
5,05 \\
6,55 \\
8,10 \\
8,60 \\
8,55\end{array}$ & $\begin{array}{l}3,55 \\
4,90 \\
6,00 \\
7,50 \\
8,65 \\
9,00\end{array}$ & $\begin{array}{l}3,60 \\
4,90 \\
6,20 \\
7,85 \\
9,00 \\
9,00\end{array}$ & $\begin{array}{l}3,70 \\
5,10 \\
6,50 \\
7,90 \\
9,00 \\
9,00\end{array}$ \\
\hline$A C \quad 12$ & BDA & $\begin{array}{l}\text { D1 } \\
\text { D2 } \\
\text { D3 } \\
\text { D4 } \\
\text { D5 } \\
\text { D6 }\end{array}$ & $\begin{array}{l}3,80 \\
5,20 \\
6,55 \\
7,80 \\
8,35 \\
8,50\end{array}$ & $\begin{array}{l}3,65 \\
5,00 \\
6,40 \\
7,75 \\
8,45 \\
8,80\end{array}$ & $\begin{array}{l}3,70 \\
5,00 \\
6,40 \\
7,80 \\
9,00 \\
9,00\end{array}$ & $\begin{array}{l}3,85 \\
5,10 \\
6,40 \\
7,80 \\
9,00 \\
9,00\end{array}$ \\
\hline & $B D A-D$ & $\begin{array}{l}\text { D1 } \\
\text { D2 } \\
\text { D3 } \\
\text { D4 } \\
\text { D5 } \\
\text { D6 }\end{array}$ & $\begin{array}{l}3,60 \\
5,20 \\
6,75 \\
8,65 \\
9,00 \\
9,00\end{array}$ & $\begin{array}{l}3,65 \\
5,10 \\
6,75 \\
8,15 \\
8,55 \\
8,70\end{array}$ & $\begin{array}{l}3,50 \\
5,00 \\
6,50 \\
8,05 \\
8,50 \\
8,50\end{array}$ & $\begin{array}{l}3,40 \\
4,90 \\
6,50 \\
7,95 \\
8,75 \\
9,00\end{array}$ \\
\hline & BDMT & $\begin{array}{l}\text { D1 } \\
\text { D2 } \\
\text { D3 } \\
\text { D4 } \\
\text { D5 } \\
\text { D6 }\end{array}$ & $\begin{array}{l}3,70 \\
4,90 \\
6,10 \\
7,40 \\
8,10 \\
8,35\end{array}$ & $\begin{array}{l}3,45 \\
4,70 \\
6,00 \\
7,35 \\
8,20 \\
8,85\end{array}$ & $\begin{array}{l}3,45 \\
4,65 \\
6,00 \\
7,45 \\
8,05 \\
8,10\end{array}$ & $\begin{array}{l}3,40 \\
4,70 \\
6,00 \\
7,20 \\
7,65 \\
7,85\end{array}$ \\
\hline
\end{tabular}


Tabela 1. Continuação.

\begin{tabular}{|c|c|c|c|c|c|c|}
\hline & & & RI & RI I & RII I & RIV \\
\hline & MNM & $\begin{array}{l}\text { D1 } \\
\text { D2 } \\
\text { D3 } \\
\text { D4 } \\
\text { D5 } \\
\text { D6 }\end{array}$ & $\begin{array}{l}2,20 \\
3,65 \\
5,20 \\
7,10 \\
8,70 \\
9,00\end{array}$ & $\begin{array}{l}2,40 \\
3,90 \\
5,55 \\
7,55 \\
9,00 \\
9,00\end{array}$ & $\begin{array}{l}2,15 \\
4,30 \\
5,95 \\
8,10 \\
9,00 \\
9,00\end{array}$ & $\begin{array}{l}2,35 \\
4,00 \\
5,65 \\
7,70 \\
9,00 \\
9,00\end{array}$ \\
\hline & MNMB & $\begin{array}{l}\text { D1 } \\
\text { D2 } \\
\text { D3 } \\
\text { D4 } \\
\text { D5 } \\
\text { D6 }\end{array}$ & $\begin{array}{l}2,05 \\
3,60 \\
5,10 \\
6,80 \\
8,10 \\
8,90\end{array}$ & $\begin{array}{l}1,95 \\
3,20 \\
4,40 \\
5,65 \\
6,60 \\
7,55\end{array}$ & $\begin{array}{l}2,05 \\
3,55 \\
4,95 \\
6,35 \\
7,00 \\
7,35\end{array}$ & $\begin{array}{l}1,75 \\
3,25 \\
4,80 \\
6,50 \\
7,75 \\
8,75\end{array}$ \\
\hline PI203 & $B D A$ & $\begin{array}{l}\text { D1 } \\
\text { D2 } \\
\text { D3 } \\
\text { D4 } \\
\text { D5 } \\
\text { D6 }\end{array}$ & $\begin{array}{l}1,80 \\
3,50 \\
5,10 \\
6,75 \\
8,05 \\
9,00\end{array}$ & $\begin{array}{l}2,20 \\
3,95 \\
5,35 \\
6,85 \\
7,75 \\
8,85\end{array}$ & $\begin{array}{l}2,15 \\
4,00 \\
5,55 \\
7,25 \\
8,35 \\
8,90\end{array}$ & $\begin{array}{l}2,15 \\
3,85 \\
5,35 \\
7,05 \\
8,25 \\
9,00\end{array}$ \\
\hline & $B D A-D$ & $\begin{array}{l}\text { D1 } \\
\text { D2 } \\
\text { D3 } \\
\text { D4 } \\
\text { D5 } \\
\text { D6 }\end{array}$ & $\begin{array}{l}2,70 \\
4,60 \\
6,15 \\
7,85 \\
9,00 \\
9,00\end{array}$ & $\begin{array}{l}2,40 \\
4,25 \\
5,90 \\
7,50 \\
8,35 \\
9,00\end{array}$ & $\begin{array}{l}2,20 \\
4,10 \\
5,70 \\
7,20 \\
8,20 \\
8,70\end{array}$ & $\begin{array}{l}2,40 \\
4,20 \\
5,75 \\
7,40 \\
8,85 \\
9,00\end{array}$ \\
\hline & BDMT & $\begin{array}{l}\text { D1 } \\
\text { D2 } \\
\text { D3 } \\
\text { D4 } \\
\text { D5 } \\
\text { D6 }\end{array}$ & $\begin{array}{l}1,90 \\
3,10 \\
4,15 \\
5,30 \\
6,00 \\
6,90\end{array}$ & $\begin{array}{l}1,85 \\
2,90 \\
3,90 \\
4,95 \\
5,70 \\
6,35\end{array}$ & $\begin{array}{l}2,00 \\
3,15 \\
4,25 \\
5,45 \\
6,15 \\
6,85\end{array}$ & $\begin{array}{l}1,70 \\
2,80 \\
3,65 \\
4,70 \\
5,40 \\
6,15\end{array}$ \\
\hline
\end{tabular}


Tabela 1. Continuação.

\begin{tabular}{|c|c|c|c|c|c|c|}
\hline & & & RI & RII & RII I & RIV \\
\hline & MNM & $\begin{array}{l}\text { D1 } \\
\text { D2 } \\
\text { D3 } \\
\text { D4 } \\
\text { D5 } \\
\text { D6 }\end{array}$ & $\begin{array}{l}3,25 \\
4,10 \\
5,95 \\
7,05 \\
7,95 \\
9,00\end{array}$ & $\begin{array}{l}3,10 \\
3,95 \\
5,70 \\
6,75 \\
7,60 \\
9,00\end{array}$ & $\begin{array}{l}3,00 \\
3,80 \\
5,40 \\
6,45 \\
7,20 \\
8,80\end{array}$ & $\begin{array}{l}3,10 \\
3,95 \\
5,65 \\
6,70 \\
7,50 \\
9,00\end{array}$ \\
\hline & MNMB & $\begin{array}{l}\text { D1 } \\
\text { D2 } \\
\text { D3 } \\
\text { D4 } \\
\text { D5 } \\
\text { D6 }\end{array}$ & $\begin{array}{l}2,60 \\
3,20 \\
4,40 \\
5,10 \\
5,65 \\
6,65\end{array}$ & $\begin{array}{l}2,50 \\
3,05 \\
4,10 \\
4,60 \\
5,10 \\
6,00\end{array}$ & $\begin{array}{l}2,65 \\
3,25 \\
4,30 \\
4,90 \\
5,45 \\
6,45\end{array}$ & $\begin{array}{l}2,60 \\
3,20 \\
4,15 \\
4,85 \\
5,35 \\
6,15\end{array}$ \\
\hline PI312 & $B D A$ & $\begin{array}{l}\text { D1 } \\
\text { D2 } \\
\text { D3 } \\
\text { D4 } \\
\text { D5 } \\
\text { D6 }\end{array}$ & $\begin{array}{l}2,55 \\
3,25 \\
4,10 \\
4,80 \\
5,30 \\
6,40\end{array}$ & $\begin{array}{l}2,80 \\
3,30 \\
4,30 \\
4,95 \\
5,60 \\
6,65\end{array}$ & $\begin{array}{l}2,65 \\
3,10 \\
4,15 \\
4,80 \\
5,40 \\
6,35\end{array}$ & $\begin{array}{l}2,50 \\
3,15 \\
4,10 \\
4,80 \\
5,30 \\
6,40\end{array}$ \\
\hline & $B D A-D$ & $\begin{array}{l}\text { D1 } \\
\text { D2 } \\
\text { D3 } \\
\text { D4 } \\
\text { D5 } \\
\text { D6 }\end{array}$ & $\begin{array}{l}2,55 \\
3,05 \\
4,00 \\
4,55 \\
5,10 \\
6,05\end{array}$ & $\begin{array}{l}2,70 \\
3,30 \\
4,35 \\
5,00 \\
5,60 \\
6,55\end{array}$ & $\begin{array}{l}2,65 \\
3,20 \\
4,10 \\
4,80 \\
5,30 \\
6,30\end{array}$ & $\begin{array}{l}2,90 \\
3,35 \\
4,30 \\
5,00 \\
5,50 \\
6,40\end{array}$ \\
\hline & BDMT & $\begin{array}{l}\text { D1 } \\
\text { D2 } \\
\text { D3 } \\
\text { D4 } \\
\text { D5 } \\
\text { D6 }\end{array}$ & $\begin{array}{l}2,50 \\
3,20 \\
4,50 \\
5,20 \\
6,00 \\
7,25\end{array}$ & $\begin{array}{l}2,70 \\
3,30 \\
4,45 \\
5,20 \\
6,00 \\
7,10\end{array}$ & $\begin{array}{l}2,45 \\
3,20 \\
4,40 \\
5,10 \\
5,90 \\
6,80\end{array}$ & $\begin{array}{l}2,50 \\
3,15 \\
4,20 \\
4,90 \\
5,50 \\
6,45\end{array}$ \\
\hline
\end{tabular}

Continua 
Tabela 1. Continuação.

\begin{tabular}{|c|c|c|c|c|c|c|}
\hline & & & RI & RII & R I I I & RIV \\
\hline & MNM & $\begin{array}{l}\text { D1 } \\
\text { D2 } \\
\text { D3 } \\
\text { D4 } \\
\text { D5 } \\
\text { D6 }\end{array}$ & $\begin{array}{l}2,55 \\
4,05 \\
5,40 \\
7,00 \\
8,10 \\
8,75\end{array}$ & $\begin{array}{l}2,80 \\
4,50 \\
6,00 \\
7,55 \\
8,65 \\
9,00\end{array}$ & $\begin{array}{l}2,95 \\
4,65 \\
6,05 \\
7,60 \\
8,75 \\
9,00\end{array}$ & $\begin{array}{l}2,85 \\
4,45 \\
6,10 \\
7,80 \\
9,00 \\
9,00\end{array}$ \\
\hline & MNMB & $\begin{array}{l}\text { D1 } \\
\text { D2 } \\
\text { D3 } \\
\text { D4 } \\
\text { D5 } \\
\text { D6 }\end{array}$ & $\begin{array}{l}3,20 \\
4,65 \\
5,70 \\
6,70 \\
7,55 \\
8,30\end{array}$ & $\begin{array}{l}2,95 \\
4,25 \\
5,15 \\
6,30 \\
7,15 \\
7,75\end{array}$ & $\begin{array}{l}2,95 \\
4,30 \\
5,20 \\
6,25 \\
7,10 \\
7,80\end{array}$ & $\begin{array}{l}3,05 \\
4,40 \\
5,35 \\
6,45 \\
7,35 \\
8,00\end{array}$ \\
\hline PI314 & $B D A$ & $\begin{array}{l}\text { D1 } \\
\text { D2 } \\
\text { D3 } \\
\text { D4 } \\
\text { D5 } \\
\text { D6 }\end{array}$ & $\begin{array}{l}3,20 \\
4,90 \\
6,25 \\
7,60 \\
8,60 \\
9,00\end{array}$ & $\begin{array}{l}3,05 \\
4,90 \\
6,15 \\
7,65 \\
8,55 \\
9,00\end{array}$ & $\begin{array}{l}3,55 \\
4,40 \\
6,75 \\
8,30 \\
9,00 \\
9,00\end{array}$ & $\begin{array}{l}2,65 \\
4,50 \\
5,75 \\
7,10 \\
8,20 \\
9,00\end{array}$ \\
\hline & $B D A-D$ & $\begin{array}{l}\text { D1 } \\
\text { D2 } \\
\text { D3 } \\
\text { D4 } \\
\text { D5 } \\
\text { D6 }\end{array}$ & $\begin{array}{l}3,85 \\
5,60 \\
6,90 \\
8,40 \\
9,00 \\
9,00\end{array}$ & $\begin{array}{l}3,35 \\
4,90 \\
6,05 \\
7,45 \\
8,15 \\
8,85\end{array}$ & $\begin{array}{l}3,30 \\
4,85 \\
6,10 \\
7,60 \\
8,55 \\
9,00\end{array}$ & $\begin{array}{l}3,45 \\
5,15 \\
6,55 \\
8,00 \\
8,60 \\
9,00\end{array}$ \\
\hline & BDMT & $\begin{array}{l}\text { D1 } \\
\text { D2 } \\
\text { D3 } \\
\text { D4 } \\
\text { D5 } \\
\text { D6 }\end{array}$ & $\begin{array}{l}2,00 \\
3,15 \\
4,00 \\
4,90 \\
5,65 \\
6,25\end{array}$ & $\begin{array}{l}2,80 \\
3,90 \\
4,80 \\
5,85 \\
6,40 \\
6,96\end{array}$ & $\begin{array}{l}2,15 \\
3,35 \\
4,30 \\
5,25 \\
6,00 \\
6,60\end{array}$ & $\begin{array}{l}2,95 \\
4,35 \\
5,30 \\
6,25 \\
6,90 \\
7,40\end{array}$ \\
\hline
\end{tabular}

Continua 
Tabela 1 . Continuação.

\begin{tabular}{|c|c|c|c|c|c|c|}
\hline & & & $R I$ & RII & RII I & RIV \\
\hline & MNM & $\begin{array}{l}\text { D1 } \\
\text { D2 } \\
\text { D3 } \\
\text { D4 } \\
\text { D5 } \\
\text { D6 }\end{array}$ & $\begin{array}{l}2,40 \\
3,60 \\
4,40 \\
6,00 \\
7,20 \\
8,40\end{array}$ & $\begin{array}{l}2,30 \\
3,50 \\
4,20 \\
5,90 \\
7,20 \\
8,55\end{array}$ & $\begin{array}{l}2,20 \\
3,40 \\
4,05 \\
5,65 \\
6,95 \\
8,70\end{array}$ & $\begin{array}{l}2,40 \\
3,45 \\
4,15 \\
5,65 \\
7,00 \\
8,25\end{array}$ \\
\hline & MNMB & $\begin{array}{l}D 1 \\
D 2 \\
D 3 \\
D 4 \\
D 5 \\
D 6\end{array}$ & $\begin{array}{l}2,40 \\
3,10 \\
3,55 \\
4,45 \\
5,05 \\
5,85\end{array}$ & $\begin{array}{l}2,45 \\
3,15 \\
3,55 \\
4,45 \\
5,05 \\
5,75\end{array}$ & $\begin{array}{l}2,10 \\
2,80 \\
3,30 \\
4,20 \\
4,95 \\
5,65\end{array}$ & $\begin{array}{l}2,40 \\
3,10 \\
3,50 \\
4,45 \\
5,05 \\
5,80\end{array}$ \\
\hline PI316 & BDA & $\begin{array}{l}\text { D1 } \\
\text { D2 } \\
\text { D3 } \\
\text { D4 } \\
\text { D5 } \\
\text { D6 }\end{array}$ & $\begin{array}{l}2,75 \\
3,65 \\
4,30 \\
5,45 \\
6,25 \\
7,00\end{array}$ & $\begin{array}{l}2,75 \\
3,45 \\
3,95 \\
5,10 \\
5,95 \\
6,80\end{array}$ & $\begin{array}{l}3,00 \\
3,70 \\
4,15 \\
4,90 \\
5,60 \\
6,75\end{array}$ & $\begin{array}{l}3,05 \\
3,75 \\
4,30 \\
5,00 \\
5,70 \\
6,80\end{array}$ \\
\hline & $B D A-D$ & $\begin{array}{l}\text { D1 } \\
\text { D2 } \\
\text { D3 } \\
\text { D4 } \\
\text { D5 } \\
\text { D6 }\end{array}$ & $\begin{array}{l}2,70 \\
3,60 \\
4,10 \\
5,15 \\
6,00 \\
6,85\end{array}$ & $\begin{array}{l}2,60 \\
3,50 \\
4,05 \\
5,15 \\
6,10 \\
6,85\end{array}$ & $\begin{array}{l}2,60 \\
3,50 \\
4,00 \\
5,10 \\
6,00 \\
6,85\end{array}$ & $\begin{array}{l}2,90 \\
3,80 \\
4,30 \\
5,40 \\
6,15 \\
7,00\end{array}$ \\
\hline & BDMT & $\begin{array}{l}\text { D1 } \\
\text { D2 } \\
\text { D3 } \\
\text { D4 } \\
\text { D5 } \\
\text { D6 }\end{array}$ & $\begin{array}{l}2,80 \\
3,40 \\
3,85 \\
4,65 \\
5,30 \\
5,90\end{array}$ & $\begin{array}{l}2,60 \\
3,20 \\
3,65 \\
4,40 \\
5,00 \\
5,65\end{array}$ & $\begin{array}{l}2,10 \\
2,70 \\
3,15 \\
3,85 \\
4,30 \\
4,85\end{array}$ & $\begin{array}{l}2,50 \\
3,10 \\
3,50 \\
4,30 \\
4,90 \\
5,50\end{array}$ \\
\hline
\end{tabular}

Continua 
Tabela 1. Continuação.

\begin{tabular}{|c|c|c|c|c|c|c|}
\hline & & & $R I$ & RI I & RI I I & RIV \\
\hline & MNM & $\begin{array}{l}\text { D1 } \\
\text { D2 } \\
\text { D3 } \\
\text { D4 } \\
\text { D5 } \\
\text { D6 }\end{array}$ & $\begin{array}{l}3,00 \\
4,40 \\
5,95 \\
6,75 \\
7,30 \\
8,50\end{array}$ & $\begin{array}{l}3,20 \\
4,80 \\
6,30 \\
7,00 \\
7,40 \\
8,00\end{array}$ & $\begin{array}{l}3,30 \\
4,70 \\
6,30 \\
6,90 \\
7,30 \\
8,20\end{array}$ & $\begin{array}{l}3,50 \\
4,95 \\
6,45 \\
7,00 \\
7,45 \\
8,15\end{array}$ \\
\hline & MNMB & $\begin{array}{l}\text { D1 } \\
\text { D2 } \\
\text { D3 } \\
\text { D4 } \\
\text { D5 } \\
\text { D6 }\end{array}$ & $\begin{array}{l}3,00 \\
4,05 \\
5,30 \\
5,80 \\
6,25 \\
7,20\end{array}$ & $\begin{array}{l}2,80 \\
3,90 \\
5,20 \\
5,80 \\
6,30 \\
7,60\end{array}$ & $\begin{array}{l}3,10 \\
4,25 \\
5,60 \\
6,25 \\
6,80 \\
8,00\end{array}$ & $\begin{array}{l}3,15 \\
4,25 \\
5,55 \\
6,15 \\
6,75 \\
7,50\end{array}$ \\
\hline ITAG & $B D A$ & $\begin{array}{l}\text { D1 } \\
\text { D2 } \\
\text { D3 } \\
\text { D4 } \\
\text { D5 } \\
\text { D6 }\end{array}$ & $\begin{array}{l}2,90 \\
4,40 \\
5,65 \\
6,25 \\
6,85 \\
8,15\end{array}$ & $\begin{array}{l}2,80 \\
4,30 \\
5,65 \\
6,20 \\
6,90 \\
8,20\end{array}$ & $\begin{array}{l}2,85 \\
4,25 \\
5,60 \\
6,20 \\
6,80 \\
8,10\end{array}$ & $\begin{array}{l}2,85 \\
4,20 \\
5,60 \\
6,25 \\
6,85 \\
8,00\end{array}$ \\
\hline & $B D A-D$ & $\begin{array}{l}\text { D1 } \\
\text { D2 } \\
\text { D3 } \\
\text { D4 } \\
\text { D5 } \\
\text { D6 }\end{array}$ & $\begin{array}{l}3,20 \\
4,40 \\
5,60 \\
6,20 \\
6,80 \\
7,90\end{array}$ & $\begin{array}{l}3,00 \\
4,30 \\
5,50 \\
6,05 \\
6,65 \\
7,75\end{array}$ & $\begin{array}{l}3,05 \\
4,40 \\
5,70 \\
6,20 \\
6,80 \\
8,25\end{array}$ & $\begin{array}{l}3,00 \\
4,15 \\
5,45 \\
5,95 \\
6,60 \\
7,95\end{array}$ \\
\hline & BDMT & $\begin{array}{l}\text { D1 } \\
\text { D2 } \\
\text { D3 } \\
\text { D4 } \\
\text { D5 } \\
\text { D6 }\end{array}$ & $\begin{array}{l}2,35 \\
3,55 \\
4,75 \\
5,30 \\
5,90 \\
7,10\end{array}$ & $\begin{array}{l}2,75 \\
3,85 \\
4,90 \\
5,40 \\
5,95 \\
7,00\end{array}$ & $\begin{array}{l}3,00 \\
4,10 \\
5,20 \\
5,70 \\
6,20 \\
7,60\end{array}$ & $\begin{array}{l}2,95 \\
4,05 \\
5,15 \\
5,70 \\
6,20 \\
7,40\end{array}$ \\
\hline
\end{tabular}

Continua 
Tabela 1 . Continuação.

\begin{tabular}{|c|c|c|c|c|c|c|}
\hline & & & RI & RII & RI I I & RIV \\
\hline & MNM & $\begin{array}{l}\text { D1 } \\
\text { D2 } \\
\text { D3 } \\
\text { D4 } \\
\text { D5 } \\
\text { D6 }\end{array}$ & $\begin{array}{l}3,00 \\
4,50 \\
5,75 \\
6,20 \\
6,70 \\
7,50\end{array}$ & $\begin{array}{l}3,20 \\
4,60 \\
5,95 \\
6,35 \\
6,85 \\
8,00\end{array}$ & $\begin{array}{l}2,80 \\
4,10 \\
5,45 \\
6,00 \\
6,45 \\
7,50\end{array}$ & $\begin{array}{l}3,10 \\
4,65 \\
6,00 \\
6,45 \\
7,05 \\
8,15\end{array}$ \\
\hline & MNMB & $\begin{array}{l}\text { D1 } \\
\text { D2 } \\
\text { D3 } \\
\text { D4 } \\
\text { D5 } \\
\text { D6 }\end{array}$ & $\begin{array}{l}2,20 \\
3,30 \\
4,40 \\
5,00 \\
5,55 \\
7,10\end{array}$ & $\begin{array}{l}2,10 \\
3,10 \\
4,30 \\
4,80 \\
5,40 \\
6,85\end{array}$ & $\begin{array}{l}2,05 \\
3,05 \\
4,10 \\
4,70 \\
5,40 \\
6,95\end{array}$ & $\begin{array}{l}2,05 \\
2,90 \\
4,05 \\
4,65 \\
5,30 \\
6,80\end{array}$ \\
\hline ITA 11 & $B D A$ & $\begin{array}{l}\text { D1 } \\
\text { D2 } \\
\text { D3 } \\
\text { D4 } \\
\text { D5 } \\
\text { D6 }\end{array}$ & $\begin{array}{l}2,05 \\
3,00 \\
4,05 \\
4,70 \\
5,35 \\
7,25\end{array}$ & $\begin{array}{l}2,30 \\
3,30 \\
4,40 \\
4,90 \\
5,50 \\
6,95\end{array}$ & $\begin{array}{l}2,40 \\
3,25 \\
4,35 \\
4,90 \\
5,50 \\
7,05\end{array}$ & $\begin{array}{l}2,30 \\
3,15 \\
4,15 \\
4,75 \\
5,25 \\
6,65\end{array}$ \\
\hline & $B D A-D$ & $\begin{array}{l}\text { D1 } \\
\text { D2 } \\
\text { D3 } \\
\text { D4 } \\
\text { D5 } \\
\text { D6 }\end{array}$ & $\begin{array}{l}1,95 \\
2,90 \\
4,05 \\
4,55 \\
5,25 \\
6,60\end{array}$ & $\begin{array}{l}2,40 \\
3,35 \\
4,55 \\
5,05 \\
5,60 \\
7,00\end{array}$ & $\begin{array}{l}2,10 \\
2,90 \\
4,00 \\
4,50 \\
5,05 \\
6,30\end{array}$ & $\begin{array}{l}1,90 \\
2,90 \\
3,95 \\
4,55 \\
5,10 \\
6,45\end{array}$ \\
\hline & BDMT & $\begin{array}{l}\text { D1 } \\
\text { D2 } \\
\text { D3 } \\
\text { D4 } \\
\text { D5 } \\
\text { D6 }\end{array}$ & $\begin{array}{l}2,25 \\
3,10 \\
4,10 \\
4,60 \\
5,10 \\
6,30\end{array}$ & $\begin{array}{l}2,00 \\
3,10 \\
4,10 \\
4,65 \\
5,15 \\
6,30\end{array}$ & $\begin{array}{l}2,00 \\
2,95 \\
3,95 \\
4,45 \\
5,00 \\
6,20\end{array}$ & $\begin{array}{l}2,20 \\
3,00 \\
4,10 \\
4,55 \\
5,10 \\
6,20\end{array}$ \\
\hline
\end{tabular}

Continua 
Tabela 1. Continuação.

\begin{tabular}{|c|c|c|c|c|c|c|}
\hline & & & $R I$ & RII & R I I I & RIV \\
\hline & MNM & $\begin{array}{l}\text { D1 } \\
\text { D2 } \\
\text { D3 } \\
\text { D4 } \\
\text { D5 } \\
\text { D6 }\end{array}$ & $\begin{array}{l}4,90 \\
6,10 \\
7,70 \\
8,10 \\
8,10 \\
8,10\end{array}$ & $\begin{array}{l}4,95 \\
6,05 \\
8,15 \\
8,65 \\
9,00 \\
9,00\end{array}$ & $\begin{array}{l}5,05 \\
6,20 \\
8,05 \\
8,80 \\
9,00 \\
9,00\end{array}$ & $\begin{array}{l}4,90 \\
5,95 \\
8,00 \\
8,75 \\
9,00 \\
9,00\end{array}$ \\
\hline & MNMB & $\begin{array}{l}\text { D1 } \\
\text { D2 } \\
\text { D3 } \\
\text { D4 } \\
\text { D5 } \\
\text { D6 }\end{array}$ & $\begin{array}{l}3,00 \\
3,60 \\
4,10 \\
4,45 \\
4,70 \\
5,40\end{array}$ & $\begin{array}{l}3,25 \\
3,95 \\
4,75 \\
5,35 \\
5,85 \\
6,60\end{array}$ & $\begin{array}{l}2,50 \\
3,15 \\
4,05 \\
4,55 \\
5,10 \\
5,85\end{array}$ & $\begin{array}{l}3,50 \\
4,40 \\
5,50 \\
6,50 \\
7,30 \\
8,20\end{array}$ \\
\hline Pt 185 & BDA & $\begin{array}{l}\text { D1 } \\
\text { D2 } \\
\text { D3 } \\
\text { D4 } \\
\text { D5 } \\
\text { D6 }\end{array}$ & $\begin{array}{l}2,45 \\
2,80 \\
3,65 \\
4,25 \\
4,80 \\
6,00\end{array}$ & $\begin{array}{l}2,30 \\
2,70 \\
3,50 \\
4,20 \\
4,70 \\
5,90\end{array}$ & $\begin{array}{l}2,40 \\
2,85 \\
3,60 \\
4,20 \\
4,80 \\
5,90\end{array}$ & $\begin{array}{l}2,30 \\
2,75 \\
3,60 \\
4,25 \\
4,75 \\
5,90\end{array}$ \\
\hline & $B D A-D$ & $\begin{array}{l}\text { D1 } \\
\text { D2 } \\
\text { D3 } \\
\text { D4 } \\
\text { D5 } \\
\text { D6 }\end{array}$ & $\begin{array}{l}2,80 \\
3,25 \\
3,85 \\
4,25 \\
4,55 \\
5,20\end{array}$ & $\begin{array}{l}2,75 \\
3,15 \\
3,70 \\
4,00 \\
4,30 \\
5,20\end{array}$ & $\begin{array}{l}2,75 \\
3,15 \\
3,80 \\
4,10 \\
4,35 \\
5,10\end{array}$ & $\begin{array}{l}2,95 \\
3,55 \\
4,25 \\
4,75 \\
5,10 \\
6,30\end{array}$ \\
\hline & BDMT & $\begin{array}{l}\text { D1 } \\
\text { D2 } \\
\text { D3 } \\
\text { D4 } \\
\text { D5 } \\
\text { D6 }\end{array}$ & $\begin{array}{l}2,40 \\
2,70 \\
3,50 \\
4,00 \\
4,60 \\
5,70\end{array}$ & $\begin{array}{l}2,30 \\
2,65 \\
3,50 \\
4,05 \\
4,60 \\
5,70\end{array}$ & $\begin{array}{l}2,00 \\
2,35 \\
3,15 \\
3,80 \\
4,30 \\
5,30\end{array}$ & $\begin{array}{l}2,50 \\
2,80 \\
3,50 \\
4,10 \\
4,60 \\
5,75\end{array}$ \\
\hline
\end{tabular}

Continua 
Tabela 1. Continuação.

\begin{tabular}{|c|c|c|c|c|c|c|}
\hline & & & RI & RII & RII I & RIV \\
\hline & MNM & $\begin{array}{l}\text { D1 } \\
\text { D2 } \\
\text { D3 } \\
\text { D4 } \\
\text { D5 } \\
\text { D6 }\end{array}$ & $\begin{array}{l}4,30 \\
5,00 \\
6,30 \\
6,80 \\
7,35 \\
8,05\end{array}$ & $\begin{array}{l}4,15 \\
5,00 \\
6,25 \\
7,15 \\
7,75 \\
8,50\end{array}$ & $\begin{array}{l}4,00 \\
4,90 \\
6,10 \\
6,80 \\
7,45 \\
8,20\end{array}$ & $\begin{array}{l}4,20 \\
4,95 \\
6,15 \\
6,90 \\
7,50 \\
8,50\end{array}$ \\
\hline & MNMB & $\begin{array}{l}\text { D1 } \\
\text { D2 } \\
\text { D3 } \\
\text { D4 } \\
\text { D5 } \\
\text { D6 }\end{array}$ & $\begin{array}{l}2,95 \\
3,55 \\
4,45 \\
4,90 \\
5,25 \\
6,10\end{array}$ & $\begin{array}{l}2,65 \\
3,25 \\
4,20 \\
4,80 \\
5,20 \\
6,10\end{array}$ & $\begin{array}{l}3,05 \\
3,60 \\
4,60 \\
5,10 \\
5,45 \\
6,35\end{array}$ & $\begin{array}{l}2,65 \\
3,15 \\
4,00 \\
4,30 \\
4,75 \\
5,60\end{array}$ \\
\hline Pt taeda & $\mathrm{BDA}$ & $\begin{array}{l}\text { D1 } \\
\text { D2 } \\
\text { D3 } \\
\text { D4 } \\
\text { D5 } \\
\text { D6 }\end{array}$ & $\begin{array}{l}2,60 \\
3,05 \\
4,00 \\
4,45 \\
5,25 \\
6,00\end{array}$ & $\begin{array}{l}2,75 \\
3,30 \\
4,15 \\
4,80 \\
5,20 \\
6,55\end{array}$ & $\begin{array}{l}2,60 \\
3,15 \\
4,10 \\
4,90 \\
5,45 \\
6,80\end{array}$ & $\begin{array}{l}2,70 \\
3,30 \\
4,20 \\
4,90 \\
5,75 \\
6,60\end{array}$ \\
\hline & $B D A-D$ & $\begin{array}{l}\text { D1 } \\
\text { D2 } \\
\text { D3 } \\
\text { D4 } \\
\text { D5 } \\
\text { D6 }\end{array}$ & $\begin{array}{l}3,00 \\
3,55 \\
4,20 \\
4,65 \\
4,95 \\
5,60\end{array}$ & $\begin{array}{l}3,20 \\
3,85 \\
4,85 \\
5,15 \\
5,45 \\
6,20\end{array}$ & $\begin{array}{l}3,15 \\
3,85 \\
4,85 \\
5,35 \\
5,80 \\
6,50\end{array}$ & $\begin{array}{l}2,90 \\
3,30 \\
3,95 \\
4,35 \\
4,75 \\
5,65\end{array}$ \\
\hline & BDMT & $\begin{array}{l}\text { D1 } \\
\text { D2 } \\
\text { D3 } \\
\text { D4 } \\
\text { D5 } \\
\text { D6 }\end{array}$ & $\begin{array}{l}2,80 \\
3,25 \\
4,00 \\
4,60 \\
5,05 \\
6,20\end{array}$ & $\begin{array}{l}2,80 \\
3,15 \\
3,90 \\
4,45 \\
4,95 \\
5,85\end{array}$ & $\begin{array}{l}2,70 \\
3,15 \\
4,15 \\
4,85 \\
5,50 \\
7,00\end{array}$ & $\begin{array}{l}2,50 \\
2,95 \\
3,60 \\
4,30 \\
4,90 \\
5,90\end{array}$ \\
\hline
\end{tabular}


Tabela 2. Medidas dos pesos secos de micelio (g) das isolados $A C 1, A C 3, A C 6, A C 8, A C 12, P I 203, P I 312, P I 314$, PI316, ITA6, ITA11, Pt 185 e Pt taeda em diferentes meios de cultura após 30 dias de incubação.

\begin{tabular}{|c|c|c|c|c|c|}
\hline Isolados & Meios & RI & RI I & RIII & RIV \\
\hline$A C_{1}$ & $\begin{array}{l}\text { MNM } \\
\text { MNMB } \\
\text { BDA } \\
\text { BDA-D } \\
\text { BDMT }\end{array}$ & $\begin{array}{l}0,05 \\
0,13 \\
0,08 \\
0,09 \\
0,10\end{array}$ & $\begin{array}{l}0,04 \\
0,14 \\
0,10 \\
0,08 \\
0,10\end{array}$ & $\begin{array}{l}0,04 \\
0,14 \\
0,11 \\
0,09 \\
0,11\end{array}$ & $\begin{array}{l}0,04 \\
0,13 \\
0,09 \\
0,08 \\
0,11\end{array}$ \\
\hline$A C 3$ & $\begin{array}{l}\text { MNM } \\
\text { MNMB } \\
\text { BDA } \\
\text { BDA-D } \\
\text { BDMT }\end{array}$ & $\begin{array}{l}0,04 \\
0,12 \\
0,10 \\
0,08 \\
0,08\end{array}$ & $\begin{array}{l}0,04 \\
0,16 \\
0,09 \\
0,08 \\
0,09\end{array}$ & $\begin{array}{l}0,05 \\
0,11 \\
0,09 \\
0,09 \\
0,09\end{array}$ & $\begin{array}{l}0,05 \\
0,41 \\
0,10 \\
0,08 \\
0,09\end{array}$ \\
\hline AC6 & $\begin{array}{l}\text { MNM } \\
\text { MNMB } \\
\text { BDA } \\
\text { BDA-D } \\
\text { BDMT }\end{array}$ & $\begin{array}{l}0,04 \\
0,12 \\
0,08 \\
0,08 \\
0,10\end{array}$ & $\begin{array}{l}0,04 \\
0,12 \\
0,08 \\
0,10 \\
0,10\end{array}$ & $\begin{array}{l}0,03 \\
0,14 \\
0,10 \\
0,08 \\
0,09\end{array}$ & $\begin{array}{l}0,05 \\
0,13 \\
0,10 \\
0,08 \\
0,09\end{array}$ \\
\hline ACB & $\begin{array}{l}\text { MNM } \\
\text { MNMB } \\
\text { BDA } \\
\text { BDA-D } \\
\text { BDMT }\end{array}$ & $\begin{array}{l}0,05 \\
0,13 \\
0,12 \\
0,10 \\
0,11\end{array}$ & $\begin{array}{l}0,06 \\
0,13 \\
0,12 \\
0,10 \\
0,11\end{array}$ & $\begin{array}{l}0,06 \\
0,13 \\
0,12 \\
0,10 \\
0,11\end{array}$ & $\begin{array}{l}0,05 \\
0,13 \\
0,11 \\
0,10 \\
0,11\end{array}$ \\
\hline$A C 12$ & $\begin{array}{l}\text { MNM } \\
\text { MNMB } \\
\text { BDA } \\
\text { BDA-D } \\
\text { BDMT }\end{array}$ & $\begin{array}{l}0,05 \\
0,09 \\
0,09 \\
0,07 \\
0,09\end{array}$ & $\begin{array}{l}0,05 \\
0,13 \\
0,09 \\
0,08 \\
0,08\end{array}$ & $\begin{array}{l}0,05 \\
0,10 \\
0,09 \\
0,09 \\
0,10\end{array}$ & $\begin{array}{l}0,04 \\
0,12 \\
0,10 \\
0,09 \\
0,10\end{array}$ \\
\hline PI203 & $\begin{array}{l}\text { MNM } \\
\text { MNMB } \\
\text { BDA } \\
\text { BDA-D } \\
\text { BDMT }\end{array}$ & $\begin{array}{l}0,01 \\
0,06 \\
0,02 \\
0,02 \\
0,02\end{array}$ & $\begin{array}{l}0,02 \\
0,04 \\
0,02 \\
0,02 \\
0,02\end{array}$ & $\begin{array}{l}0,03 \\
0,04 \\
0,02 \\
0,02 \\
0,02\end{array}$ & $\begin{array}{l}0,01 \\
0,04 \\
0,03 \\
0,02 \\
0,02\end{array}$ \\
\hline PI312 & $\begin{array}{l}\text { MNM } \\
\text { MNMB } \\
\text { BDA } \\
\text { BDA-D } \\
\text { BDMT }\end{array}$ & $\begin{array}{l}0,03 \\
0,09 \\
0,08 \\
0,07 \\
0,08\end{array}$ & $\begin{array}{l}0,03 \\
0,05 \\
0,08 \\
0,07 \\
0,08\end{array}$ & $\begin{array}{l}0,03 \\
0,11 \\
0,08 \\
0,07 \\
0,08\end{array}$ & $\begin{array}{l}0,04 \\
0,09 \\
0,08 \\
0,07 \\
0,08\end{array}$ \\
\hline
\end{tabular}


Tabela 2. Continuação.

\begin{tabular}{|c|c|c|c|c|c|}
\hline Isolados & Meios & RI & RII & RIII & RIV \\
\hline$P I 314$ & $\begin{array}{l}\text { MNM } \\
\text { MNMB } \\
\text { BDA } \\
\text { BDA-D } \\
\text { BDMT }\end{array}$ & $\begin{array}{l}0,05 \\
0,07 \\
0,05 \\
0,03 \\
0,03\end{array}$ & $\begin{array}{l}0,05 \\
0,05 \\
0,04 \\
0,03 \\
0,03\end{array}$ & $\begin{array}{l}0,06 \\
0,05 \\
0,04 \\
0,05 \\
0,03\end{array}$ & $\begin{array}{l}0,05 \\
0,08 \\
0,04 \\
0,03 \\
0,04\end{array}$ \\
\hline PI316 & $\begin{array}{l}\text { MNM } \\
\text { MNMB } \\
\text { BDA } \\
\text { BDA-D } \\
\text { BDMT }\end{array}$ & $\begin{array}{l}0,05 \\
0,09 \\
0,08 \\
0,07 \\
0,08\end{array}$ & $\begin{array}{l}0,04 \\
0,09 \\
0,07 \\
0,08 \\
0,07\end{array}$ & $\begin{array}{l}0,04 \\
0,10 \\
0,08 \\
0,08 \\
0,07\end{array}$ & $\begin{array}{l}0,05 \\
0,10 \\
0,07 \\
0,07 \\
0,08\end{array}$ \\
\hline ITAG & $\begin{array}{l}\text { MNM } \\
\text { MNMB } \\
\text { BDA } \\
\text { BDA-D } \\
\text { BDMT }\end{array}$ & $\begin{array}{l}0,05 \\
0,13 \\
0,11 \\
0,11 \\
0,11\end{array}$ & $\begin{array}{l}0,06 \\
0,13 \\
0,12 \\
0,11 \\
0,12\end{array}$ & $\begin{array}{l}0,05 \\
0,13 \\
0,11 \\
0,11 \\
0,12\end{array}$ & $\begin{array}{l}0,05 \\
0,13 \\
0,11 \\
0,11 \\
0,11\end{array}$ \\
\hline ITA 11 & $\begin{array}{l}\text { MNM } \\
\text { MNMB } \\
\text { BDA } \\
\text { BDA-D } \\
\text { BDMT }\end{array}$ & $\begin{array}{l}0,05 \\
0,13 \\
0,09 \\
0,09 \\
0,10\end{array}$ & $\begin{array}{l}0,04 \\
0,12 \\
0,09 \\
0,10 \\
0,11\end{array}$ & $\begin{array}{l}0,04 \\
0,12 \\
0,09 \\
0,09 \\
0,11\end{array}$ & $\begin{array}{l}0,06 \\
0,12 \\
0,10 \\
0,09 \\
0,11\end{array}$ \\
\hline Pt 185 & $\begin{array}{l}\text { MNM } \\
\text { MNMB } \\
\text { BDA } \\
\text { BDA-D } \\
\text { BDMT }\end{array}$ & $\begin{array}{l}0,07 \\
0,15 \\
0,20 \\
0,11 \\
0,13\end{array}$ & $\begin{array}{l}0,07 \\
0,14 \\
0,21 \\
0,11 \\
0,14\end{array}$ & $\begin{array}{l}0,07 \\
0,13 \\
0,20 \\
0,11 \\
0,14\end{array}$ & $\begin{array}{l}0,06 \\
0,14 \\
0,17 \\
0,11 \\
0,14\end{array}$ \\
\hline Pt taeda & $\begin{array}{l}\text { MNM } \\
\text { MNMB } \\
\text { BDA } \\
\text { BDA-D } \\
\text { BDMT }\end{array}$ & $\begin{array}{l}0,06 \\
0,12 \\
0,17 \\
0,11 \\
0,13\end{array}$ & $\begin{array}{l}0,05 \\
0,13 \\
0,19 \\
0,10 \\
0,12\end{array}$ & $\begin{array}{l}0,06 \\
0,12 \\
0,18 \\
0,10 \\
0,12\end{array}$ & $\begin{array}{l}0,06 \\
0,13 \\
0,18 \\
0,10 \\
0,13\end{array}$ \\
\hline
\end{tabular}


Tabela 3. Avaliação visual em escalas de notas de 0 a 5 da sintese de ectomicorriza em Eucalyptus urophylla em diferentes niveis de alumínio.

\begin{tabular}{|c|c|c|c|c|c|c|}
\hline \multirow{2}{*}{\multicolumn{2}{|c|}{ Isolados }} & \multicolumn{5}{|c|}{ Concentração de Al (ppm) } \\
\hline & & \multirow{2}{*}{$\frac{0}{0}$} & \multirow{2}{*}{$\frac{5}{1}$} & \multirow{2}{*}{$\frac{10}{2}$} & \multirow{2}{*}{$\frac{15}{0}$} & \multirow{2}{*}{$\frac{20}{0}$} \\
\hline & R1 & & & & & \\
\hline & $R 2$ & 0 & 0 & 1 & 0 & 0 \\
\hline & R3 & 2 & 3 & 1 & 1 & 0 \\
\hline & R4 & 1 & 0 & 2 & 0 & 0 \\
\hline & R5 & 2 & 1 & 0 & 0 & 1 \\
\hline & R6 & 2 & 0 & 1 & 0 & 1 \\
\hline & R7 & 2 & 0 & 3 & 1 & 0 \\
\hline \multirow[t]{16}{*}{$A C 6$} & R8 & 1 & 0 & 1 & 1 & 1 \\
\hline & R9 & 1 & 0 & 0 & 1 & 0 \\
\hline & $R 10$ & 0 & 0 & 1 & 1 & 1 \\
\hline & $R 11$ & 0 & 1 & 1 & 2 & 1 \\
\hline & $\mathrm{R} 12$ & 0 & 2 & 1 & 1 & 0 \\
\hline & $R 13$ & 1 & 0 & 3 & 1 & 1 \\
\hline & $\mathrm{R} 14$ & 1 & 0 & 1 & 1 & 1 \\
\hline & $R 15$ & 0 & 1 & 0 & 1 & 0 \\
\hline & R16 & 1 & 3 & 1 & 1 & 1 \\
\hline & $R_{1}$ & 2 & 2 & 4 & 2 & 0 \\
\hline & $\mathrm{R} 2$ & 1 & 2 & 4 & 2 & 1 \\
\hline & R3 & 1 & 1 & 4 & 2 & 1 \\
\hline & R4 & 1 & 2 & 3 & 3 & 0 \\
\hline & R5 & 1 & 1 & 1 & 1 & 1 \\
\hline & R6 & 1 & 1 & 1 & 2 & 1 \\
\hline & R7 & 2 & 0 & 1 & 1 & 2 \\
\hline \multirow[t]{9}{*}{ ACB } & $R B$ & 1 & 2 & 3 & 1 & 0 \\
\hline & RQ & 1 & 1 & 1 & 2 & 1 \\
\hline & $R 10$ & 1 & 1 & 1 & 0 & 0 \\
\hline & $R 11$ & 1 & 1 & 0 & 2 & 1 \\
\hline & $R 12$ & 2 & 1 & 1 & 2 & 0 \\
\hline & $R 13$ & 1 & 1 & 1 & 3 & 1 \\
\hline & $R 14$ & 3 & 0 & 2 & 3 & 2 \\
\hline & $R 15$ & 0 & 1 & 1 & 1 & 3 \\
\hline & $R 16$ & 1 & 1 & 1 & 2 & 1 \\
\hline
\end{tabular}


Tabela 3. Continuação.

\begin{tabular}{|c|c|c|c|c|c|c|}
\hline \multirow{2}{*}{\multicolumn{2}{|c|}{ Isolados }} & \multicolumn{5}{|c|}{ Concentração de Al (ppm) } \\
\hline & & \multirow{2}{*}{$\frac{0}{1}$} & \multirow{2}{*}{$\frac{5}{2}$} & \multirow{2}{*}{$\frac{10}{1}$} & \multirow{2}{*}{$\frac{15}{2}$} & \multirow{2}{*}{$\frac{20}{1}$} \\
\hline & R1 & & & & & \\
\hline & $R 2$ & 1 & 1 & 1 & 2 & 1 \\
\hline & R3 & 2 & 0 & 3 & 3 & 0 \\
\hline & R4 & 2 & 1 & 1 & 2 & 1 \\
\hline & R5 & 1 & 5 & 2 & 1 & 3 \\
\hline & R6 & 1 & 5 & 1 & 1 & 2 \\
\hline & R7 & 3 & 5 & 2 & 3 & 1 \\
\hline \multirow{16}{*}{$A C 12$} & $\mathrm{RB}$ & 0 & 1 & 1 & 1 & 1 \\
\hline & R9 & 3 & 0 & 2 & 3 & 1 \\
\hline & $R 10$ & 0 & 2 & 1 & 4 & 0 \\
\hline & $R 11$ & 1 & 0 & 3 & 1 & 1 \\
\hline & $\mathrm{R} 12$ & 0 & 1 & 2 & 1 & 1 \\
\hline & $R 13$ & 2 & 1 & 3 & 5 & 1 \\
\hline & R14 & 2 & 1 & 1 & 1 & 0 \\
\hline & R15 & 0 & 1 & 5 & 1 & 1 \\
\hline & R16 & 1 & 1 & 4 & 2 & 0 \\
\hline & $R 1$ & 3 & 2 & 2 & 1 & 2 \\
\hline & $\mathrm{R} 2$ & 3 & 2 & 3 & 1 & 3 \\
\hline & R3 & 0 & 3 & 5 & 3 & 1 \\
\hline & R4 & 2 & 1 & 4 & 1 & 2 \\
\hline & $R 5$ & 3 & 1 & 2 & 4 & 0 \\
\hline & R6 & 0 & 4 & 1 & 2 & 1 \\
\hline & $R 7$ & 3 & 1 & 1 & 4 & 3 \\
\hline \multirow[t]{9}{*}{$P I 314$} & $R B$ & 2 & 3 & 4 & 2 & 1 \\
\hline & R9 & 4 & 2 & 2 & 1 & 1 \\
\hline & R10 & 2 & 4 & 2 & 1 & 1 \\
\hline & $R 11$ & 4 & 3 & 3 & 2 & 0 \\
\hline & $\mathrm{R} 12$ & 0 & 4 & 4 & 3 & 0 \\
\hline & $R 13$ & 3 & 1 & 5 & 5 & 2 \\
\hline & $R 14$ & 3 & 1 & 4 & 4 & 1 \\
\hline & R15 & 3 & 3 & 2 & 2 & 1 \\
\hline & R16 & 0 & 3 & 4 & 3 & 0 \\
\hline
\end{tabular}


Tabela 4. Avaliação em escalas de notas de 0 a 10 da sintese de ectomicorriza em Eycalyptus urophylla em diferentes niveis de aluminio, atraves de coloração de raizes.

\begin{tabular}{|c|c|c|c|c|c|c|}
\hline \multirow{2}{*}{\multicolumn{2}{|c|}{ Isolados }} & \multicolumn{5}{|c|}{ Concentração de Al (Ppm) } \\
\hline & & \multirow{2}{*}{$\frac{0}{3}$} & \multirow{2}{*}{$\frac{5}{8}$} & \multirow{2}{*}{$\frac{10}{3}$} & \multirow{2}{*}{$\frac{15}{2}$} & \multirow{2}{*}{$\frac{20}{3}$} \\
\hline & RI & & & & & \\
\hline & RI I & 1 & 3 & 1 & 1 & 1 \\
\hline & RI I I & 2 & 1 & 3 & 1 & 1 \\
\hline \multirow[t]{8}{*}{ AC6 } & RIV & 3 & 2 & 5 & 8 & 2 \\
\hline & RV & 7 & 8 & 6 & 3 & 1 \\
\hline & RVI & 8 & 3 & 5 & 6 & 5 \\
\hline & RVI I & 5 & 4 & 3 & 3 & 1 \\
\hline & RVIII & 7 & 1 & 3 & 2 & 4 \\
\hline & RI & 5 & 8 & 1 & 3 & 3 \\
\hline & RI I & 2 & 5 & 1 & 2 & 4 \\
\hline & RIII & 4 & 3 & 5 & 10 & 0 \\
\hline \multirow[t]{8}{*}{$A C B$} & RIV & 3 & 5 & 3 & 3 & 8 \\
\hline & RV & 9 & 3 & 5 & 2 & 4 \\
\hline & RVI & 7 & 4 & 3 & $\overline{8}$ & 5 \\
\hline & RVI I & 9 & 8 & 1 & 3 & 5 \\
\hline & RVI I I & 4 & 1 & 8 & 1 & 2 \\
\hline & RI & 3 & 3 & 8 & 3 & 1 \\
\hline & RI I & 4 & 2 & 5 & 7 & 5 \\
\hline & R I I I & 3 & 3 & 3 & 5 & 2 \\
\hline \multirow[t]{8}{*}{$A C 12$} & RIV & 1 & 4 & 1 & 4 & 3 \\
\hline & RV & 2 & 1 & 8 & 4 & 2 \\
\hline & RVI & 6 & 2 & 4 & 5 & 8 \\
\hline & RVI I & 9 & 9 & 3 & 9 & 1 \\
\hline & RVI I I & 1 & 2 & 3 & 7 & 1 \\
\hline & RI & 2 & 6 & 3 & 8 & 2 \\
\hline & RII & 2 & 3 & 7 & 3 & 5 \\
\hline & RII I & 1 & 3 & 3 & 2 & 5 \\
\hline \multirow[t]{5}{*}{ PI 314} & RIV & 3 & 3 & 4 & 2 & 2 \\
\hline & RV & 3 & 1 & 4 & 1 & 7 \\
\hline & RVI & 2 & 7 & 10 & 4 & 7 \\
\hline & RVI I & 8 & 3 & 4 & 3 & 1 \\
\hline & RVI I I & 1 & 2 & 2 & 4 & 1 \\
\hline
\end{tabular}


Tabela 5. Avaliaçăo em escalas de notas de 0 a 5 do grau de micorrização de mudas de Eycalyptus proveniente de semeio direto e pläntulas inoculadas com isolados de Pisolythus tinctorius.

\begin{tabular}{|c|c|c|c|c|c|c|c|c|c|c|c|c|c|c|}
\hline & $A T$ & 502 & AT & 503 & AT & 504 & AT & 555 & $A T$ & 507 & $A T$ & 509 & AT $=$ & 510 \\
\hline & SEM & FLAN & SEM & PLAN & SEM & PLAN & SEM & PLAN & SEM & PLAN & SEM & PLAN & SEM & PLAN \\
\hline R1 & 2 & 3 & 3 & 4 & 0 & 3 & 0 & 4 & 3 & 3 & 0 & 3 & 0 & 0 \\
\hline$R 2$ & 5 & 4 & 0 & 5 & 0 & 4 & 0 & 2 & 1 & 1 & 0 & 4 & 0 & 3 \\
\hline R3 & 3 & 5 & 2 & 4 & 1 & 5 & 0 & 3 & 2 & 4 & 0 & 5 & 0 & 5 \\
\hline R4 & 4 & 4 & 1 & 1 & 0 & 3 & 2 & 5 & 0 & 3 & 3 & 4 & 0 & 3 \\
\hline R5 & 5 & 5 & 1 & 3 & 1 & 4 & 0 & 4 & 2 & 3 & 1 & 5 & 3 & 3 \\
\hline R6 & 3 & 2 & 3 & 4 & 0 & 4 & 0 & 3 & 4 & 4 & 0 & 2 & 1 & 4 \\
\hline$R 7$ & 0 & 4 & 0 & 4 & 0 & 3 & 1 & 3 & 0 & 5 & 0 & 1 & 1 & 3 \\
\hline R8 & 5 & 5 & 0 & 4 & 0 & 1 & 1 & 2 & 2 & 2 & 2 & 4 & 0 & 4 \\
\hline$R 9$ & 2 & 2 & 5 & 2 & 0 & 3 & 0 & 5 & 3 & 4 & 1 & 1 & 3 & 5 \\
\hline R10 & 3 & 3 & 3 & 5 & 0 & 5 & 3 & 2 & 3 & 2 & 2 & 4 & 3 & 3 \\
\hline R11 & 4 & 3 & 0 & 4 & 0 & 5 & 3 & 4 & 0 & 1 & 4 & 5 & 0 & 4 \\
\hline $\mathrm{R} 12$ & 3 & 4 & 5 & 5 & 0 & 5 & 0 & 5 & 5 & 5 & 2 & 4 & 3 & 4 \\
\hline R13 & 4 & 3 & 4 & 4 & 0 & 4 & 3 & 5 & 3 & 3 & 3 & 5 & 0 & 4 \\
\hline R14 & 5 & 4 & 0 & 4 & 0 & 3 & 3 & 5 & 0 & 2 & 0 & 2 & 1 & 4 \\
\hline R15 & 3 & 3 & 2 & 3 & 0 & 3 & 0 & 5 & 0 & 4 & 0 & 3 & 0 & 2 \\
\hline R16 & 3 & 5 & 4 & 2 & 0 & 4 & 4 & 3 & 0 & 2 & 0 & 2 & 3 & 3 \\
\hline
\end{tabular}

Dados originais não transformados. Para efeito de análise estatística foram transformados em $1 \times$ na poténcia $0,7129+0$. 